San Jose State University

SJSU ScholarWorks

Master's Theses

Master's Theses and Graduate Research

1998

\title{
Ecology of breeding Caspian terns (Sterna Caspia) in Elkhorn Slough, California
}

Jennifer Lee Parkin

San Jose State University

Follow this and additional works at: https://scholarworks.sjsu.edu/etd_theses

\section{Recommended Citation}

Parkin, Jennifer Lee, "Ecology of breeding Caspian terns (Sterna Caspia) in Elkhorn Slough, California" (1998). Master's Theses. 1663.

DOI: https://doi.org/10.31979/etd.bgg9-w5sv

https://scholarworks.sjsu.edu/etd_theses/1663

This Thesis is brought to you for free and open access by the Master's Theses and Graduate Research at SJSU ScholarWorks. It has been accepted for inclusion in Master's Theses by an authorized administrator of SJSU ScholarWorks. For more information, please contact scholarworks@sjsu.edu. 


\section{INFORMATION TO USERS}

This manuscript has been reproduced from the microfilm master. UMI films the text directly from the original or copy submitted. Thus, some thesis and dissertation copies are in typewriter face, while others may be from any type of computer printer.

The quality of this reproduction is dependent upon the quality of the copy submitted. Broken or indistinct print, colored or poor quality illustrations and photographs, print bleedthrough, substandard margins, and improper alignment can adversely affect reproduction.

In the unlikely event that the author did not send UMI a complete manuscript and there are missing pages, these will be noted. Also, if unauthorized copyright material had to be removed, a note will indicate the deletion.

Oversize materials (e.g., maps, drawings, charts) are reproduced by sectioning the original, beginning at the upper left-hand comer and continuing from left to right in equal sections with small overlaps. Each original is also photographed in one exposure and is included in reduced form at the back of the book.

Photographs included in the original manuscript have been reproduced xerographically in this copy. Higher quality 6" $\times 9$ " black and white photographic prints are available for any photographs or illustrations appearing in this copy for an additional charge. Contact UMI directly to order.

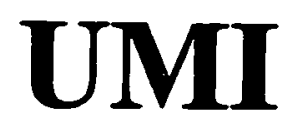

A Bell \& Howell Information Company 300 North Zeeb Road, Ann Arbor MI 48106-1346 USA 



\section{NOTE TO USERS}

The original manuscript received by UMI contains pages with slanted print. Pages were microfilmed as received.

This reproduction is the best copy available

UMI 


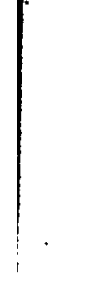
$-$

.. . 


\title{
ECOLOGY OF BREEDING CASPIAN TERNS \\ (STERNA CASPIA) IN ELKHORN SLOUGH, CALIFORNIA
}

\author{
A Thesis \\ Presented to \\ The Faculty of Moss Landing Marine Laboratories \\ San Jose State University
}

\author{
In Partial Fulfillment \\ of the Requirements for the Degree \\ Master of Science
}

by
Jennifer Lee Parkin

May 1998 
UMI Number: 1389674

\title{
Copyright 1998 by
}

Parkin, Jennifer Lee

All rights reserved.

UMI Microform 1389674

Copyright 1998, by UMI Company. All rights reserved.

This microform edition is protected against unauthorized copying under Title 17, United States Code.

\author{
UMI \\ 300 North Zeeb Road \\ Ann Arbor, MI 48103
}


(C) 1998

Jennifer Lee Parkin

ALL RIGHTS RESERVED 
APPROVED FOR THE DEPARTMENT OF BIOLOGY Di.James T. Harvey, Assogate Professor of Vertebrate Biology Hegon M. Catier

Dr. Gregod M. Cailliet, Professor of Ichthyology

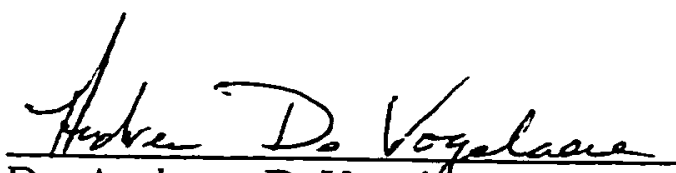

Dr. Andrew DeVogeldere, Research Coordinator/Sr. Scientist Monterey Bay National Marine Sanctuary

APPROVED FOR THE UNIVERSITY

Wiltian Bish 


\section{ABSTRACT \\ ECOLOGY OF BREEDING CASPIAN TERNS \\ (STERNA CASPIA) IN ELKHORN SLOUGH, CALIFORNIA \\ By Jennifer Lee Parkin}

Breeding Caspian Terns were studied from 1992 through 1995 at Elkhorn Slough and 1996 at the Salinas River. Mean clutch size was 1.7 $(\mathrm{SE}=0.01, \mathrm{n=3}$ ) for years 1994 through 1996, with greatest fledging success (79.4\%) in 1994. Activity patterns indicated significant differences among chick age groups during 1994 and 1995. Caspian Terns mainly consumed shiner surfperch, northern anchovy/silversides, crayfish, and Pacific staghorn sculpin. During 1995, this colony suffered extensive reproductive failure following a major flood event in the region. Fledging success decreased to $19.4 \%$ in 1995 and $0 \%$ in 1996. Concentrations of DDE in eggs increased from a mean $3.06 \mathrm{ppm}(n=2)$ in 1994 to a mean $6.98 \mathrm{ppm}(n=24)$ in 1995.

Organochlorine contaminant concentrations in eggs were correlated negatively with eggshell thickness in 1995 and 1996. It appears that the increase in organochlorine contaminant residues adversely affected the reproductive capacity of this colony of breeding terns. 


\section{ACKANOWLEDGMENTS}

I would like to thank my advisory committee Dr. Jim Harvey, Dr. Gregor Cailliet, and Dr. Andrew DeVogelaere for their assistance, guidance, encouragement, and helpful comments on this manuscript. I also thank Joan Parker, Sheila Baldridge, Gail Johnston, and Aldo Derose for all of their help and assistance.

This study could not have been completed without Steve Kimple, Bob Hosea, Mark Silberstein, the staff at Elkhorn Slough National Estuarine Research Reserve, and the California Department of Fish and Game.

I thank Tony Orr, Tomoharu Eguchi, Michelle Lander, Jill Pettinger, Mike Weise, Dion Oxman, Lisa Cheney, and all of the fellow students and interns who helped me conduct this study. I thank Dr. Charles Collins and Dr. Michael Horn for their invaluable help. I thank Rick Fournier for his assistance, data and observations at the start of this project. I thank the U.S. Fish and Wildlife Service for making expedient arrangements to continue this study at the Salinas River National Wildlife Refuge. I also thank Tony Orr and Tom Ryan for their superb editing skills. A special thank you to my father-in-law William F. Parkin for his assistance in building the bird blind that lasted for five plus years!

This study was supported by the California Department of Fish and Game, Elkhorn Slough Foundation, Earl and Ethyl Myers Oceanographic Trust Fund, Patricia Price Petersen Foundation, and the Packard Foundation.

A very special thank you to my husband, Bill, for his love, support, patience, and assistance throughout this study. 
This work is dedicated to the memory of my grandfather, Charles Maurer, who inspired me as a child to appreciate and observe the natural world and to become a biologist. 
TABLE OF CONTENTS

Page

ACKNOWLEDGMENTS.

TABLE OF CONTENTS .

LIST OF TABLES. .

LIST OF FIGURES.

INTRODUCTION .

OBJECTIVES

HYPOTHESES .

METHODS .

STUDY AREA. .

POPULATION DYNAMICS.

CASPIAN TERN ACTIVITY PATTERNS

FOOD HABIT ANALYSIS.

CONTAMINANT ANALYSIS.

RESULTS.

POPULATION DYNAMICS

CASPIAN TERN ACTIVITY PATTERNS.

FOOD HABITS.

CONTAMINANT ANALYSIS.

DISCUSSION.

33

POPULATION DYNAMICS.

ACTIVITY PATTERNS.

FOOD HABITS.

CONTAMINANT ANALYSIS.

SUMMARY .

LITERATURE CITED.

TABLES.

FIGURES.

APPENDIX. 


\section{LIST OF TABLES}

Table

Page

1. Detection limits for organochlorine contaminant and trace metal $\quad 70$ analyses, set by California Department of Fish and Game.

2. Number of Caspian Tern nests containing zero to three eggs, total number of eggs laid, and total number of nests for each year from 1994 to 1996.

3. Fate of Caspian Tern eggs and chicks each year from 1994 to 1996.

4. Hatching, fledging, breeding success, and mean fledging rates for

Caspian Terns nesting during 1994 and 1995 at Elkhorn Slough and and 1996 at Salinas River, CA.

5. Comparison of Caspian Tern breeding success (mean clutch size, reproductive output, and hatching and fledging success) from this study compared with previous studies.

6. Mean percent number $(\% \mathrm{~N})$, mean percent mass $(\% \mathrm{M})$, mean percent frequency of occurrence (\%F), and mean index of relative importance (IRD) of prey items based on otoliths found in Caspian Tern nest cups collected in Elkhorn Slough, CA during 1994.

7. Mean percent number $(\% \mathrm{~N})$, mean percent mass (\%M), mean percent frequency of occurrence (\%F), and mean index of relative importance (IRI) of prey items based on otoliths found in Caspian Tern nest cups collected in Elkhorn Slough, CA during 1995.

8. Mean percent number (\%N), mean percent mass (\%M), mean percent frequency of occurrence (\%F), and mean index of relative importance (IRI) of prey items based on otoliths found in Caspian Tern regurgitated pellets collected at Salinas River during 1996.

9. Mean lipid content, mean concentration, range and frequency of occurrence (FO) of organochlorine residues in Caspian Tern eggs from three locations.

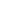


12. Correlation values of organochlorine residues and eggshell thickness in Caspian Tern eggs from SRNWR during 1996.

13. Mean DDE concentrations and mean percent lipid contents in prey items of Caspian Terns collected from Elkhorn Slough, 1994 to 1996 and Pajaro River and Watsonville Slough, 1997.

14. Organochlorine concentrations and percent lipid found in Caspian Tern and Great Egret carcasses during this study. 


\section{LIST OF FIGURES}

Figure

Page

1. Study sites at Elkhorn Slough National Estuarine Research Reserve and Salinas River National Wildlife Refuge.

2. Maximum counts of Caspian Tern adults at the breeding colony at ESNERR (1992-1995) and at both ESNERR (20 April to 25 May) and SRNWR during 1996.

3. Maximum counts of Caspian Tern chicks at the breeding colony at ESNERR (1992-1995) and SRNWR (1996).

4. Weekly variation in Caspian Tern parental activities as a function of brood age by week.

5. Weekly variation in mean length of fish fed to Caspian Tern chicks as a function of chick age.

6. Cumulative species curves for samples collected from Caspian Tern nest cups in ESNERR (1994 and 1995) and regurgitated pellets collected at SRNWR (1996).

7. Species comparison among years, using percent number of prey identified in Caspian Tern nest cup samples during 1994 and 1995, and regurgitated pellets collected during 1996.

8. Annual variation in mean number of species (S), mean diversity index $\left(\mathrm{H}^{\prime}\right)$, index of specialization (R), and dominance (D) of prey of Caspian Terns identified from nest cup (1994 and 1995) collected from Elkhorn Slough and pellet (1996) samples collected from Salinas River Mouth, CA.

9. Species comparison among years, using percentage number of prey identified from direct observations of Caspian Tern foraging trips during 1993 to 1995.

10. Species comparison, using percentage number, between prey identified in Caspian Tern nest cups and by direct observations in Elkhorn Slough during 1994 (A) and 1995 (B).

11. Frequency histograms of the estimated length of shiner surfperch using otoliths recovered from Caspian Tern nest cups and pellets collected at Elkhorn Slough during 1994 and 1995 and the Salinas River mouth during 1996. 
12. Frequency histograms of the estimated length of northern anchovy 95 and topsmelt using otoliths recovered from Caspian Tern nest cups and pellets collected at Elkhorn Slough during 1994 and 1995 and the Salinas River mouth during 1996.

13. Frequency histograms of the estimated length of white croaker and Pacific staghorn sculpin using otoliths recovered from Caspian Tern nest cups and pellets collected at Elkhorn Slough CA.

14. Frequency histograms of the estimated length of plainfin midshipman and jacksmelt using otoliths recovered from Caspian Tern nest cups and pellets collected at Elkhorn Slough CA.

15. Frequency histograms of the estimated length of shiner surfperch and northern anchovy/silversides recorded from direct observations of Caspian Tern feeding trips in Elkhorn Slough CA.

16. Frequency histograms of the estimated length of Pacific staghorn 99 sculpin recorded from direct observations of Caspian Tern feeding trips at Elkhorn Slough CA. 


\section{INTRODUCTION}

The Caspian Tern (Sterna caspia) is a colonial species that breeds at large lakes or along coasts on all continents except Antarctica (Bent 1921, L'Arrivee and Blokpoel 1988, Palacios and Alfaro 1992). The North American population is disjunct, but is the largest of the worldwide populations. Breeding occurs along the Pacific, Atlantic, and Gulf of Mexico coasts and interior at rivers, marshes, and large lakes including the Great Lakes (Bent 1921, Ludwig 1965, Kirven 1969, Gill and Mewaldt 1983, L'Arrivee and Blokpoel 1988, Terres 1991). Along coastal California during the last 25 years, breeding colonies have occurred at San Francisco Bay, Monterey Bay, and in San Diego, Orange, Napa and Humboldt counties (Sowls et al. 1980, Gill and Mewaldt 1983).

Caspian Terns are part-time residents of northern North America, migrating south for the winter. Great Lakes and Atlantic Coast populations generally winter in the Caribbean, Gulf of Mexico to eastern Mexico, and northern Columbia to Venezuela (American Ornithologists Union 1983, Ewins et al. 1994). Pacific coast populations winter along the Pacific coasts of mainland Mexico, Baja California, and as far south as extreme northern Central America (Kirven 1969, American Ornithologists Union 1983).

The average life span of Caspian Terns is 10 to 15 years, however, a banded adult aged at 26 years and two months was collected at the Great Lakes (Terres 1991).

Many larid species exhibit philopatry (returning to the same breeding site each year), although, if the location and surrounding environment changes they may shift to new locations. Breeding adults may be deterred 
from returning to sites when islands become submerged, or the breeding colony is disturbed due to reproductive failure, predation, or human activity (Cuthbert 1985, 1988). Nests typically are placed close together, and consist of shallow scrapes in the substrate with no or meager nesting material (Bent 1921, Ludwig 1965, Buckley and Buckley 1972). Two to four eggs are laid asynchronously, two to three days apart. Incubation begins with the first egg, thus, hatching occurs several days apart (Soikkeli 1973). Duration of incubation is about 24 to 27 days, with chicks fledging approximately 30 to 40 days after hatching (Ludwig 1968, Soikkeli 1973, Fetterolf and Blokpoel 1983, Mitchell and Custer 1986, L'Arrivee and Blokpoel 1988). Both adults incubate eggs and care for young.

In California, the first Caspian Tern nests were documented in 1899 when Bailey (1902) discovered Caspian Terns nesting at Tule Lake. In 1922, Caspian Terns were observed nesting on levees around salt evaporation ponds in San Francisco Bay (DeGroot 1931, Grinnell and Miller 1944). This colony increased in size and expanded to other areas in south San Francisco Bay (Miller 1943, Gill 1972). Another colony nested on salt dikes near the town of Drawbridge until 1970 (Chanoit 1970). Emblen (1954), Kirven (1969) and Evans (1973) described several colonies on salt pond levees in San Diego Bay. Gill and Mewaldt (1983) suggested that Pacific coast populations were expanding northward to Washington and shifting from smaller inland nesting sites, to larger coastal sites typically associated with man-made habitats such as dikes and levees. In fact, during 1997, a large concentration of breeding Caspian Terns, about 8,000 breeding pairs, occurred along the Columbia River at Rice Island, Oregon (D. Roby OCWRU-OSU, pers. comm.). The first record of Caspian Terns nesting in Elkhorn Slough, California, 
was at salt evaporation ponds near Moss Landing in 1970 (Baldridge et al. 1970). Caspian Terns were not consistent breeders in the Moss Landing area after 1970 with the exception of the summers of 1978 to 1980 . During this period a colony consistently nested at the salt ponds (Harvey 1982). Shortly after the 1980 nesting season the colony again abandoned the salt ponds (Bailey 1993). The only recorded breeding attempts in the Monterey Bay region after 1980 were at the Salinas River Mouth, 8 to $10 \mathrm{~km}$ south of Elkhorn Slough in 1983, when less than 10 nests were observed and no reproductive success evident (Roberson 1985). In 1992, a new breeding colony established itself on a dredged material island in the Elkhorn Slough National Estuarine Research Reserve (ESNERR; Bailey 1993).

Few researchers have studied activity patterns of Caspian Terns and their chicks (Kirven 1969, Fetterolf and Blokpoel 1983). Activity budgets can provide quantitative descriptions of behavior and aid in assessing modes of reproduction and foraging habits (Levenson 1979). Because Caspian Tern chicks become more active several days after hatching, they are easily observed. Plumage colors of Caspian Tern chicks range from white or buff to brown, and their leg colors from yellow to bright orange (Chanoit 1970). Because chicks do not lose all of their down until 30 days of age, researchers have distinguished individual chicks from the same brood for most of their growth period (Kirven 1969, Quinn 1980, Fetterolf and Blokpoel 1983). Family units also are distinguishable from each other because adults tending chicks from the same nest remain in closer proximity to each other than to their neighbors (Fetterolf and Blokpoel 1983).

Chick feeding rates represent a useful index of parental costs during a successful breeding season. Kirven (1969) observed differences in Caspian 
Tern fledging success among various brood sizes in San Diego Bay. When compared to 1-chick and 2-chick broods, 3-chick broods suffered twice the mortality due to the parents greater difficulty in maintaining feeding rates. In contrast, Quinn (1980) observed that 2-chick and 3-chick broods had similar feeding rates and no significant difference in mortality at Lake Huron. Also, he found that first-hatched chicks were fed at a greater rate than second hatched chicks, especially at ages from one to 10 days.

Many seabirds feed their young at discrete times of the day. Kirkham and Morris (1979) found that Ring-billed gull (Larus delawarensis) chicks, a coastal species, were fed during the first two hours after sunrise and two hours just before sunset. Feedings occurred periodically throughout the day, however, these early morning and late afternoon periods represented the greatest number of feedings. Pelagic White-tailed Tropicbird (Phaethon lepturus) chicks frequently were fed early during the day between 0600 and 0900 (Schaffner 1990). Intervals of maximum frequency of feeding indicated periods when chicks received the greatest amount of caloric energy. Few researchers have studied the time of day when the greatest number of feedings occurred at a breeding Caspian Tern colony.

Caspian Terns forage in many habitats including: rivers, estuaries, lakes, and coastal areas. This species is mainly piscivorous, although, shrimp, fresh-water mussels, insects, and eggs and young of other birds also are consumed (Bent 1921, Ewins et al. 1994). Previous studies in California, however, have indicated that Caspian Terns prey exclusively on fishes (Kirven 1969, Baltz et al. 1979, Harvey 1982, Horn et al. 1996, Loeffler 1996). Abundance and accessibility of fish may directly affect the number of fish that terns may catch (Smith 1990). However, unlike some other tern 
species, Caspian Terns are opportunistic feeders and are able to change their foraging behavior in response to prey availability (Koli and Soikkeli 1974, Horn et al. 1996, Loeffler 1996). For example, Elegant Terns (Sterna elegans) at Bolsa Chica Ecological Reserve (BCER), heavily relied on only a few fish species for food, whereas, Caspian Terns foraged on a wider variety of prey and switched to different prey when favored items were not available (Horn et al. 1996, Loeffler 1996, C. Collins CSULB, pers. comm.). At Elkhorn Slough, Harvey (1982) observed that Caspian Terns fed on greater than 30 species of fishes.

Researchers have relied on regurgitated pellets (bones, otoliths, and scales of prey), dropped fish, and direct observations to determine food habits of seabirds (Koli and Soikkeli 1974, Atwood and Kelly 1984, Wiggins and Morris 1987, Hulsman and Smith 1988, Ewins et al. 1994). Horn et al. (1996) and Loeffler (1996) reported diets of Caspian, Elegant, and Forster's Terns (Sterna forsteri), and Black Skimmers (Rhynchops niger) at BCER using all three methods. Studies of Caspian Tern prey in San Diego Bay were conducted using regurgitated pellets (Martini 1964, Kirven 1969). Harvey (1982) determined Caspian Tern diets in Elkhorn Slough relying mainly on pellets and direct observations.

Previous researchers of Caspian Terns in California have concentrated mainly on reproductive biology (Kirven 1969, Harvey 1982) and food habits (Gill 1976, Baltz et al. 1979, Harvey, 1982, Horn et al. 1996, Loeffler 1996), but few have studied effects of pollutants (Ohlendorf et al. 1985, 1988). Soikkeli (1973) reported that Caspian Terns in Finland had been killed by hunters and fish pool-keepers, and he suggested that many losses could occur with increasing water pollution in Europe. Water pollution has been linked to 
reproductive failure of Caspian Terns during the last several decades (Ohlendorf et al. 1985, Struger and Weseloh 1985, Ohlendorf et al. 1988, Ludwig et al. 1993, Ewins et al. 1994).

Since the introduction and use of DDT and other pesticides beginning in the 1940s, many researchers have reported the harmful effects of DDT on eggshell thickness in a variety of seabird and shorebird species (Fox 1976, Blus et al. 1977, Findholt and Trost 1985, Holthem et al. 1995). In North America, several tern species have been the subject of contaminant studies (King et al. 1983, Nisbet and Reynolds 1984, Custer et al. 1985, Ludwig et al. 1993, Holthem and Zador 1995). The effects of contaminants on reproductive success, eggshell thickness, and other factors have been examined for Caspian Terns, especially at the Great Lakes region (Ohlendorf et al. 1985, Struger and Weseloh 1985, Ohlendorf et al. 1988, Ludwig et al. 1993, Ewins et al. 1994, Mora 1996). Unlike the Brown Pelican (Pelecanus occidentalis) or Bald Eagle (Haliaeetus leucocephalus), which exhibited toxicological effects during the early-1970s, these effects increasingly occurred with Caspian Terns several years after the ban on DDT, in 1972. High levels of DDE, a metabolite of DDT, persisted in eggs into the 1980s. In addition, other metabolites such as DDD and DDMU were problematic.

The objectives of this study were to document abundance, activity patterns, and food habits of Caspian Terns breeding at ESNERR. The last study on Caspian Terns in this region was conducted more than 12 years ago (Harvey 1982). While studying activity patterns and food habits, I observed severe reproductive problems during the 1995 breeding season after a flood event during March 1995. Because of this catastrophic development, I wanted to determine the cause of this reproductive collapse, which I suspected was 
based on pollutants. Ludwig et al. (1993) conducted a study of the impacts of organochlorine pollutants on breeding colonies of Caspian Terns in the Great Lakes after a flood event, however, this situation has not been studied in California. Furthermore, it was a rare opportunity to witness a reproductive collapse having already collected previous information on this particular colony.

\section{OBJECTIVES}

The main objectives of this study were to:

1. determine population fluctuations and activity patterns of Caspian Tern adults and chicks at the breeding colony in Elkhorn Slough,

2. identify and determine relative importance of prey consumed by Caspian Terns in Elkhorn Slough,

3. determine prey size, number consumed, and biomass taken by Caspian Terns in Elkhorn Slough and compare annually and with previous studies, 4. determine the possible causes of reproductive failure during the 1995 breeding season in Elkhorn Slough, and 5. compare pesticide information on Caspian Terns in Elkhorn Slough with previous descriptions of Caspian Tern reproductive failure within the last 20 years.

\section{HYPOTHESES}

1. Because many seabird species are philopatric, the numbers of adult Caspian Terns returning to breed at Elkhorn Slough should remain about the same or increase due to immigration to this new colony site. 
2. Activity patterns of Caspian Tern adults should be similar to trends exhibited by other larid species.

3. Caspian Terns are opportunistic piscivores, therefore, they should consume seasonally abundant prey. Dominant prey items should include fish species that are known to be abundant in Elkhorn Slough, Moss Landing Harbor, and Monterey Bay regions.

4. Caspian Tern reproductive failure should be related to the extensive flood event that occurred during March 1995 because of the timing of breeding and unusual observations.

\section{METHODS -}

\section{STUDY AREA}

The Caspian Tern colony was located on a small dredged-material island in the South Marsh area of ESNERR $\left(36^{\circ} 48^{\prime} \mathrm{N}, 121^{\circ} 47^{\prime} \mathrm{W}\right)$, located $6.4 \mathrm{~km}$ east of Moss Landing, California (Fig. 1). This region is along the Pacific coast flyway, and is an important stopover for many bird species because of the highly productive waters in the slough (Elkhorn Slough Estuarine Sanct. Adv. Comm. et al. 1985).

The study island (Boomerang Island) is elongated in shape, approximately $61 \mathrm{~m}$ by $12 \mathrm{~m}$, and surrounded by water at all tides. During low tide, expansive mudflats are uncovered nearby. Additionally, this island provides a roosting area for Brown Pelicans and Double-crested Cormorants (Phalacrocorax auritus). Several Western Gull (Larus occidentalis) pairs nest on this and other nearby islands. Elegant Terns roost on nearby mudflats 
during July and August.

Dominant vegetation on the island included: alkali heath (Frankenia grandifolia), Australian salt bush (Atriplex semibaccata), common pickleweed (Salicomia virginica), and salt grass (Distichlis spicata). Caspian Terns generally do not nest on vegetated areas, therefore, during late-March from 1993 through 1996, vegetation was trimmed from the nesting island to maintain its attraction for breeding. To aid in erosion control, vegetation along the periphery of the island was not trimmed, and trimmings and pulled vegetation were placed along the sides of the island.

During the 1995 breeding season, evidence of voles (Microtus sp.) was discovered on the breeding island. Given the size of the island, a colony of subterranean rodents could cause further erosion of the island, which was already subject to heavy tidal influences. Live traps were used in March 1996 to verify the existence of these small animals and to ensure that this species would not jeopardize Caspian Tern eggs. A sizable colony of Microtus sp. had exploited the vegetation on the island, but there was no evidence during the breeding season that they had an impact on the breeding terns. Most likely these rodents colonized this island during the flood event of 1995. When the Caspian Terns returned to breed in 1996, the number of voles had probably increased dramatically from their numbers in 1995.

\section{POPULATION DXNAMICS}

A $1.8 \mathrm{~m} \times 1.2 \mathrm{~m} \times 1.8 \mathrm{~m}$ blind was constructed in April 1993 approximately $100 \mathrm{~m}$ from the breeding island. Throughout all study years, observations and counts of adults and chicks were conducted from this blind, which had a view of the length of the island. During June 1996, the nesting 
colony relocated to the Salinas River National Wildlife Refuge (SRNWR), where observations continued from a distance of about $120 \mathrm{~m}$.

During 1994 through 1996, the island with the colony was visited twice annually. During late incubation/early hatching in late May, I counted nests and eggs, marked nests with color-coded stakes to form a visual grid, and took sediment samples from several nest cups. Entering colonies of breeding birds during late incubation reduces abandonment of eggs and chicks (Thompson and Tabor 1981, C. Collins CSULB, pers. comm.). At the end of the breeding season in August, I collected addled eggs, carcasses, and nest cup samples. Trips into the colony were not conducted during 1993 because of possible disturbances to this newly formed colony. Several studies of Caspian Tern colonies suffering serious ill-effects due to human activities have been documented (Shugart et al. 1978, Blokpoel 1981, Blokpoel and Harfenist 1986). Therefore, the colony was allowed two years to stabilize before allowing human disturbance. During 1996, five trips into the SRNWR colony were on a random basis due to accessibility.

Observations of the Caspian Tern colony were conducted using a $45 \mathrm{X}$ spotting scope and $10 \times 50$ binoculars. From 1993 through 1996, counts began in April and concluded in August. Observations occurred on randomly selected days totaling four to six days every week during the incubation and chick rearing period of the breeding season (May-August). Maximum counts from 1992 were obtained from Rick Fournier, a docent at ESNERR. During 1996, counts of adults were recorded at ESNERR and SRNWR, whereas, counts of chicks were at SRNWR only.

Adults and chicks were counted a minimum of two times, at the start and finish of each observation day. Systematic visual observations of the 
colony, starting from the left side of the island and ending towards the right, were conducted separately for adults and chicks. Counts were most likely underestimates of the actual colony size because terns were hidden behind vegetation, portions of the island were out of view, and adults were flying to and from the colony. Therefore, maximum counts of adults and chicks were used to determine the number present during a study day. Additionally, number of nests was used to describe the number of breeding pairs each year.

To compare reproductive success of the Elkhorn Slough colony to other colonies I calculated rates of hatching, fledging, breeding success, and mean fledging following Fetterolf and Blokpoel (1983). Variables were determined as follows:

$$
\begin{array}{ll}
\text { Hatching success }=\frac{\mathrm{CH}}{\mathrm{EL}} & \text { Fledging success }=\frac{\mathrm{CF}}{\mathrm{CH}} \\
\text { Breeding success }=\frac{\mathrm{CF}}{\mathrm{EL}} & \text { Mean Fledging Rate }=\frac{\mathrm{CH}}{\# \text { Nests }}
\end{array}
$$

where $\mathrm{CH}$ is number of chicks hatched and surviving past week five, EL is number of eggs laid, and CF is number of chicks fledged.

\section{CASPIAN TERN ACTIVITY PATTERNS}

Caspian Terns were monitored for 2.5 to $8 \mathrm{~h}$ on random days during 1994 and 1995. During 1995, observations were more consistently 7 to $8 \mathrm{~h}$ duration, whereas in 1994, duration of observation periods was more variable. Observation periods were conducted during hours of daytime. Morning sessions were from 0730 to $1400 \mathrm{~h}$ and afternoon sessions from 1400 to $2000 \mathrm{~h}$. Observations were conducted during consecutive days alternating between morning and afternoon to compensate for biases with changing tides, 
daylight, and other factors (temperature, wind, and disturbances). Nests sampled were randomly chosen based on visibility and proximity to a colorcoded stake. Nests were monitored for an entire observation session and again every few days. Hatching dates were recorded when a chick became visible.

During 1994, a remote video camera was placed on an adjacent island to obtain more information about the colony. The camera was set up once a week from June through August and retrieved at the end of the day. Concurrent direct observations of different nests were conducted from the blind, however, to determine the accuracy of data collected from the video tapes, two sessions were dedicated to observing the same nests as the camera. This remote camera allowed for closer observations of certain nests and provided additional data on activity patterns.

During 1994 and 1995, at the beginning of each observation session, adults were designated as Parent 1 (P1) away from nest/off of colony and Parent 2 (P2) on nest/with chicks. These designations were used to determine parental activity patterns. During observation sessions, constant monitoring of the nests was required to maintain the parental designations.

Detailed records were kept on activities of each parent at each study nest during observation sessions. Recorded parental activities included: number of nest reliefs, defined as when an adult traded places with its mate at the nest; number of feeding periods, defined as number of fish brought back to the nest and fed to young; number of feeding trips, defined as number of times adults left the nest and returned with a fish (although it was not necessarily fed to a chick); number of times a single chick from a brood was fed; number of times both adults were present at the nest; and number of 
times chicks were alone at the nest. Departure and return times were recorded for each parent to the nearest $1 \mathrm{~s}$ using a digital watch.

Frequent observations of nests were needed to monitor chick hatching and to discern between chicks of the same brood. Chicks from the same brood often had different plumage color, and the older chick generally was slightly larger than its sibling until chicks reached four to five weeks of age (Chanoit 1970, Fetterolf and Blokpoel 1983). Age of chicks was determined by recording the date a chick was first observed, usually this was within one to three days of hatching. Recording of parental care activities and chickfeeding behavior began with the hatching of the last chick in a brood. Chicks were aged by week, beginning with week of hatching (0-1 weeks) through fledging (5-6 weeks). During 1995, sample size was limited because few chicks survived past two to three weeks.

Feeding rates were analyzed using event sampling (Altmann 1974). For each activity, an analysis of variance (ANOVA) was used to determine if there was a significant difference in mean parental activities and mean length of fish fed to chicks as a function of chick age. Analysis of variance was used to determine if there was a significant difference in mean parental activities between 1994 and 1995, however, only age groups 0-1, 1-2, and 2-3 weeks could be compared because of limited sample subjects in 1995. Additionally, observed feeding activities were based on an average session time of $4.5 \mathrm{~h}$. Data collected to determine peak feeding intervals was analyzed by separating observation sessions into three time periods: 0630 to $1050 \mathrm{~h}, 1050$ to $1510 \mathrm{~h}$, and 1510 to $1930 \mathrm{~h}$. Difference in mean peak feeding was compared among these three periods and between two years using an ANOVA. Mean feeding rates between chicks of the same brood were compared using a 
paired $t$-test. Mean feeding rates among broods containing one chick versus two chicks were assessed for 1995 using a Student's t-test. During 1994, number of observations of feeding rates for broods with one chick were not sufficient for statistical comparisons. Power, the probability a statistical test will correctly reject the null hypothesis, was calculated for non-significant comparisons (Cohen 1977).

\section{EOOD HABIT ANALYSIS}

Prey of Caspian Terns were identified from hard parts and using direct observations of adults carrying fish. Prey hard parts, gastroliths and fish otoliths, were recovered from nest cup samples and regurgitated pellets. Gastroliths occur in freshwater crayfish of the families Astacidae and Parastacidae as paired, calcareous, disc-shaped structures that form during ecdysis as a site for calcium storage Johnson 1984, Pavey and Fielder 1990, Wheatly and Ayers 1995). Nest cups were chosen for sampling because terns regurgitate undigested remains of prey, as a pellet, in or around the nest (Koli and Soikkeli 1974). Through time, these pellets dry in the nest cup and prey hard parts remain in the nest. Samples from nest cups were collected during 1994 and 1995 after breeding birds and their young had left the colony. Samples were collected from the upper 1 to $3 \mathrm{~cm}$ of sediment inside nest cups. During 1995, several samples also were collected in May. Freshly regurgitated pellet samples were collected instead of nest cup samples during 1996 at SRNWR, because of the limited access into the colony which created opportunities to collect fresh samples during the nesting period.

Prey samples were placed in separate plastic bags and frozen. Fish otoliths and crayfish gastroliths were removed from nest cup and pellet 
samples and stored dry. Fish otoliths were identified to the lowest taxon possible using reference specimens at Moss Landing Marine Laboratories (MLML). Whole fishes were identified to the lowest taxon and stored frozen.

To determine the minimum number of nest cup and pellet samples needed to adequately describe the Caspian Tern diet in 1994, 1995, and 1996, the cumulative number of prey species was plotted against the number of samples.

Number of prey were determined as half the gastroliths recovered or the greatest number of left or right otoliths of each fish species from nest cup samples and regurgitated pellets. Otolith length was measured to the nearest $1.0 \mathrm{~mm}$, using hand-held calipers, parallel to the sulcus from the anterior tip of the rostrum to the posterior edge (Harvey 1989).

Otolith length was used to determine estimated lengths of fish eaten by Caspian Terns by using a least-squares linear regression equation, describing the relationship between otolith length and fish length (Harvey et al. in press). Degradation and erosion of otoliths and gastroliths during digestion in the alimentary canal and in sediment of nest cups was compensated for by not using chipped or eroded items.

Estimated crayfish lengths were calculated as the mean of samples of live crayfish collected from the Pajaro River and Watsonville Slough (probable feeding areas of Caspian Terns; pers. obs.) located about $10 \mathrm{~km}$ from Boomerang Island. Live crayfish that were larger than the maximum estimates for fish lengths were not included in the calculation for mean estimated length. None of the crayfish were molting at the time of capture, therefore, no gastroliths were obtained to calculate a regression equation that would describe the relationship between length and weight by using 
gastrolith size.

Direct observation of fish brought to the colony has been used by many researchers in prey analyses terns (Koli and Soikkeli 1974, Smith 1993, Horn et al. 1996, Loeffler 1996). Because terns deliver a single fish carried crosswise in the bill, identification is possible and fish lengths can be estimated to 0.5 bill units (about $20 \mathrm{~mm}$ ) based on the adult's bill length (Chapdelaine et al. 1985, Wiggins and Morris 1987, Hulsman and Smith 1988, Loeffler 1996).

Estimated weights of fish eaten were obtained by using regression equations describing the relationship between length and weight of fishes (Harvey et al. in press). Estimated crayfish weights were calculated as the mean of samples of live crayfish.

Because of the long viewing distance and the use of a spotting scope to determine fish length and species brought to the colony, some prey were not identifiable to species. Observations were detailed enough to form a category that included, northern anchovy (Engraulis mordax) and silversides (topsmelt, Atherinops affinis; and jacksmelt, Atherinopsis californiensis). Information from the video camera was not used for identification of fish species due to the lack of clarity but length of fish and time of feeding were recorded.

Abundance of individual prey species identified using otoliths and direct observations was compared separately by method among years using a Kruskal-Wallis test. Distribution of prey length was compared among years using a Kolmogorov-Smirnov test. For 1994 data, Student t-tests and Mann Whitney-U tests were used to determine if there was any difference in mean length of prey between otolith sampling and direct observations. 
The following indices were used to describe the array of prey items consumed by Caspian Terns based on otolith samples only:

Species richness $(S)=$ number of prey species

Shannon-Wiener diversity index: $H^{\prime}=\mid \Sigma$ pi $\operatorname{lnpi}||$, where

$$
\mathrm{pi}=\% \mathrm{~N}
$$

Prey Evenness: $\mathrm{J}=\mathrm{H}^{\prime} / \mathrm{H}^{\prime} \max$, where $\mathrm{H}^{\prime} \max =\mathrm{InS}$

Index of Specialization: $R=1-\mathrm{J}$

Prey Dominance: $\mathrm{D}=\mathbf{\Sigma} \mathrm{pi}^{2}$

Prey array indices were calculated for each nest cup and regurgitated pellet sample to generate a mean for statistical comparison among years using a Kruskal-Wallis test.

Individual prey items for nest cup and pellet samples were evaluated for importance during each year using a mean Index of Relative Importance (IRI, Pinkas et al. 1971). Percent number $(\% \mathrm{~N})$ and percent frequency of occurrence (\%FO) were used to calculate the IRI, percent mass (\%M) was substituted for percent volume (\%V; Hyslop 1980), which was used in the original equation (Pinkas et al. 1971):

$$
\text { mean IRI }=(\text { mean } \% \mathrm{~N}+\text { mean } \% \mathrm{M}) \times \% \mathrm{FO} .
$$

\section{CONTAMINANT ANALYSIS}

During 1994, after all birds had vacated the colony, four eggs that remained at the site were collected and frozen for analysis. Also, several fishes were collected near nests in the colony, identified, and frozen for future analysis.

During July 1995, when reproductive failure was observed, approximately 92 eggs were collected because they were abandoned or chicks 
had died during pipping. Eggs were individually wrapped in aluminum foil, placed in separate ziplock bags, and placed in the refrigerator until shipped to the California Department of Fish and Game, Pesticides Investigation Unit (CDFGPIU). Approximately 65 chicks that died during hatching or after a few days of hatching also were collected, placed in ziplock bags, and refrigerated until shipped. Soil samples of the first 1 to $3 \mathrm{~cm}$ depth, from inside four nest cups also were collected and shipped.

During late August of 1995, fish samples were collected using an ottertrawl from areas of Elkhorn Slough where terns had fed. One adult Caspian Tern found in Moss Landing Harbor in April and a juvenile Great Egret (Casmerodius albus) found in August below the egret/heron rookery at ESNERR, also were collected. These birds were found sick or injured and were euthanized, frozen, and shipped to CDFGPIU for analysis. To determine any links between the ecosystem and pesticides found in egg samples, grab samples of water and sediment were collected during September from several regions of Elkhorn Slough including: behind the firehouse on Elkhorn Road, Hudson's Landing tidegates, upstream areas of the main channel of Elkhorn Slough (north of Kirby Park), and the Old Salinas River Mouth (Fig. 1). All of these samples were shipped to CDFGPIU during autumn 1995.

Additionally, 11 eggs were collected from SRNWR in 1996. One egg per nest was collected randomly from 11 nests after all eggs were laid per clutch, therefore, laying order of eggs was unknown. Also, eggs collected from SRNWR were fresher than eggs collected from ESNERR during 1995. Handling methods were the same as those used in 1995. In July, four decapitated chicks were collected and shipped to CDFGPIU for analysis. 
During August 1996, fish samples were collected by beach seine in Moss Landing Harbor near the Highway 1 Bridge and from ESNERR, placed in ziplock bags, and frozen for shipment to CDFGPIU for chemical analysis.

In 1996, eleven eggs also were collected from a Caspian Tern colony in Napa Marsh, California, to be used as a control group for comparisons of PCB and organochlorine residues. Sampling methods were the same as previously mentioned.

During May 1997, I was able to trap 13 crayfish in Watsonville Slough and four in the Pajaro River. Caspian Terns foraged at these locations and they roosted regularly at the mouth of the Pajaro River (pers. obs.). Live crayfish were weighed to the nearest $0.1 \mathrm{~g}$ and measured to the nearest 0.01 $\mathrm{mm}$, then frozen and sent to CDFGPIU for chemical analysis. Also, one adult Caspian Tern, that was hit by a car, was salvaged from the Monterey SPCA after it was euthanized, and sent to CDFGPIU for analysis.

All eggs were processed using the same methods. Egg length and breadth were measured to the nearest $0.01 \mathrm{~mm}$ and volume was measured to the nearest $0.1 \mathrm{ml}$ by water displacement. Eggs were opened, contents were removed and placed in chemically clean jars and frozen for future analysis. Late stage chicks were separated from their yolk sack and placed in $10 \%$ buffered formalin. Eggs were cut longitudinally, and after eggshells had dried completely, eggshell thickness was measured to the nearest $0.001 \mathrm{~mm}$ at the equator with a modified Starett micrometer (Ohlendorf et al. 1985). Measurements included the eggshell and shell membrane. Forty-four archived Caspian Tern eggshells collected before 1945 from San Francisco Bay, were measured at the Western Foundation of Vertebrate Zoology, Los Angeles, California as a comparison of mean eggshell thickness before the use 
of DDT.

Because individual fishes and crayfish were small in mass, samples were pooled according to species and similar size, and ground in a blender before organochlorine analysis was done. This process decreased sample size, but allowed for adequate organochlorine analysis.

Egg samples and livers and brains from dead or moribund Caspian Tern adults, chicks, and the juvenile Great Egret were tested for PCB and organochlorine residues. Each sample was analyzed using standard CDFGPIU methods for a series of organochlorine contaminants and PCBs (Appendix A; Table 1). A Varian 3600 capillary gas chromatograph (GC) with an electron capture detector (ECD) was used to determine PCB and organochlorine residue levels, additionally, percentage lipids of each sample was calculated. Sample results were converted from $\mathrm{ppb}$ to $\mathrm{ppm}$, and residue concentrations were adjusted to fresh wet weight as suggested by (Stickel et al. 1973). Sediment and nest cup samples also were converted from Ppb to ppm and are reported on a dry weight basis.

Trace metals were analyzed in subsamples of egg samples from 1994, 1995, and the 1996 control group at Napa Marsh (Table 1). Samples were analyzed using standard CDFG methods (CDFG 1986). Results are reported as $\mu \mathrm{g} / \mathrm{g}$ (ppm) fresh weight. Because of small sample sizes statistical comparisons could not be performed.

Because an insufficient number of egg samples were analyzed for chemical contaminants from 1994 and the 1996 (Napa Marsh) control group, statistical comparisons could not be conducted among years.

Concentrations of organochlorine contaminants detected in more than one-half of egg samples from 1995 and 1996 (SRNWR) each were transformed 
to natural logarithms for comparisons using t-tests. Also, when a contaminant was detected in at least fifty percent of the samples, a value of one-half the limit of detection (i.e. $0.0025 \mathrm{ppm}$ for most organochlorines) was substituted for the "not detected" values (Ohlendorf et al. 1985). Mean eggshell thickness was compared among years using an ANOVA. Correlations among pesticide concentrations and eggshell thickness characteristics for 1995 and 1996 (SRNWR) samples were determined using Spearman rank correlations. Eggshell thickness was compared with log-transformed DDE concentrations for 1995 data using regression analysis. Concentrations of DDE in prey items were compared among years using an ANOVA after transforming data to natural logarithms. A Tukey multiple comparison test was performed on prey samples that were significantly different among years. Power was calculated for non-significant comparisons.

\section{RESULTS}

\section{ROPULATION DKNAMICS}

For most years, the greatest numbers of adults were observed during May, except in 1995 when greatest numbers occurred in early June (Fig. 2). Maximum counts of adults increased from 200 and 219 individuals during 1992 and 1993 to 402 adults in 1994, decreased 36.3\% from 402 individuals during 1994 to 256 adults in 1995, and decreased to 179 birds in 1996 (Fig. 2). There were approximately 90 adult pairs in 1992 and 110 pairs in 1993. During 1994, the colony increased to almost 200 breeding pairs. In 1995, there were 160 breeding pairs, whereas the most dramatic reduction occurred 
during 1996 when there were only 34 breeding pairs.

Numbers of adults present at the colony remained stable throughout June in 1992, 1993, and 1995 (Fig. 2). During 1994, adult numbers decreased steadily during the entire breeding season. Between 22 July and 28 July of each year, except 1996, numbers of adults present at the colony declined markedly, an average $57.3 \%(S E=5.3, n=4)$. This reduction coincided with more observations of terns around Monterey Bay and other areas of Elkhorn Slough. Data collected during 1996 indicated three major declines in breeding adults present at the two breeding locations; at ESNERR (20 April through 22 May) and SRNWR (28 May through 4 June, and 12 July through 15 July; Fig. 2).

The maximum number of chicks counted during 1992 was 108 and during 1993 was 134 chicks (Fig. 3). Maximum number of chicks in 1994 was 189, a $41.1 \%$ increase. During 1995, a maximum of 14 individual chicks were counted, a $92.6 \%$ decrease from the 189 individuals counted in 1994 (Fig. 3). During 1996, the maximum number of chicks counted was 12. During 1995 and 1996, maximum counts of chicks were based on those individuals that were alive on monitoring days.

During all years except 1996, counts of chicks decreased an average $49.7 \%(\mathrm{SE}=5.0, \mathrm{n}=4)$ from 22 July through 28 July, the same week that adult counts decreased. These annual grand-scale emigrations from the breeding colony coincided with more observations of fledglings, accompanied by their parents, in and around Elkhorn Slough.

Annual counts of nests and eggs were conducted during late May in 1994,1995 , and 1996. For the three years, an average $30.2 \%$ of nests had one egg present, $61.9 \%$ had two eggs, and $3.8 \%$ had 3 eggs (Table 2). Total number 
of eggs laid each year declined from a maximum of 323 eggs in 1994 to 53 eggs in 1996, coinciding with a substantial decrease in nests during the same three years.

The fate of eggs and chicks each year was recorded for 1994 through 1996. During 1994, net reproductive output (a minimum of $46.4 \%$ ) was greater than 1995 (2.6\%; Tables 3 and 4). During 1995, more than 27\% of eggs did not hatch, $6 \%$ died during hatching, and $24 \%$ died several days after hatching. An average $27.5 \%$ of eggs had an unknown fate for all three years, which included: eggs not hatching, chick death after hatching, eggs not located during retrieval, or unobserved fledging.

Mean clutch size for three years was $1.73(\mathrm{SE}=0.01, \mathrm{n}=3$; Table 4). Only one nest containing a three-egg clutch was observed with three chicks during 1994. The third chick survived only three to four weeks. Caspian Terns were most reproductively successful during 1994 (79.4\% fledging success) and least successful during 1996 ( $0 \%$ fledging success; Table 4). Hatching success

declined markedly from 1994 to 1995, but increased somewhat in 1996 (Tables 4 and 5).

\section{CASPIAN TERN ACTIVITY PATTERNS}

During 1994, mean number of nest reliefs per nest per observation period increased between 0-1 and 1-2 week broods, whereas during 1995, a decrease in nest reliefs occurred as brood age increased (Fig. 4A). For each year, no significant differences were found among age groups (ANOVA; $F=0.85$ (1994), $P>0.05$; Power $<38 \%$; and F=1.76 (1995), $P>0.05$; Power $<30 \%$ ). Although, the two years (1994 and 1995) were significantly different from each other with 1995 being significantly greater (ANOVA; F=7.95, P=0.006). 
There were no significant differences in mean number of foraging trips per brood per observation period among brood ages for 1994 (ANOVA; $\mathrm{F}=1.35, \mathrm{P}>0.05 ;$ Power $<38 \%$ ) or 1995 (ANOVA; F=1.10, P>0.05; Power $<30 \%$; Fig. 4B). However, mean number of foraging trips during 1995 was significantly greater than during 1994 (ANOVA; $F=19.49, \mathrm{P}=0.001$ ).

During 1994, mean number of feeding periods per brood per observation period greatly increased between ages 0-1 and 1-2 weeks and decreased at 3-4 weeks, indicating a significant difference among age groups (ANOVA; F=4.37, P=0.002; Fig. 4C). No significant differences in mean number of feeding periods occurred among the three age groups during 1995 (ANOVA; F=0.12, P>0.05; Power<30\%), however, the mean in 1995 was significantly greater than 1994 (ANOVA; $F=8.87, P=0.004$ ).

During 1994, mean number of times both parents were present at the nest decreased significantly as chicks aged (ANOVA; F=12.41, $P=0.001$; Fig. 4D). A similar trend was found for 1995, however, mean number of times both parents were present did not decrease significantly among age groups as in 1994 (ANOVA; F=0.94, P>0.05; Power<30\%; Fig. 4D). During 1994, parental attendance decreased between 0-1 and 1-2 week chicks, and during 1995, a decrease occurred between 1-2 and 2-3 week chicks. In contrast, mean number of times chicks were alone increased significantly with chick growth during 1994 (ANOVA; F=8.25, P=0.001; Fig. 4E). In 1995, mean number of times chicks were alone also increased as they aged, but there was no significant difference among age groups (ANOVA; $F=1.97, P>0.05$; Power $=30 \%$; Fig. 4E). Mean number of times both parents were present during 1995 was significantly greater than 1994 (ANOVA; $F=8.10, P=0.006$ ), but the two years did not differ significantly in mean number of times chicks 
were alone (ANOVA; F=0.09, P>0.05; Power $<40 \%$ ).

During 1994, there was a significant difference in mean number of feedings to single chicks among the age groups, whereas ages 1-2 and 2-3 were more frequently fed (ANOVA; F=3.78, P=0.004; Fig. 4F). During 1995, a steady increase in mean number of feedings to single chicks occurred as chicks aged, but not significantly (ANOVA; F=1.77, P>0.05; Power $<30 \%$; Fig. 4F). Again, 1995 was significantly greater than 1994 (ANOVA; $F=13.04$, $\mathrm{P}=0.001$ ).

During 1994, length of fish fed to chicks increased significantly with chick growth, from a mean of $5.0 \mathrm{~cm}(\mathrm{SD}=2.3, \mathrm{n}=16)$ at age $0-1$ weeks to an average $9.7 \mathrm{~cm}(\mathrm{SD}=1.9, \mathrm{n}=12)$ at age 4-5 weeks (ANOVA; $\mathrm{F}=44.89, \mathrm{P}=0.001$; Fig. 5). Also, a significant increase in size of fish fed to chicks occurred in 1995 , with an average $4.2 \mathrm{~cm}(\mathrm{SD}=1.3, \mathrm{n}=25)$ at age $0-1$ weeks to a mean of 6.1 $\mathrm{cm}(\mathrm{SD}=1.2, \mathrm{n}=22)$ at age 2-3 weeks (ANOVA; $\mathrm{F}=26.51, \mathrm{P}=0.001$; Fig. 5).

There was no significant difference in feeding rates between first and second hatched chicks during 1994 (Paired $t$-test; $t=0.38, P>0.05$ ) or in 1995 (Paired $t$-test; $t=0.47, P>0.05$ ). Power of both of these comparisons was $86 \%$. Overall mean duration between feedings was $35.3 \mathrm{~min}(\mathrm{SD}=35.2 ; \mathrm{n}=27)$ during 1994 and $31.9 \min (\mathrm{SD}=30.2 ; \mathrm{n}=33)$ during 1995. Durations were between less than one minute to greater than $200 \mathrm{~min}$ during 1994 and $100 \mathrm{~min}$ during 1995. In 1995, there was no significant difference in feeding rates between broods with one or two chicks (Student's $t$-test; $t=-1.36, P>0.05$; Power $<10 \%$ ). There was no time period during the day when adults were carrying a maximum number of prey for 1994 (ANOVA; $F=1.50, P>0.05$ ) or 1995 (ANOVA; $F=0.07$, $P>0.05)$. Power of these comparisons, however, was less than $30 \%$. 


\section{EOOD HABITS}

Although a cumulative species curve indicated about seven samples were required to adequately describe the number of species eaten in 1994 (Fig. 6a), 14 nest cup samples were collected at the breeding colony that year. Samples each contained one to four prey species. Fifty-seven percent of the samples were fish species and $43 \%$ were the freshwater Red swamp crayfish (Procambarus clarkii; Fig. 7). All fish otoliths were identifiable to species or genus. During 1994, eight taxa of prey were identified in nest cup samples (Table 6). Crayfish represented the most important prey item having a greater mean IRI value and occurring more frequently than shiner surfperch (Cymatogaster aggregata), although shiner surfperch occurred in the diet almost as frequently as crayfish.

Thirty-five nest cup samples were collected during 1995, although a cumulative species curve indicated only 10 to 15 samples were required to adequately describe the number of species eaten (Fig. 6b). One to nine prey species were present in each nest cup sample, with $84.7 \%$ representing fish species, $14.6 \%$ representing crayfish, and $0.7 \%$ unidentifiable otoliths (Fig. 7). The greatest number of taxa $(n=12)$ were identified in nest cup samples collected during 1995 (Table 7). Shiner surfperch had the greatest frequency of occurrence and mean IRI values, whereas crayfish were second in IRI rankings.

During 1996, 32 samples of freshly regurgitated pellets were collected at nests, a cumulative species curve indicated that about seven samples were required (Fig. 6c). Diversity of prey recovered from regurgitated pellets was less during 1996 than 1994 and 1995 nest cup samples. Regurgitated pellet samples did not all contain identifiable hard parts, therefore, pellets each 
contained zero to three prey species ( $98 \%$ of prey were fish species and $2 \%$ crayfish; Fig. 7). Caspian Terns ate only five taxa in 1996 as represented in regurgitated pellets (Table 8). Shiner surfperch were the most important prey item and crayfish decreased to fourth important. Pacific staghorn sculpin (Leptocottus armatus) were not found in any samples.

Mean number of species (S) found per nest cup or regurgitated pellet sample was compared among years. A significantly greater number of prey species occurred during 1995 with a mean 3.4 species $(S E=0.4, n=29)$ and least number in $1996(\bar{x}=1.43, S E=0.14, n=23$; Kruskal-Wallis; $H=19.91, P=0.001$; Fig. 8). Significant differences were found among years in mean species diversity ( $\mathrm{H}^{\prime}$; Kruskal-Wallis; $\mathrm{H}=13.24, \mathrm{P}=0.001$ ), the least species diversity occurred in $1996\left(\mathrm{H}^{\prime} ; \bar{x}=0.27, \mathrm{SE}=0.08\right)$. A significantly greater mean dominance (D) index occurred during $1996(\bar{x}=0.81, S E=0.05)$, and the least dominance in prey eaten was in 1994 ( $x=0.46, S E=0.05$; Kruskal-Wallis; $H=13.46, P=0.001$; Fig. 8). Significant differences were found in mean index of specialization (R) among years (Kruskal Wallis; $\mathrm{H}=6.38, \mathrm{P}=0.042$ ), in 1996 there was the greatest mean specialization $(\bar{x}=0.65, \mathrm{SE}=0.1)$ and during 1994 least mean specialization $(x=0.16$, SE$=0.07$; Fig. 8$)$.

The percentage number of northern anchovy/silversides fed to Caspian Terns (as determined by direct observation) was greater than shiner surfperch during 1993 (72.4\%) and 1994 (74.3\%), but were equally abundant during 1995 (Fig. 9). Pacific staghorn sculpin were observed rarely during all three years and crayfish were observed as prey only in 1995. No significant differences in abundance of shiner surfperch or northern anchovy/silversides as prey were found among the three years of direct observations (Kruskal-Wallis; $\mathrm{H}=5.92$ and $H=3.49, P^{\prime} s>0.05$, respectively). 
Diversity and percentage of number of species differed between the two sample collection methods. Prey determined from otolith samples of nest cups were more diverse than prey observed by direct observations during 1994 and 1995 (Figs. 10A and 10B).

Estimated lengths of fish prey eaten by Caspian Terns identified from otoliths were compared annually from 1994 through 1996. Mean length of shiner surfperch consumed during the three years was $8.5 \mathrm{~cm}(S D=1.4, n=256)$, and there was no significant difference in size distribution among years (Kolmogorov-Smirnov; D's=0.175, 0.139, 0.088, P's>0.05, respectively; Fig. 11). The mean length of topsmelt was $14.1 \mathrm{~cm}(\mathrm{SD}=2.4, \mathrm{n}=38)$ and did not differ significantly among years (Kolmogorov-Smirnov; D's=0.371, 0.333, 0.238, $P^{\prime}$ s>0.05, respectively; Fig. 12), although, sample size for 1996 was smaller than previous years.

The following species were not well represented in pellet samples during 1996, therefore, comparisons were made only between 1994 and 1995. No significant differences were found in mean estimated length of northern anchovy $(\bar{x}=8.3 \mathrm{~cm}, \mathrm{SD}=1.2, \mathrm{n}=22$ ) between years (Kolmogorov-Smirnov, $D=0.352, P>0.05 ;$ Fig. 12). Pacific staghorn sculpin $(\vec{x}=7.2 \mathrm{~cm}, S D=1.9, n=35)$ consumed by Caspian Terns were similar in size during both years (Kolmogorov-Smirnov; $D=0.333, P>0.05$; Fig. 13). During 1994, only two samples contained white croaker (Genyonemus lineatus) and during 1996, this species was not found in samples (Fig. 13). Plainfin midshipman (Porichthys notatus), and jacksmelt were not represented in otolith samples during 1994 and 1996, however, their size distributions for 1995 were of interest (Fig. 14). 
Mean length of fish observed eaten in the colony, from 1993 through 1995, was $8.2 \mathrm{~cm}(\mathrm{SD}=2.9, \mathrm{n}=471)$. Caspian Terns were observed consuming shiner surfperch with a mean estimated length of $7.5 \mathrm{~cm}(\mathrm{SD}=2.2, \mathrm{n}=139 ;$ Fig. 15). Estimated lengths eaten during 1994 were significantly larger than those consumed in 1993 (Kolmogorov-Smirnov; D=0.660, P=0.001) and 1995 (Kolmogorov-Smirnov; $D=0.777, P=0.001$, Fig. 15). Estimated lengths of northern anchovy/silversides $(x=8.6 \mathrm{~cm}, \mathrm{SD}=3.1, n=299)$ were larger in 1994 than those eaten in 1993 (Kolmogorov-Smirnov; $D=0.571, P=0.001$ ) and 1995 (Kolmogorov-Smirnov; $D=0.724, P=0.001$; Fig. 15). Pacific staghorn sculpin were observed more frequently during 1994 than 1993 or 1995, however, due to small sample size, no comparisons could be made among the three years (Fig. 16).

Sample collection methods were compared to determine if otolith sampling and direct observations equally assessed the length of prey items of Caspian Terns. No significant differences in length were found for shiner surfperch documented by either method (Student's t-test; $\mathrm{T}=1.14, \mathrm{P}>0.05$; Power $<10 \%$ ) or Pacific staghorn sculpin (Student's t-test; $T=-0.54, P>0.05$; Power $<10 \%$ ). However, northern anchovy/silversides prey lengths assessed using otolith samples were significantly greater than prey lengths determined by direct observations (Mann-Whitney test; $U=669.00, P=0.001$ ).

\section{CONTAMINANT ANALYSIS}

All Caspian Tern eggs contained concentrations of DDE, PCB 1260, and trans-nonachlor (Table 9). Concentrations of DDE in eggs increased from a mean of $3.06 \mathrm{ppm}$ in $1994(\mathrm{SD}=0.1, \mathrm{n}=2)$ to a mean of $6.98 \mathrm{ppm}$ in $1995(\mathrm{SD}=5.7$, $\mathrm{n}=24$ ). In 1995 , more than $25 \%$ of whole eggs analyzed had DDE 
concentrations greater than $8.4 \mathrm{ppm}$, a quantity found in San Diego Bay that ostensibly affected hatching (Ohlendorf et al. 1985). PCBs increased between $1994(\bar{x}=0.79$ ppm, SD=0.4, $\mathrm{n}=2)$ and 1995 ( $\bar{x}=1.43$ ppm, SD=0.7, $n=24)$.

Of forty compounds screened, twelve were detected in 1995 samples and eleven in 1996 (SRNWR) samples (Table 9). However, not all of these twelve contaminants were detected in 1994 samples nor in the control samples from Napa Marsh (1996). Toxaphene ranging between 0.38 and $6.56 \mathrm{ppm}$, was found in about half of eggs sampled during 1995. All other years and sites indicated no or low residue levels of toxaphene (Table 9).

Except for DDD and trans-nonachlor, no significant differences in mean organochlorine concentrations occurred in eggs between ESNERR (1995) and SRNWR (1996; t-test; $n=35, P>0.05$ ). Power of this comparison was less than $10 \%$, and different times and locations possibly confounded the results. Mean DDD coricentrations significantly differed between years ( $t$-test; $t=2.85$, $\mathrm{P}=0.007$ ), also trans-nonachlor differed between years ( $t$-test; $t=2.19, \mathrm{P}=0.03$ ). Mean egg volume did not differ significantly among years and sites (ANOVA; $F=1.27, P>0.05$ ), nor did mean eggshell thickness differ significantly (ANOVA; F=0.87, $\mathrm{P}>0.05$; Table 10). Power of both comparisons, however, was less than $10 \%$.

DDE, DDD, DDMU, PCB, dieldrin, trans-nonachlor, and hexachlorobenzene concentrations in eggs were correlated negatively with eggshell thickness in samples from 1995 (Table 11). Specifically, DDE concentrations were the most negatively correlated with eggshell thickness during $1995\left(r^{2}=-0.230, P=0.018, n=24\right)$. Also, significant positive intercorrelations occurred between DDE, DDMU, $\mathrm{PCB}$, trans-nonachlor, oxychlordane, and hexachlorobenzene concentrations (Table 11). 
Although correlations were not significant as in 1995, DDE, PCB, and oxychlordane concentrations in 1996 were correlated negatively with eggshell thickness (Table 12). Significant positive intercorrelations occurred between DDE, DDMU, dieldrin, PCB, trans-nonachlor, and oxychlordane concentrations (Table 12).

Mean DDE:PCB ratios for 1994 and 1995 were 3:1 and 7:2, respectively. Ratios from SRNWR and Napa Marsh in 1996 were 6:2 and 4:1, respectively.

All prey items contained detectable levels of DDE residue. Fish collected in 1994 contained the least amount of DDE residue (Table 13) and did not contain detectable residues of any other contaminant, whereas crayfish collected in April 1997 contained the greatest amount of DDE residue and substantial concentrations of DDD, DDMU, DDT, transnonachlor, and dieldrin. Fish sampled in 1995 also contained DDE residues. One pooled sample of shiner surfperch contained $0.470 \mathrm{ppm}$ DDE, 0.0099 ppm DDD, 0.0061 ppm DDT, and 0.0022 ppm dieldrin. Samples containing shiner surfperch, collected during 1995 and 1996, had the greatest amount of DDE residue of all fish species collected in those years. Other samples contained low levels of DDD, DDT, and dieldrin. Mean DDE residues differed significantly among the four years (ANOVA; $F=8.94, P<0.01$ ), the 1997 samples being greater than other years. Toxaphene and PCBs were not detected in any prey items.

Of four nest cup samples collected in 1995, all contained detectable levels of DDE residue. One sample contained $0.300 \mathrm{ppm}$ (dry weight) DDE, as well as $0.320 \mathrm{ppm}$ toxaphene. This particular sample contained detectable residues of 16 organochlorine contaminants and PCB-1260. The remaining three samples did not contain toxaphene, nor many other organochlorine 
contaminants.

Levels of DDE, PCBs, and toxaphene were below detection limits in the water of five grab samples collected during 1995 from the northern region of Elkhorn Slough. In the sediment of eight grab samples collected, DDE concentrations were between 0.002 and $0.053 \mathrm{ppm}$ dry weight. DDE concentrations in sediment from grab samples collected from Hudson's Landing tidegates $(x=0.016 \mathrm{ppm}, \mathrm{SD}=0.025, \mathrm{n}=4)$, Elkhorn Slough main channel upstream of Kirby Park ( $\bar{x}=0.012$ ppm, SD=0.004, $n=3$ ), and behind the Firehouse $(\bar{x}=0.021 \mathrm{ppm}, \mathrm{SD}=0.001, \mathrm{n}=2)$ were greater than elsewhere. These areas encountered much of the flood waters that spilled from the Pajaro River (Steve Kimple pers. comm.). Toxaphene was not detected in any of these sediment grabs, and PCBs were detected in only three samples and at low levels.

Of 28 chicks retrieved from the colony during July 1995, all were too decomposed for organochlorine analysis, however, several were noted to have crossed beaks and "cranial malformations" (abnormal skull protrusions). Chicks removed from eggs in late stages of development also exhibited signs of deformity (B. Hosea CDFGPIU, pers. comm.).

The adult Caspian Tern, collected in 1995, did contain levels of DDE, $\mathrm{PCBs}$, and toxaphene in its liver and brain that were greater than detection limits (Table 14), but these levels were not considered lethal doses (B. Hosea CDFGPIU, pers. comm.). Levels of DDE, PCBs, and dieldrin were less in the Caspian Tern adult collected in 1997 than the one sampled in 1995. Toxaphene, which was present in the liver of the 1995 adult, was not detected in the 1997 adult (Table 14). Organochlorine concentrations found in livers of four decapitated chicks from SRNWR during 1996 were not markedly lower 
than concentrations found in the adult's liver collected in 1995. The most unusual observation was that no toxaphene was detected in the chick livers (Table 14).

During 1995, a juvenile Great Egret was found below nests at ESNERR with a broken wing and leg. Organochlorine analysis indicated DDE residues were not as notable as the 1995 adult Caspian Tern, but dieldrin and toxaphene levels were similar (Table 14). PCB-1260 was not detected in the liver or the brain, however, PCB-1254 was detected in the liver.

Sub-samples of eggs collected during 1994 and 1995 at ESNERR, and 1996 Napa Marsh (control) were analyzed for nine trace metals (Table 1). Mean concentrations of mercury in $1994(\bar{x}=0.66 \mu \mathrm{g} / \mathrm{g}, \mathrm{SD}=0.20, \mathrm{n}=2)$ and 1995 $\sqrt{x}=0.99 \mu \mathrm{g} / \mathrm{g}, \mathrm{SD}=0.34, \mathrm{n}=11)$ were less than the control group in $1996(\bar{x}=1.29$ $\mu \mathrm{g} / \mathrm{g}, \mathrm{SD}=0.08, \mathrm{n}=2)$. Mean selenium levels were greatest in $1994(\bar{x}=0.60$ $\mu \mathrm{g} / \mathrm{g}, \mathrm{SD}=0.11, \mathrm{n}=2)$, less in $1995(\mathrm{x}=0.48 \mu \mathrm{g} / \mathrm{g}, \mathrm{SD}=0.09, \mathrm{n}=11)$, and intermediate in $1996(x=0.51 \mu g / g, S D=0.11, n=2)$. Samples from 1994 indicated increased concentrations of copper and zinc, whereas samples from 1995 and 1996 did not appear to contain these elements. Remaining trace metals were not detected at reporting limits or were not at concentrations of concern (B. Hosea, CDFGPIU, pers. comm.).

\section{DISCUSSION}

\section{POPULATION DYNAMICS}

After a 12-year absence, Caspian Terns returned to Elkhorn Slough. In 1992, the Caspian Tern population in Monterey Bay, which had been virtually 
non-existent, began to increase rapidly. This increase in colony size may have been the result of immigration, redistribution, or recruitment of other individuals.

San Francisco Bay is the nearest known location for other Caspian Tern breeding colonies. A breeding colony has existed near Mowry Slough, located on the southeastern end of San Francisco Bay, during the past 60 years. Recent maximum counts at this colony were between 300 and 700 adults during the 1980's (SFBBO unpubl. data). However, beginning in 1990, the maximum adult counts decreased to 200 individuals. While the ESNERR colony increased, the maximum count at Mowry Slough was only 189 adults and 79 nests during 1994, and only 210 adults and 65 nests during 1995 (SFBBO unpubl. data). Some San Francisco birds may have joined the Elkhorn Slough colony at wintering grounds, along migration routes, or expanded their breeding range to Monterey Bay, thus increasing the breeding colony at Elkhorn Slough. The changes in the San Francisco Bay colonies, however, may have no relevance to the Elkhorn Slough colony. The decrease in San Francisco Bay may have been due to red fox (Vulpes vulpes) and feral cat predation or an increased breeding population of California Gulls (Larus californicus) that may have out-competed Caspian Terns for prime breeding locations. During 1997, a California Gull colony was at Mowry Slough, a site previously used by Caspian Terns (pers. obs.).

Recently, Caspian Terns have been expanding their range (Gill and Mewaldt 1983). It is conceivable that as more birds are traveling northward they may take residence in Elkhorn Slough. Gill and Mewaldt (1983), using band returns, suggested that segregation that is dependent on natal origin did not occur on the wintering grounds. However, samples from Grays Harbor, 
Washington and San Francisco Bay colonies were too small to quantify the amount of mixing that occurs at wintering areas. Mixing of Caspian Terns at wintering areas, allows for the possibility that Caspian Terns from other colonies may redistribute to new or different colonies. In Gill and Mewaldt's (1983) study, it seemed that the San Diego Bay colony was the primary source of birds expanding to more northerly colonies. Moreover, recent studies based on banding records indicated a greater dispersal rate to other colonies by first-time breeders than older breeders (Ludwig 1965, Gill and Mewaldt 1983, L'Arrivee and Blokpoel 1988). Gill and Mewaldt (1983) suggested that first-time breeders have difficulty establishing a territory in their natal colonies, therefore, relocate to other areas possibly creating new colonies. Cuthbert (1988) found that birds banded as adults were philopatric by returning to breed at colonies they used the previous year. ESNERR may have been partially colonized by young breeders relocating to a new area and these individuals returned to the same location each year to continue breeding.

During 1995 at Elkhorn Slough, the maximum number of adults decreased $36.3 \%$ from 1994 . They may have emigrated, dispersed, or redistributed due to overpopulation. Because the breeding island is small and space not readily available, some breeders may have moved to new locations or returned to previously used colonies. Other factors that may have influenced the decrease in adults during 1995 may have included the heavy rainy season that occurred during the winter/spring of 1994-1995. Vast flooding occurred along the Pajaro River Valley affecting Elkhorn Slough and surrounding rivers emptying into Monterey Bay. Adults arrived at the breeding area later than previous years and in fewer numbers. Monterey Bay 
was not the only area affected by unusual spring rains, most of the Pacific coast was deluged for several weeks, possibly impacting the spring migration of the terns and other shorebirds that winter in Mexico and further south. Nevertheless, everything appeared as it had in previous years once the colony began breeding activities.

Because only one visit was made into the colony and observations were from a distance, exact dates for clutch initiation and completion were not determined. Thus, the Mayfield method for calculating hatching success could not be used (Mayfield 1975).

Mean clutch size was 1.7 in Elkhorn Slough, whereas it was 1.8 for years 1992 to 1997 at BCER, and 2.1 to 2.3 at the Great Lakes region (Ewins et al. 1994, Collins unpubl. data; Table 5). Ewins et al. (1994) found significant differences in mean clutch sizes among colonies at different sites within the same lake, for example mean clutch size at Hat Island (1.9) was significantly less than mean clutch size at Gull Island (2.2). Harvey (1982) reported a mean clutch size of 1.9 in Elkhorn Slough, and a mean of 1.6 was found in Mowry Slough in 1986 (SFBBO unpubl. data; Table 5). All areas except Mowry Slough, had a greater mean clutch size than Elkhorn Slough. The colonies of the Great Lakes have more occurrences of three chick broods than California or Texas colonies of Caspian Terns (Ludwig 1965, Quinn 1980, Harvey 1982, Mitchell and Custer 1986, Ewins et al. 1994).

The Great Lakes colonies have existed for decades and are well established, whereas the ESNERR colony had a brief history at the current site and a discordant history in the Monterey Bay region. Fluctuations in population and reproductive success are more likely to occur in a new colony that is not well established and possibly colonized by more first time 
breeders. Reproductive output in 1994 was similar to that presented by Harvey (1982) and greater than San Francisco Bay (Table 5). Data related to reproductive output was not collected during 1992 or 1993, but counts of Caspian Tern chicks steadily increased during the three-year period between 1992 and 1994. Decreased reproductive output after 1994 probably was due to contaminants and predation.

During 1996, numbers of Caspian Terns decreased by 30\% from the previous year in Elkhorn Slough. Eggs were laid by mid-May, but by lateMay a predator had eaten all of them. Most likely a raccoon (Procyon lotor) or red fox swam across to the island and ate the eggs. I believe, based on timing of egg-laying and chicks hatching, that individuals from ESNERR relocated and began a second nesting attempt at SRNWR. Because these birds were not banded, there is a possibility that they were birds from a different colony. There is evidence, however, indicating that if initial nests fail, especially early in the breeding season, pairs may renest (Shugart et al. 1978, Cuthbert 1985, 1988). Moreover, disturbances such as predation, human visitations, and storms can cause abandonment of nesting sites (Cuthbert 1988). When disturbed early in the nesting season, terns display an inclination for desertion of the colony which seems to be an antipredator response (Buckley and Buckley 1980). As with most larid species, Caspian Terns also use other anti-predator strategies which include: synchronous timing of breeding (hence, synchronous hatching of most chicks), mobbing predators, noise, and colony flushes to ward off some disturbances. If attacked at night, however, they may respond by leaving the site. Conover and Miller (1978) showed that Ring-Billed Gulls (Larus delawarensis) were more likely to desert their colonies when disturbed after dark. 
During 1995, the loss of young was primarily due to eggs not hatching and chicks dying during hatching. Predation on several chicks that hatched and survived several weeks, occurred after most of the colony had departed. Two chicks, one about four to five weeks of age, the other three to four weeks, were found decapitated and one adult head with no body also was found. These may have been the result of an owl or raptor attack. Because fewer birds were in attendance at the colony, the risk of predator attacks may have increased greatly. During 1996, predation early in the nesting season may have caused total abandonment from the ESNERR colony site. Because there was no prior evidence of predation at this colony, especially during the years the colony was increasing, predation probably had a minimal effect on this colony until late in the 1995 breeding season.

During 1996, a second predation event occurred at the relocated colony at SRNWR. The twelve chicks that survived for more than a week were attacked within a 48-hour period. Four decapitated chicks were found near nests, and the other eight chicks never were found. The evidence indicated that the predator was most likely an owl. Owl predation is characterized by decapitated and partially eaten bodies of victims (Burger and Gochfeld 1991).

The proportion of Caspian Tern eggs that failed to hatch or died during hatching increased markedly from 1994 to 1995 . Furness and Hutton (1980), studying Great Skuas (Catharacta skua), indicated that addled eggs and chicks dying during hatching usually form only a small proportion of the total eggs laid by many seabird species, and that on occasion, there will be years adversely affected by pollutants or disturbance. In their study, maximum incidences of addled eggs and chicks dying during hatching of 
four tern species was $1.3 \%$ to $8.0 \%$. In Elkhorn Slough, $34 \%$ of the eggs were addled or chicks died during hatching in 1995 and 40\% in 1996.

During July of each year, departure of adults and fledglings from the breeding colony was gradual until the third week of July when adults and fledglings departed en masse. Hulsman and Smith (1988) described a similar pattern in Black-naped Tern (Sterna sumatrana) colonies in Australia. The young of this species are dependent on parents for food for several months. A large proportion of chicks hatch during the same period, therefore, they are ready to fledge at about the same time. Food abundance (e.g. juvenile fish) in Elkhorn Slough and Monterey Bay may peak during late July, which may ensure that chicks will catch food relatively easily. Caspian Tern chicks will remain with adults for up to a year learning foraging techniques and migration routes (L'Arrivee and Blokpoel 1988, Terres 1991).

\section{ACTIVITY PATTERNS}

Caspian Terns exhibit a great amount of parental care. Both adults incubate the eggs and feed and care for chicks. During early stages of egglaying, males continue to feed females, while they lay and incubate eggs, as a courtship activity (Nisbet 1973). Because adults rotate duties at the nest, activity patterns can be determined for adult care of chicks.

Comparisons of activity patterns between years was limited by the small sample sizes for the 0-1 and 5-6 week groups during 1994, and the lack of data for chicks past the 2-3 week stage due to reproductive failure and high mortality during 1995 . The 0-1 age group indicated non-significant results more frequently, most likely because of greater variability or small sample size. 
As with many seabirds, Caspian Tern chicks are poikilothermic for several days after hatching and must be brooded by an adult until they can thermoregulate (Ricklefs 1974). During brooding, parents alternate the amount of time spent at the nest and foraging for themselves or the chicks. As expected the frequency of nest reliefs decreased with increasing growth of chicks. As chicks became more independent and needed less brooding, beginning around the 1-2 week age, one adult was able to stay away from the colony for longer periods. Nest reliefs occurred minimally after chicks reached 3-4 weeks. This trend differs greatly with a study on Double-crested Cormorants in the Gulf of St. Lawrence, whereby, nest reliefs continued to increase as chicks grew and remained at great frequencies until chicks were more than 36 days of age (Leger and McNeil 1985). An explanation for this difference could be because Double-crested Cormorant chicks are not as precocial as larid chicks and require a longer period of intense parental attendance.

Mean number of foraging trips remained steady throughout all age groups of chicks in 1994, but number of trips fluctuated and were at a greater intensity in 1995. I expected the mean number of foraging trips to decrease with increased brood age because adults caught larger prey as chicks grew larger, thereby, reducing the number of foraging trips needed. Leger and McNeil (1985) found that the mean number of foraging trips of Doublecrested Cormorants decreased with increased chick age. Small sample sizes, foggy weather, and the time of day that observations were conducted may have affected the data in 1994. Also, some observations of adults returning with fish could have been missed. Because chick survival rates were less in 
1995, adults may have increased their foraging effort, by increasing foraging trips, to ensure their chicks survival.

Feeding patterns exhibited by Caspian Terns in Elkhorn Slough were consistent with previous studies of other larid species (Kirkham and Morris 1979, Quinn 1980, 1990). During brooding in the first week, fewer feeding periods (meals to chicks) occurred because chicks were small and often had to be persuaded to emerge from under their parent. As 1-2 and 2-3 week-old chicks became more independent and were growing at an increased rate, more feeding periods occurred. Feeding periods decreased after 4-5 weeks probably because chicks could be fed larger fish at one feeding, which would sustain them for longer periods. Chapdelaine et al. (1985) reported prey delivery rates of Common and Arctic Terns to be greatest at 11-20 days, whereas, 1-10 day and > 20 day aged chicks received similar numbers of fish, indicating that the greatest growth period for larid chicks is during one to three weeks of age.

The number of times both adults were present at the nest site coincided with the age of the brood. Both parents often were visible at the nest until chicks were more than one week of age. Adults began to spend less time at the nest when chicks had attained a larger size and more independence (2-3 weeks). Also, feeding periods decreased at this brood age. By the third and fourth weeks, chicks were large enough to defend themselves from neighbors, however, those chicks alone at nests may have suffered energetic costs to their growth (i.e., chicks may be attacked by neighbors or by predators). Variability occurred among family units, at some nests chicks were alone frequently because both parents departed from the colony, whereas other pairs continued alternating stays at the nest. Broods that receive continuous 
protection and care by at least one parent, most likely the more experienced individuals, may be fed more frequently, remain in better overall condition, and may fledge earlier due to the extended care. Observing the number of times parents are present may be a good indicator of parental breeding experience.

Length of fish fed to Caspian Tern chicks steadily increased as they aged. This was consistent with previous studies (Kirven 1969, Quinn 1990). While chicks are brocding, they do not eat large fish, but as they grow they are able to consume larger fish. Caspian Terns in Elkhorn Slough tried to feed their chicks large fish at early ages, possibly to increase the growth of chicks, decrease the number of trips adults made to maintain the energy demands of chicks, or that was what was available. These attempts to feed large fish to chicks generally resulted in a failed feeding because the fish were larger than the chick, but several chicks did eventually swallow these large fish. As mean number of feeding periods (meals to chicks) decreased with brood age, size of fish steadily increased. Adults most likely gained more time to forage for themselves at this stage of chick rearing. In Common Terns, fish size significantly increased after chicks were more than 20 days old (Chapdelaine et al. 1985). Observations in Elkhorn Slough indicated a steadier increase than Common Terns, with a significant increase occurring between ages 0-1 and 1-2 weeks(Fig. 5).

Frequency of feedings was similar for first and second hatched chicks from the same brood in Elkhorn Slough. In contrast, a study in Ontario, Canada, indicated that first hatched chicks were fed significantly more frequently than second hatched chicks (Quinn 1980). Experience of the adults may be a factor determining whether chicks were fed alternately. At 
ESNERR, there was variability in number of feedings to individual chicks, whereby in some broods, chicks were fed alternately and others were not. Most likely, when an adult arrived with a fish, the reaction time of chicks determined which one was fed. Hulsman and Smith (1988) found that Blacknaped Terns fed whichever chick reached the adult first, therefore, chicks were not necessarily fed alternately or equally. I also found, for recognizable broods in Elkhorn Slough, all chicks were not fed equally in a brood.

Mean duration between feedings of Caspian Terns in Elkhorn Slough was consistent with previous studies of tern species. Hulsman and Smith (1988) reported a mean interval of $49.6 \mathrm{~min}(\mathrm{SD}=52.9, \mathrm{n}=102)$ with a range of one to $276 \mathrm{~min}$ between chick feedings of Black-naped Terns. Most likely, longer durations between feedings indicated adults had flown further distances to forage or they may have been feeding themselves and resting. In Elkhorn Slough, adults returning without fish for a chick, often stimulated the other parent to depart and return within several minutes with a fish.

Feeding rates of Caspian Terns in Elkhorn Slough varied throughout the day, but peak times were not discrete. Quinn (1990) found similar results with a Caspian Tern colony in Texas. In contrast, several studies have indicated two discrete feeding periods for other larids, one shortly after sunrise, the other late afternoon (Kirkham and Morris 1979, Schaffner 1990, Smith 1990). Possibly climate was a factor in some studies and in Elkhorn Slough. During the summer, Elkhorn Slough frequently is enshrouded in fog and this may impair the Caspian Terns ability to locate fish. Early morning observations often could not be conducted due to heavy fog; 1994 was an especially foggy summer, therefore, fewer early morning observations were conducted than during 1995. Smith (1990) suggested that Black-naped Terns, 
a tropical species, tended to "loaf" during the hotter parts of the day and increased chick feeding activities during early morning and late afternoon. Because of summer fog, which may remain all day, Elkhorn Slough generally does not have a hotter time of day. During 1994, nine of ten days sampled were foggy and cool all day.

Because the mean duration between feedings was less than $40 \mathrm{~min}$ in 1994 and 1995, Caspian Terns probably were not traveling long distances to forage. Foraging activities were observed regularly in the main channel of Elkhorn Slough and in some of the outlying channels nearer to ESNERR. Food was available at a close proximity to the colony, hence, discrete feeding periods early and late in the day may not have been necessary.

\section{EOOD HABITS}

Many methods are employed to determine diets of seabirds, most of which are intrusive or cause mortality. Duffy and Jackson (1986) suggested sampling methods they considered ideal, because they inflicted minimal disturbance to birds, and simplified collection and replication. Methods included using hard parts of ingested prey or of prey dropped around nests, stomach casts or pellets, and direct observations of prey carried in bills.

Regurgitated pellets have been used by many biologists to determine diets of seabirds (Martini 1964, Koli and Soikkeli 1974, Harvey 1982, Ewins et al. 1994). Horn et al. (1996) reported that pellets found in Caspian Tern colonies were the direct result of regurgitations from both chicks and incubating adults. Also, they confirmed that Caspian Terns were one of a few species that had retrievable pellets. Smaller species, like the Forster's Tern 
(sterna forsteri), generally did not have intact pellets in their colonies (Horn et al. 1996, Loeffler 1996).

The limitations involved with sampling from nest cups at the end of the breeding season included possible buildup in number of gastroliths and otoliths from previous years and the effects of digestion and weathering of otoliths before recovery. Smaller otoliths may erode causing underestimates of prey diversity. For example, northern anchovy and staghorn sculpin have small and thin otoliths, this may be one reason why these two species were not as well represented in otolith samples, but were well represented during direct observations. Because prey items may be misrepresented in size, diversity, and quantity of fish in the diet of Caspian terns, chipped or eroded otoliths were not used. Erosion from digestion occurs within hours of the fish being consumed, therefore, fish length also may be underestimated.

Although, seabirds regurgitate pellets within a short time after swallowing their prey (Gales 1988), Koli and Soikkeli (1974) suggested that different groups of fish may be digested differently and that the size and number of fish in a tern's crop may affect rate of digestion. This was further supported by Gales (1988) study on Little Penguins (Eudyptula minor), which indicated that the rate of digestion of otoliths decreased with increased meal size. No conclusion can be made on whether or not meal sizes affected otolith erosion because the number of fish Caspian Terns consumed while foraging was not sampled. Furthermore, because samples from 1994 and 1995 were obtained from deposits in nest cups, the potential for erosion may have occurred as much outside the body as within.

Harvey et al. (1995) used a similar technique of collecting otoliths on sediments at a documented haul-out site of harbor seals to determine their 
diet. They found this technique had few biases in determining prey diversity, but may have indicated fewer numbers of certain fish species, especially those with smaller otoliths. The same may be true for Caspian Tern nest cup samples. Chicks were fed smaller fish and possibly unknown species of fish while they were young, generally this was about two months before nest cup samples were collected. This indicated a greater probability that erosion of otoliths occurred in the nest cup. Moreover, because observations of otoliths in freshly regurgitated pellets sampled during 1996 at SRNWR were less degraded and cleaner than otoliths from nest cup samples, digestive erosion probably was not a factor in this study. The greater source of erosion probably originated from otoliths weathering in nest cup debris.

Nest cup samples and freshly regurgitated pellets were compared to determine prey of Caspian Terns. I believe this was a fair comparison because the difference between the two sampling methods was that nest cup samples contained desiccated regurgitated pellets and dropped fish, whereas, freshly regurgitated pellets were still intact. Also, freshly regurgitated pellets were obtained opportunistically during the breeding season and collected from within nests or just outside nests. The result was the same, otoliths were present and could be used to determine which prey species were consumed. The advantage of collecting nest cup samples after the birds depart was that less disturbance occurred to the breeding colony. Researchers have reported many abandonments of eggs or breeding sites when frequently disturbed (Koli and Soikkeli 1974, Harvey 1982, Cuthbert 1985). Most food habit studies entail entering a colony at least once a week to collect fresh pellets or dropped fish, many of which cause great disturbances to the breeding birds, and biases to the study. Sampling of nest cups after birds have left for the 
season avoided major disturbances. This method provided a somewhat biased but consistent indication of prey ingested by Caspian Terns.

Direct observations of prey have limitations, primarily in that fish identification can be misrepresented. Silver thin-bodied fishes such as northern anchovy, topsmelt, and jacksmelt were difficult to identify, therefore, they were grouped. This method proved somewhat accurate when compared to nest cup samples, therefore, the biases probably were negligible.

Caspian Terns were observed feeding mainly in Elkhorn Slough, Moss Landing Harbor, and near shore coastal areas between Salinas and Pajaro Rivers. All species consumed, with the exception of crayfish, were abundant in these habitats. Crayfish are found only in freshwater and probably were captured along rivers, river mouths, and possibly at small ponds that remained after the rainy season. Although few white croaker and plainfin midshipman otoliths were found in nest cups, they have been noted previously in the Caspian Tern diet (Harvey 1982, Loeffler 1996).

Surfperches were the most numerous and frequently occurring prey during 1995 and 1996. In 1994, shiner surfperch were almost equal to crayfish in number and frequency of occurrence, but not in mass. The IRIs may be biased because mass most likely was overestimated for the crayfish specimens. Because crayfish were weighed while alive with their carapaces still attached, the mean weight probably did not accurately assess the mass that would be digested by a predator, considering that chiton is not important energetically. Obviously, shiner surfperch were a very important part of the Caspian Tern diet. Previous studies also have indicated that shiner surfperch often were the dominant food item of Caspian Terns in California (Kirven 1969, Baltz et al. 1979, Harvey 1982). In contrast, recent studies at BCER 
indicated northern anchovy as the dominant prey item (Horn et al. 1996, Loeffler 1996). This difference could be based on geographical abundance of certain prey species.

Previous fish surveys indicated that Elkhorn Slough serves as a spawning and nursery ground, resulting in greater abundance and species richness during the summer (Yoklavich et al. 1991, Barry et al. 1996). Shiner surfperch are viviparous and use tidal creeks, the upper slough (near Hudson's Landing), and the main channel of Elkhorn Slough as a nursery ground during late spring and summer (Barry and Cailliet 1981, Yoklavich et al. 1991). The increase in juvenile surfperch coincides with most of the Caspian Tern chick hatching. This provides a plentiful food resource of fish the appropriate size for small and growing chicks. Although, Oxman (1995) indicated a decrease in shiner surfperch abundance compared to studies conducted during the 1970 's, this species was still ranked first or second in overall abundance in Elkhorn Slough during 1991.

Caspian Terns in this study also fed largely on silversides and northern anchovy. Because of sampling method biases, abundance of these species in Elkhorn Slough probably have been underestimated (Yoklavich et al. 1991). Yoklavich et al. (1991) noted that topsmelt and jacksmelt abundance increased dramatically when sampled by beach seine rather than otter trawl. These species also use Elkhorn Slough habitats as spawning and nursery grounds, thus, supplying more juvenile fish into the foraging waters of Caspian Terns.

Pacific staghorn sculpin were a small but consistent component of the diet. Most likely Caspian Terns were catching these fish in Bennett Slough or the upper reaches of Elkhorn Slough near Hudson's Landing. Staghorn 
sculpins were found abundantly in both habitats (Yoklavich et al. 1991, Oxman 1995).

Several studies have indicated that various tern species consume crustaceans. Smith (1993) reported that in Australia, Crested Terns (Sterna bergii) fed prawns to their young and Chapdelaine et al. (1985) reported finding specimens of crustacea in Quebec colonies of Common (Sterna hirundo) and Arctic Terns (Sterna paradisaea). Crayfish have not been documented previously as a prey item of Caspian Terns in Elkhorn Slough, but have been documented at the Great Lakes (Ewins et al. 1994). Gastroliths were found abundantly during 1994 and 1995, but not in 1996. Because they were not sampled during those years, the abundance and availability of crayfish during those years was unknown. However, based on the ease of collection in the Pajaro River and Watsonville Slough during 1997, it is probable that this food source was relatively stable.

Direct observations of adult terns carrying crayfish into the colony were noted during 1995. These adults were flying towards the colony from the direction of the Pajaro River. During 1997, when crayfish were sampled, several terns were observed flying above the Pajaro River searching for food. Also, crayfish were visible in the water from at least three meters distance. Sampling of crayfish was not conducted at the Salinas River because Caspian Terns were not sighted returning from that direction during the years when crayfish were a large part of the diet. Also, while nesting at SRNWR in 1996, only a small percentage of crayfish were found in the diet. Harvey (1982) noted that Caspian Terns were feeding in the Pajaro and Salinas Rivers during his study from 1978 to 1980, however, he did not document crayfish in the diet. 
During 1996, prey items changed from previous years. Shiner surfperch remained the dominant prey, but there was less diversity in prey species consumed. Because the tern colony relocated to SRNWR, they may have changed feeding areas as well. Observations in Elkhorn Slough indicated fewer numbers of Caspian Terns feeding in traditionally used areas. Also, numbers observed at the Pajaro River mouth decreased, possibly indicating this was no longer a primary feeding area.

Direct observations of fish species carried in the bills of adult Caspian Terns corresponded with those species found from otolith identification. Several prey species, such as white croaker, plainfin midshipman, and spotted cusk-eel (Chilara taylori), collected in nest cup samples were not observed directly, however, these may have resembled other fish species and were identified incorrectly. Because of the distance of observations, observer mis-identification of fish, especially small fish, could have occurred.

Because silversides and northern anchovy were grouped together, percentage number of prey items was variable. The percentage of northern anchovy/silversides was greater than other species, although, shiner surfperch were abundant. During 1995, percentage number of shiner surfperch was equal to northern anchovy/silversides. Differences in results between direct observations and otolith samples, may be due to the size of fish brought to chicks. Small fishes, which were observed directly, may not have been identified from otoliths in nest cup samples because these small otoliths were eroded before collection of samples.

Differences in prey length between visual and nest cup samples were negligible for shiner surfperch and staghorn sculpin but there were differences with northern anchovy/silversides. Otoliths from two to five $\mathrm{cm}$ 
juvenile fish may have been small and fragile enough to degrade rapidly. Therefore, they were not well represented in otolith samples. Otolith samples represented adult and chick food habits, whereby direct observations generally represented what chicks were fed. Additionally, direct observations of fish length indicated a greater representation of the smaller size groups. Distributions of prey lengths in this study were similar to other studies of prey items of Caspian Terns. Baltz et al. (1979) reported prey of 7.5 to $10.0 \mathrm{~cm}$ for Caspian Terns in Elkhorn Slough. Loeffler (1996) found a range of two to $20 \mathrm{~cm}$ for dropped fish samples and four to $28 \mathrm{~cm}$ for directly observed samples of Caspian Tern prey items at BCER. Length distributions from ESNERR were within the same ranges as previous studies.

During this study, three to four prey species comprised $80 \%$ to $90 \%$ of Caspian Tern diets each year. In San Diego Bay only two species, shiner surfperch and topsmelt, comprised 88\% of the tern diet (Martini 1964). Other studies have indicated a similar dependence on few prey species by Caspian Terns. However, main prey items used by Caspian Terns may differ depending on geographic region. Gill (1972) noted of 21 prey species used, three species totaled $71 \%$ of the diet in San Francisco Bay. Baltz et al. (1979) determined that Caspian Terns in Elkhorn Slough were preying $100 \%$ on only two species, shiner surfperch and northern anchovy. Loeffler (1996) reported more than 30 fish species eaten but only two species accounted for $60 \%$ of the diet. Caspian Terns seem to prey on the most abundant fish species in the surrounding region where they are breeding. The ability to switch prey items when favored prey are unavailable allows Caspian Terns to adapt and survive in a wide range of areas. 


\section{CONTAMINANT ANALYSIS}

Criteria for egg selection in this study, was neither spatially nor temporally uniform. During 1994, eggs were collected by chance; in 1995, eggs were collected because of reproductive failure; in 1996, SRNWR eggs were collected freshly laid, and Napa Marsh eggs were obtained as a control group. Consequently, statistical comparisons with certain years were not possible due to the bias associated with the various collection methods and different sites. Because organochlorine analysis was not an original component of this study, there was a limited number of egg samples available during 1994. Additionally, the eggs collected in 1994 were found buried in soil and had been laying on the breeding island for the entire summer, possibly biasing measurements of eggshell thickness, composition of eggs, and fertility. During 1996, only 11 eggs were collected, however, these eggs were collected in the early stages of incubation. Because of small sample sizes, and in some analyses great variability, most comparisons had power less than $10 \%$. To increase power, most comparisons needed greater and equal sample sizes. For example, to obtain power of $80 \%$ for DDE concentration comparisons, years 1995 and 1996 would require a sample size of at least 28 samples each. Ohlendorf et al. (1979), however, suggested that ten eggs collected from randomly selected nests is a sufficient sample size to determine differences in pollutant concentrations.

The Caspian Terns of Elkhorn Slough suffered a devastating reproductive year during 1995 with greater than $95 \%$ of eggs failing to hatch or chicks dying during hatching. After major flooding occurred in Elkhorn Slough and throughout the Monterey Bay region during March, the terns arrived several weeks later and began acquiring energy reserves for the 
breeding season. Because of the relatively great hatching success during the three years before the floods, reproductive failure in 1995 was not expected. Therefore, background information on this colony before reproductive failure, greatly enhanced the determination of the cause of this reproductive collapse.

Eggs collected after the 1995 floods had the greatest number of pesticide contaminants compared with other years. Reproductive failure in birds that contained organochlorine contaminants was well documented when these chemicals were in widespread use during the 1960's (Blus et al. 1977). Since most of these chemicals were banned in the early 1970's in the United States, many studies have indicated increased populations of many detrimentally affected bird species; for example, ospreys and bald eagles (Ohlendorf and Fleming 1988). Several recent studies, however, have indicated disturbing increases in chemical residues found in birds and their eggs during the last two decades (King et al. 1983, Ohlendorf et al. 1985, Ludwig et al. 1993). Many of these elevated chemical residues and reproductive impacts have occurred after heavy rains and major flooding of waterways.

The probable cause of Caspian Tern reproductive failure in 1995 was organochlorine poisoning whereby pesticide residues were resuspended into the ecosystem after heavy rains and widespread flooding of waterways in the Monterey Bay region. Eggs collected in 1995 had twice the amount of DDE as 1994 eggs. Although only two eggs collected in 1994 were analyzed, observations of population dynamics and activity patterns of the Caspian Tern colony verified that reproduction was increasing until 1995. Observations of the tern colony during 1992, 1993, and 1994 indicated a 
healthy colony. Eggs were incubated the average amount of time, chicks were hatching normally and surviving, and no signs of deformities were evident in carcasses during those years.

Although mean DDE concentrations were slightly less than levels previously found in Elkhorn Slough during 1982 ( $x=7.64$ ppm, $n=10$; Ohlendorf et al. 1988) and San Diego Bay, California $(\bar{x}=9.30$ ppm, $n=25$; Ohlendorf et al. 1985), it is clear that organochlorine contaminants contributed to the Caspian Tern decline. Several eggs collected in 1995 had DDE concentrations greater than $10 \mathrm{ppm}$. Also, other contaminants found at elevated levels in this study were not detected or were detected only in extremely low concentrations in studies conducted by Ohlendorf et al. (1985, 1988). For example, toxaphene, found in somewhat high concentrations in Caspian Terns of Elkhorn Slough during 1995, was found only in one sample at a low level (residue $=0.17 \mathrm{ppm}$ ) in Elkhorn Slough in 1982. San Diego Bay samples also did not indicate substantial levels of toxaphene. During 1995, several other contaminants, DDD, DDT, dieldrin, cis-nonachlor, and oxychlordane, occurred in more samples and in greater mean concentrations, than either study by Ohlendorf et al. $(1985,1988)$. The combination of many pollutants at substantial concentrations may have impacted the reproductive success of Caspian Terns in 1995.

A recent study conducted at the Great Lakes indicated decreased concentrations of DDE (Ewins et al. 1994). Historically, organochlorine pollutant levels have been elevated at all the Great Lakes (Gilbertson et al. 1976, Pearce et al. 1979, Ludwig et al. 1993, Ewins et al. 1994), but Elkhorn Slough in 1995 had levels far greater than those found in studies at the Great Lakes (1980-1981 and 1991; Struger and Weseloh 1985, Ewins et al. 1994). 
Struger and Weseloh (1985) found DDE values ranging from 3.3 to $8.8 \mathrm{ppm}$, whereas Ewins et al. (1994) found values at about $3.0 \mathrm{ppm}$. Organochlorine pollutants at these levels were not at lethal levels in either of these studies.

During 1995, PCB concentrations were nearly equal to the concentrations found during 1982 in Elkhorn Slough, when deformities were not reported ( $\bar{x}=1.83, n=10$; Ohlendorf et al. 1988). In 1995, however, there were deformed chicks at the colony and chicks dying during hatching, both are classic signs of PCB-caused deaths (Ludwig et al. 1993, Mora 1996). In consideration of this important observation, PCB levels were expected to be greater. The levels of other pollutants in combination with each other and PCBs may have resulted in effects similar to classic $\mathrm{PCB}$ poisoning.

Greater than $50 \%$ of eggs collected in 1995 and 70\% of SRNWR eggs collected in 1996 had eggshell thicknesses below $0.297 \mathrm{~mm}$, a mean thickness of abnormal shells found in 1981 at San Diego Bay (Ohlendorf et al. 1985). Mean eggshell thickness of eggs were less by $15.0 \%$ in 1995 and $16.2 \%$ in 1996 when compared to a random sample of eggs collected from San Diego Bay between 1941 and 1945 (Table 10). Mean eggshell thicknesses from this study were less by $10.6 \%$ in 1995 and $11.8 \%$ in 1996 than a random sample of eggs collected from San Francisco Bay between 1924 and 1941 (Table 10). Mean eggshell thicknesses for all years of this study were less than eggs measured in San Diego Bay (1960-1964 and 1981), in San Francisco Bay (1971), and before DDT use (CDFG unpubl. data, WFVZ unpubl. data, Ohlendorf et al. 1985; Table 10). DDT and its metabolites have been reported as the cause of eggshell thinning in many seabird species (Fox 1976, Blus et al. 1977, Pearce et al. 1979, King et al. 1983). The most problematic metabolite seems to be DDE, but DDD, DDMU, and DDT also may increase the chances of thinning. At 
ESNERR, concentrations of all these chemicals occurred in more than half of the eggs collected in 1995. All DDT metabolites potentially interacted to decrease eggshell thickness of Caspian Tern eggs. Moreover, because these eggs were collected several weeks after laying, measurements should have indicated slightly greater eggshell thicknesses. Blus et al. (1977) reported that eggshells in Brown Pelicans thicken the longer they have been incubated. This may explain the slightly thinner eggshell thicknesses found in the SRNWR eggs collected in 1996, which were collected two weeks after laying. For many egg samples collected in this study, the eggshell membrane size was calculated using a mean membrane thickness which may have introduced further bias, especially when applied to eggs that were collected earlier in the incubation stage. Generally, a better experimental design would have been to collect eggs just after laying, however, delay in egg collection in this study was due to the unexpectedness of reproductive failure.

Because most seabirds are long-lived and are near the top of their food chains, pollutants, especially DDT and its metabolites, can be stored and concentrated in body tissue. These concentrations can increase at each level of the food chain, and cause reproductive impairment when these chemicals reach a sufficient level. Biomagnification of organochlorine contaminants in Caspian Terns probably occurred via prey consumed by terns upon arrival at Elkhorn Slough in 1995. Some contaminants, however, may have been introduced into their systems throughout their lives from feeding at wintering grounds or along migration routes. DDE residues in some fish samples taken from Elkhorn Slough for this study exceeded levels found in juvenile estuarine fish from California, in 1972 to 1976, and in fish brought to Caspian Tern chicks in San Diego Bay, during 1981 (Butler and Schutzmann 
1978, Ohlendorf et al. 1985). Earnest and Benville (1971) indicated surfperch as a species that typically contained sizable concentrations of DDT. Because shiner surfperch were the dominant prey item for Caspian Terns at Elkhorn Slough and were the most important prey during 1995, it is probable that much of the DDE contamination occurred from feeding on this species. Prey items determined by otolith identification or visual observation, did not indicate a sufficient difference in prey items among years to suggest that a different or new prey species was consumed that could have increased the amount of contaminants in Caspian Terns.

Because DDT and other pesticides were used near Elkhorn Slough for many years (ABA Consultants 1987), run-off from fields may have accumulated these chemicals in the sediments of the slough. Through time these chemicals break down, however, most have half-lives that last more than 10 years and break-down products that may be more dangerous and lethal than the original chemical. DDT has many break-down products, but the most dangerous to birds is DDE. Mussels analyzed from Elkhorn Slough contained substantial levels of total DDT and toxaphene (Phillips 1988). In fact, high levels of DDT were reported at Sandholdt Bridge, in Moss Landing during 1983 to 1985. Also, toxaphene was found at high levels at Parsons Slough, Sandholdt Bridge, and Watsonville Slough during 1982 to 1983 and 1985 to 1986 (Phillips 1988). It is probable that the 1995 heavy rainfall and flooding resuspended these dormant chemicals that had attached to aquatic bottom sediments in Elkhorn Slough. Also, vast amounts of agricultural sediments poured into the slough, depositing and circulating chemicals that had probably lain dormant in the soil for many years. Moreover, flood waters from the Pajaro River emptied into Elkhorn Slough. Water from these areas 
mixed and circulated throughout the Pajaro River Watershed, migrating Caspian Terns arrived only weeks later and began feeding on prey that had been exposed to resuspended pesticides.

Crayfish samples collected two years after the flood event indicated high levels of DDE. DDE residues may have been substantially greater in crayfish fed upon by terns during 1995 and 1996, thus increasing the biomagnification. Airaksinen et al. (1977) noted that prolonged exposure to DDT in the crayfish (Cambarus bartoni) resulted in DDT residue levels of 0.1 ppm persisting for up to two years, thus indicating a relatively great resistance in this species against the harmful effects of DDT. Because crayfish have a life expectancy greater than three years, those found in Watsonville Slough and Pajaro River, likely bioaccumulated these chemicals which were passed on to the Caspian Terns.

Although PCB and toxaphene residues were found in Caspian Tern eggs, they were not evident in prey samples. Fish samples, however, were collected several months to a year after the flood event and only four of the known Caspian Tern prey species were sampled for organochlorine analysis. Likewise, sampling of crayfish was not completed until 1997. Concentrations of PCBs and toxaphene in prey may have been observed if sampling had occurred during the breeding seasons of 1995 and 1996.

Background levels of toxaphene and PCBs may have accumulated in Caspian Terns. Exposure to various pesticides may have occurred earlier in their lives at resting grounds during migration or from wintering areas in Mexico and Latin America. However, it is more likely that toxaphene and PCB contamination occurred during 1995. The organochlorine residue results of the adult Caspian Tern (1995), had substantial levels of toxaphene 
and PCB-1260, whereas the chicks collected in 1996 and adult in 1997, did not indicate any levels of toxaphene and only low levels of PCBs (Table 14). In contrast, the grab samples collected from various sites in Elkhorn Slough during 1995, did not contain toxaphene residues and levels of PCBs were not greater than the detection limits. The absence of these residues may be due to the late sampling of water and sediments in Elkhorn Slough.

Several researchers have used the ratio between DDE and PCB concentrations to characterize polluted ecosystems as an indicator of the geographic location to determine whether birds were contaminated during the nesting season or at wintering areas (Fox 1976, Findholt and Trost 1985, Struger and Weseloh 1985). In Elkhorn Slough, no ratio between DDE and PCBs for prey items could be calculated because prey items did not contain detectable levels of PCBs. Based on this result, no conclusions can be made as to whether the birds were contaminated with PCBs at another area. Nevertheless, DDE residues and other chemical concentrations were relatively similar among fishes, grab samples, carcasses, and egg samples. Because of the nature of these chemicals binding to sediment particles, it is highly likely that they were resuspended into the ecosystem and entered the food web during 1995.

Although trace metal concentrations have been linked to decreased hatchability, altered nesting behavior, and reduced fledging rates, these concentrations were probably not a major factor affecting reproductive success in Elkhorn Slough or SRNWR (Connors et al. 1975, Holthem and Zador 1995). Mercury levels in eggs from this study were not markedly different than Least Tern eggs from San Diego Bay $(\bar{x}=1.07 \mathrm{ppm}, \mathrm{n}=15$; Holthem and Zador 1995), and were less than Caspian Tern eggs from San 
Francisco Bay ( $x=1.25$ ppm, $n=37$; Ohlendorf et al. 1988) and Royal Tern eggs from the Texas coast $(x=1.2 \mathrm{ppm}, n=30$; King et al. 1983). Also, the mean mercury concentration in eggs from this study were less than during 1982 $(\bar{x}=1.13 \mathrm{ppm}, \mathrm{n}=10$; Ohlendorf et al. 1988). Selenium concentrations were less than Royal Terns $(\bar{x}=1.00$ ppm, $n=30$; King et al. 1983) and Least Terns $(\bar{x}=2.41$ Ppm, n=17; Holthem and Zador 1995). Caspian Terns in Elkhorn Slough, probably were not affected by these low levels of trace metals.

\section{SUMMARY}

The Caspian Tern population in Elkhorn Slough increased each year after reestablishment in 1992, due most likely to immigration from other colonies or mixing from wintering grounds.

After the flood event of 1995, large-scale reproductive failure may have precipitated abandonment of the Elkhorn Slough colony site in the following breeding seasons. Low productivity occurred with first and late nests during 1996, however, predation on chicks from the late nests further decreased any reproductive success during that year. Recovery still was not evident during the 1997 season, when approximately 30 pairs of breeding adults nested to SRNWR, built nests, and abandoned the site after several weeks, thus there was no reproductive success $\sigma$. Warner, PRBO pers. comm.).

Activity patterns exhibited by Caspian Terns breeding in Elkhorn Slough were consistent with previous studies of other larid species, whereby feeding periods increased during the greatest growth period for chicks (1-2 and 2-3 week ages). Nest reliefs and amount of time parents spent at nests decreased with growth of chicks, whereby amount of time chicks were alone at nests and length of fish fed to chicks increased with chick growth. 
Feeding rates of Caspian Terns in Elkhorn Slough varied throughout the day, but peak times were not discrete as with tropical larid species.

Caspian Terns are opportunistic foragers and consume a variety of species of fish, but they appear to focus on the most abundant species in the area. Types of prey, such as shiner surfperch, northern anchovy, and silversides, consumed by Caspian Terns in Elkhorn Slough were consistent with previous studies of Caspian Tern diets in Elkhorn Slough (Harvey 1982) and San Francisco Bay (Gill 1976).

Because of different variables, the two collection methods (otolith sampling and direct observation) proved to be useful in determining the overall diet and size of prey consumed by Caspian Terns.

It seems that DDE and other pollutants precipitated the reproductive collapse in 1995. It is clear that organochlorine pollutants were substantially greater and occurred more frequently in 1995 than in the previous year. Eggshell thicknesses were affected and were substantially less than eggs measured at other sites along the California Coast or the Great Lakes in previous years.

Although these pesticides have not been in use for 25 years, amounts found in this study may have caused a total reproductive collapse of a breeding colony of birds. 


\section{LITERATURE CITED}

ABA Consultants. 1987. Elkhorn Slough Wetlands Management Plan Draft Report. Prepared for The Monterey County Planning Department and The California Coastal Conservancy. 128pp.

Airaksinen, M., E.L. Valkama, and O.V. Lindqvist. 1977. Distribution of DDT in the crayfish Astacus astacus L. in acute test. Freshwater Crayfish 3:349-356.

Altmann, J. 1974. Observational study of behavior: sampling methods. Behaviour 49:227-267.

American Ornithologist's Union (AOU). 1983. Check-list of North American Birds. Sixth Edition. Allen Press, Inc., Lawrence, Kansas. 877pp.

Atwood, J.L. and P.R. Kelly. 1984. Fish dropped on breeding colonies as indicators of Least Tern food habits. Wilson Bull. 96(1):34-47.

Bailey, S.F. 1993. Caspian Tern. In: Atlas of the breeding birds of Monterey County, California. D. Roberson and C. Tenney, eds. Monterey Peninsula Audubon Society, Carmel, California. p. 138.

Bailey, V. 1902. Unprotected breeding grounds. Condor 4:62-64.

Baldridge, A., T. Chandick, and D. DeSante. 1970. Middle Pacific Coast Region. American Birds 24(5): 713-715.

Baltz, D.M., G.V. Morejohn, and B.S. Antrim. 1979. Size selective predation and food habits of two California terns. Western Birds 10:17-24.

Barry, J.P. and G.M. Cailliet. 1981. The utilization of shallow marsh habitats by commercially important fishes in Elkhorn Slough, California. CalNeva Wildlife Transactions 1981:38-47.

Barry, J.P., M.M. Yoklavich, G.M. Cailliet, D.A. Ambrose, and B.S. Antrim. 1996. Trophic ecology of the dominant fishes in Elkhorn Slough, California, 1974-1980. Estuaries 19(1):115-138.

Bent, A.C. 1921. Life histories of North American gulls and terns. Smithsonian Institution, U.S. Nat. Mus. Bulletin 113.

Blokpoel, H. 1981. An attempt to evaluate the impact of carion-netting in Caspian Tern colonies. Colonial Waterbirds 4:61-67. 
Blokpoel, H. and Harfenist, A. 1986. Comparison of 1980 and 1984 inventories of Common Tern, Caspian Tern and Double-crested Cormorant colonies in the Eastern North Channel, Lake Huron, Ontario, Canada. Colonial Waterbirds 9:61-67.

Blus, L.J., B.S. Neely, Jr., T.G. Lamont, and B. Mulhern. 1977. Residues of organochlorines and heavy metals in tissues and eggs of Brown Pelicans, 1969-73. Pest. Monit. Jrnl. 11(1):40-53.

Buckley, F.G. and P.A. Buckley. 1972. The breeding ecology of royal terns Sterna (Thalasseus) maxima maxima. Ibis 114:344-359.

Buckley, F.G. and P.A. Buckley. 1980. Habitat selection and marine birds p. 69-112. In: J. Burger, B.L. Olla, and H.E. Winn (eds). Behavior of Marine Animals. Vol. 4. Marine Birds. Plenum Press, NY.

Burger, J. and M. Gochfeld. 1991. The Common Tern. Columbia Univ. Press, New York 344pp.

Butler, P.A. and R.L. Schutzmann. 1978. Residues of pesticides and PCBs in estuarine fish, 1972-76 - National Monitoring Program. Pest. Monit. Jrn. 12(2):51-59.

California Department of Fish and Game. 1986. Digestion and analysis of trace elements in tissues by Flame AAS and Graphite Furnace AAS. CDFG Standard Operating Procedure.

California Department of Fish and Game. 1986. Procedures for analysis of selenium and arsenic in fish and wildlife tissue with an emphasis on quality control.

Chanoit, G.E. Jr. 1970. Notes on color variation in downy Caspian Terns. Condor 72:460-465.

Chapdelaine, G., P. Brousseau, R. Anderson, and R. Marsan. 1985. Breeding ecology of Common and Arctic Terns in the Mingan Archipelago, Quebec. Colonial Waterbirds 8(2):166-177.

Cohen, J. 1977. Statistical Power Analysis for the Behavioural Sciences. Academic Press. New York, rev. ed. 474pp.

Connors, P.G., V.C. Anderlini, R.W. Risebrough, M. Gilbertson, and H. Hays. 1975. Investigations of heavy metals in common tern populations. Can. Field-Nat. 89:157-162. 
Conover, M.R. and D.E. Miller. 1978. Reaction of Ring-billed Gulls to predators and human disturbances at their breeding colonies. Proc. Col. Waterbird Grp. 1978: 41-47.

Custer, T.W., C.M. Bunck, and C.J. Stafford. 1985. Organochlorine concentrations in prefledging Common Terns at three Rhode Island colonies. Col. Waterbirds 8(2):150-154.

Cuthbert, F.J. 1985. Intraseasonal movement between colony sites by Caspian Terns in the Great Lakes. Wilson Bull. 97(4):502-510.

Cuthbert, F.J. 1988. Reproductive success and colony-site tenacity in Caspian Terns. The Auk 105:339-344.

DeGroot, D.S. 1931. History of a nesting colony of Caspian Terns on San Francisco Bay. Condor 33:188-192.

Duffy, D.C. and J. Jackson. 1986. Diet studied of seabirds: a review of methods. Col. Waterbirds 9(1):1-17.

Earnest, R.D. and P.E. Benville, Jr. 1971. Correlation of DDT and lipid levels for certain San Francisco Bay fish. Pest. Monit. Jrnl. 5(3):235-241.

Elkhorn Slough Estuarine Sanctuary Advisor Committee, Calif. Dept. of Fish and Game, and National Oceanic and Atmosph. Admin. Sanctuary Prog. Div. 1985. Elkhorn Slough National Estuarine Sanctuary Management Plan.

Emblen, D.L. 1954. Caspian Terns nesting at San Diego Bay. Condor 56:109110.

Evans, M.U. 1973. The reproductive ethology of the Caspian Tern (Hydroprogne caspia) breeding at San Diego Bay. M.S. Thesis, California State University, San Diego. $154 \mathrm{pp}$.

Ewins, P.J., D.V. Weseloh, R.J. Norstrom, K. Legierse, H. J. Auman, and J.P. Ludwig. 1994. Caspian Terns on the Great Lakes: organochlorine contamination, reproduction, diet, and population changes, 1972-91. Occasional Paper No. 85 Canadian Wildlife Service.

Fetterolf, P.M. and H. Blokpoel. 1983. Reproductive performance of Caspian Terns at a new colony on Lake Ontario, 1979-1981. Journ. Field Ornith. 54(2):170-186.

Findholt, S.L. and C.H. Trost. 1985. Organochlorine pollutants, eggshell thickness, and reproductive success of Black-crowned Night Herons in Idaho, 1979. Colonial Waterbirds 8(1):32-41. 
Fox, G.A. 1976. Eggshell quality: its ecological and physiological significance in a DDE-contaminated Common Tern population. Wilson Bull. 88(3):459-477.

Furness, R.W. and M. Hutton. 1980. Pollutants and impaired breeding of Great Skuas Catharacta skua in Britain. Ibis 122:88-94.

Gales, R.P. 1988. The use of otoliths as indicators of Little Penguin Eudyptula minor diet. Ibis 130:418-426.

Gilbertson, M., R.D. Morris, and R.A. Hunter. 1976. Abnormal chicks and PCB residue levels in eggs of colonial birds on the lower Great Lakes (19711973). Auk 93:434-442.

Gill, R.E. 1972. South San Francisco Bay breeding bird survey, 1971. State of California, Resources Agency, Department of Fish and Game. Branch Admin. Report 72-6.

Gill, R.E. 1976. Notes on the foraging of nesting Caspian Terns Hydroprogne caspia (pallas). Calif. Fish and Game 62(2):155.

Gill, R.E. and L.R. Mewaldt. 1983. Pacific Coast Caspian Terns: dynamics of an expanding population. Auk 100:369-381.

Grinnell, J. and A.H. Miller. 1944. The distribution of the birds of California. Pacific Coast Avifauna 27:172-173.

Harvey, J.T. 1989. Assessment of errors associated with harbor seal (Phoca vitulina) faecal sampling. J. Zool., Lond. 219:101-111.

Harvey, J.T., R.C. Helm, and G.V. Morejohn. 1995. Food habits of harbor seals inhabiting Elkhorn Slough, California. Calif. Fish and Game 81(1):1-9.

Harvey, J.T., T.R. Loughlin, M.A. Perez, and D.S. Oxman (in press). Otolith length/fish length relationships for 63 species of fishes of the northeastern Pacific. NOAA Technical Report. Seattle Washington.

Harvey, T.E. 1982. The ecology of three larids breeding in the Elkhorn Slough salt ponds, California. Unpubl. M.A. Thesis, California State University, San Francisco, California. 108 pp.

Holthem, R.L., D.L. Roster, K.A. King, T.J. Keldsen, K.C Marois, and S.E. Wainwright. 1995. Spatial and temporal trends of contaminants in eggs of wading birds from the San Francisco Bay, California. Env. Tox. and Chem. 14(8):1319-1331. 
Holthem, R.L. and S. G. Zador. 1995. Environmental contaminants in eggs of California Least Terns (Sterna antillarum browni). Env. Contam. and Tox. 55:658-665.

Horn, M.H., P.A. Cole, and W.E. Loeffler. 1996. Prey resource base of the tern and skimmer colonies at the Bolsa Chica Ecological Reserve, Orange County, and the Western Salt Works, South San Diego Bay. Final Report prepared for U.S. Fish and Wildlife Service, Ecological Services Carlsbad Field Office, Carlsbad, California. 55pp.

Hulsman, K. and G. Smith. 1988. Biology and growth of the Black-naped Tern Sterna sumatrana: An hypothesis to explain the relative growth rates of inshore, offshore, and pelagic feeders. Emu 8(4):234-242.

Hyslop, E.J. 1980. Stomach content analysis - a review of methods and their applications. J. Fish Biol. 17:411-429.

Johnson, H.T. 1984. A method of using gastroliths to calculate length and weight of the freshwater crayfish, Cherax destructor, for use in predator-prey studies. Australian Zoologist 21:435-443.

King, K.A., C.A. Lefever, and B.M. Mulhern. 1983. Organochlorine and metal residues in Royal Terns nesting on the Central Texas Coast. J. Field Ornith. 54(3):295-303.

Kirkham, I.R. and R.D. Morris. 1979. Feeding ecology of ring-billed gull (Larus delawarensis) chicks. Can. J. Zool. 57:1086-1090.

Kirven, M. 1969. The breeding biology of Caspian Terns (Hydroprogne caspia) and Elegant Terns (Thalasseus elegans) at San Diego Bay. M.A. Thesis, San Diego State College, California. 114 pp.

Koli, L. and M. Soikkeli. 1974. Fish prey of breeding Caspian Terns in Finland. Ann. Zool. Fennici 11:304-308.

L'Arrivee, L. and H. Blokpoel. 1988. Seasonal distribution and site fidelity in Great Lakes Caspian Terns. Colonial Waterbirds 11(2):202-214.

Leger, C. and R. McNeil. 1985. Nest attendance and care of young in Doublecrested Cormorants. Colonial Waterbirds 8(2):96-103.

Levenson, H. 1979. Time and activity budget of ospreys nesting in northern California. Condor 81:364-369. 
Loeffler, W.E. 1996. Dietary overlap and its implications for coexistence in a recently established assemblage of nesting seabirds at the Bolsa Chica Ecological Reserve. Unpubl. M.A. Thesis, California State University Fullerton, California. 72pp.

Ludwig, J.P. 1965. Biology and structure of the Caspian Tern (Hydroprogne caspia) population of the Great Lakes from 1896-1964. Bird-Banding 36(4):217-233.

Ludwig, J.P. 1968. Dynamics of Ring-billed Gull and Caspian Tern populations of the Great Lakes. Ph.D. dissertation, University of Michigan. 73p.

Ludwig, J.P., H.J. Auman, H. Kurita, M.E. Ludwig, L.M. Campbell, J.P. Giesy, D.E. Tillitt, P. Jones, N. Yamashita, S. Tanabe, and R. Tatsukawa. 1993. Caspian Tern reproduction in the Saginaw Bay ecosystem following a 100-year flood event. J. Great Lakes Res. 19(1):96-108.

Martini, E. 1964. Otolithen in Gewollen der Raubseeschwalbe (Hydroprogne caspia). Bonner Zool. Beitr. 15:59-71.

Mayfield, H. 1975. Suggestions for calculating nest success. Wilson Bull. 87:456-466.

Miller, A.H. 1943. Census of a colony of Caspian Terns. Condor 45: 220-225.

Mitchell, C.A. and T.W. Custer. 1986. Hatching success of Caspian Terns nesting in the lower Laguna Madre, Texas, USA. Colonial Waterbirds 9(1):86-89.

Mora, M.A. 1996. Congener-specific polychlorinated biphenyl patterns in eggs of aquatic birds from the Lower Laguna Madre, Texas. Env. Tox. and Chem. 15(6):1003-1010.

Nisbet, I.C.T. 1973. Courtship-feeding, egg-size and breeding success in Common Terns. Nature 241:141-142.

Nisbet, I.C.T. and L.M. Reynolds. 1984. Organochlorine residues in Common Terns and associated estuarine organisms, Massachusetts, USA, 197181. Marine Environmental Research 11:33-66.

Ohlendorf, H.M., E.E. Klaas, and T.E. Kaiser. 1979. Environmental pollutants and eggshell thickness: Anhingas and wading birds in the eastern United States. U.S. Fish and Wildlife Service Special Scientific ReportWildlife No. 216. 
Ohlendorf, H.M., F.C. Schaffner, T.W. Custer, and C.J. Stafford. 1985.

Reproduction and organochlorine contaminants in terns at San Diego Bay. Colonial Waterbirds 8(1):42-53.

Ohlendorf, H.M., T.W. Custer, R.W. Lowe, M. Rigney, and E. Cromartie. 1988. Organochlorine and mercury in eggs of coastal terns and herons in California, USA. Colonial Waterbirds 11(1):85-94.

Ohlendorf, H.M. and W.J. Fleming. 1988. Birds and environmental contaminants in San Francisco and Chesapeake Bays. Marine Poll. Bull. 19(9):487-495.

Oxman, D.S. 1995. Seasonal abundance, movements, and food habits of harbor seals (Phoca vitulina richardsi) in Elkhorn Slough, California. M.S. Thesis. California State University, Stanislaus. 126pp.

Palacios, E. and L. Alfaro. 1992. First breeding records of the Caspian Tern in Baja California, (Norte), Mexico. Western Birds 23(3):143-144.

Pavey, C.R. and D.R. Fielder. 1990. Use of gastrolith development in moult staging the freshwater crayfish Cherax cuspidatus Riek, 1969. Crustaceana 59(1):101-105.

Pearce, P.A., D.B. Peakall, and C.M. Reynolds. 1979. Shell thinning and residues of organochlorines and mercury in seabird eggs, Eastern Canada, 1970-76. Pest. Monitor. Jrn. 13(2):61-68.

Phillips, P. 1988. California state mussel watch ten year data summary 19771987. Water Quality Monitoring Report No. 87-3. 313pp.

Pinkas, L., M.S. Oliphant, and I.L.K. Iverson. 1971. Food habits of albacore, bluefin tuna, and bonito in California waters. Calif. Fish and Game Fish. Bull. 152:1-105.

Quinn, J.S. 1980. Feeding rates, parental investment, and brood reduction in Caspian Terns (Sterna caspia). M.S. Thesis, Brock University, St. Catherines, Ontario. 126pp.

Quinn, J.S. 1990. Sexual size dimorphism and parental care patterns in a monomorphic and a dimorphic larid. Auk 107:260-274.

Ricklefs, R.E. 1974. Energetics of reproduction in birds. In: R.A. Paynter, Jr. (ed). Avian Energetics, Publ. Nuttall Ornith. Club No. 15.

Roberson, D. 1985. Monterey Birds. Monterey Peninsula Audubon Society, Carmel, CA. 266pp. 
Schaffner, F.C. 1990. Feed size and feeding periodicity in pelagic birds: notes on methodology. Colonial Waterbirds 13:7-15.

Shugart, G.W, W.C. Scharf, and F.J. Cuthbert. 1978. Status and reproductive success of the Caspian Tern (Sterna caspia) in the U.S. Great Lakes. Proc. Col. Waterbird Grp. 1978:146-156.

Smith, G.C. 1990. Factors influencing egg laying and feeding in Black-naped Terns (Sterna sumatrana). Emu 90(2):88-96.

Smith, G.C. 1993. Feeding and breeding of Crested Terns at a tropical locality - comparison with sympatric Black-naped Terns. Emu 93:65-70.

Soikkeli, M. 1973. Breeding success of the Caspian Tern in Finland. BirdBanding 44(3):196-204.

Sowls, A.L., A.R. DeGange, J.W. Nelson, and G.S. Lester. 1980. Catalog of California seabird colonies. FWS/OBS-80/37. 371pp.

Stickel, L.F., S.N. Weimeyer, and L.J. Blus. 1973. Pesticide residues in eggs of wild birds: adjustment for loss of moisture and lipid. Bull. Environ. Contam. Toxicol. 9(4):193-196.

Struger, J. and D.V. Weseloh. 1985. Great Lakes Caspian Terns: egg contaminants and biological implications. Col. Waterbirds 8(2):142-149.

Terres, J.K. 1991. The Audubon society encyclopedia of North American birds. Wings Books, New York.

Thompson, B.C. and J.E. Tabor. 1981. Nesting populations and breeding chronologies of gulls, terns, and herons on the upper Columbia River, Oregon and Washington. Northwest Science 55(3):209-218.

Wheatly, M.G. and J. Ayers. 1995. Scaling of calcium, inorganic contents, and organic contents to body mass during the molting cycle of the freshwater crayfish Procambarus clarkii (Girard). Jrnl. of Crustacean Biol. 15(3):409-417.

Wiggins D.A. and R.D. Morris. 1987. Parental care of the Common Tern Sterna hirundo. Ibis 129:533-540.

Yoklavich, M.M., G.M. Cailliet, J.P. Barry, D.A. Ambrose, and B.S. Antrim. 1991. Temporal and spatial patterns in abundance and diversity of fish assemblages in Elkhorn Slough, California. Estuaries 14(4):465-480. 


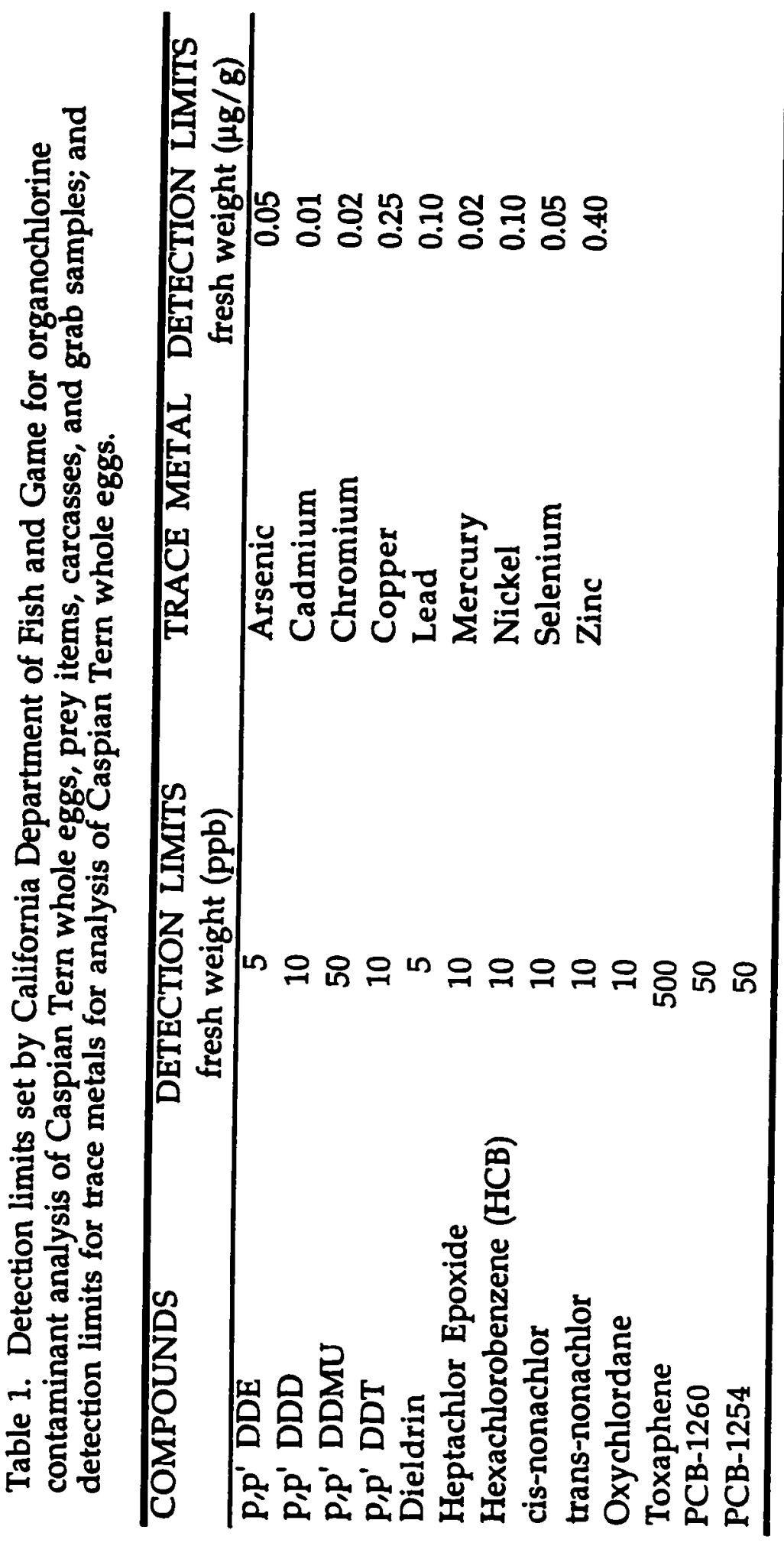


Table 2. Number of Caspian Tern nests containing 0 to 3 eggs, total number of eggs laid, and total number of nests for 1994 and 1995 at Elkhorn Slough (ESNERR) and 1996 at Salinas River (SRNWR). Percent of eggs per year in parentheses.

\begin{tabular}{|c|c|c|c|c|c|c|c|}
\hline \multirow[b]{2}{*}{ Year } & \multirow[b]{2}{*}{ Location } & \multicolumn{4}{|c|}{ Clutch size } & \multirow{2}{*}{$\begin{array}{l}\text { Total } \\
\text { Eggs }\end{array}$} & \multirow{2}{*}{$\begin{array}{l}\text { Total } \\
\text { Nests }\end{array}$} \\
\hline & & 0 & 1 & 2 & 3 & & \\
\hline 1994 & ESNERR & $3(1.6)$ & $57(30.3)$ & $118(62.8)$ & $10(5.3)$ & 323 & 188 \\
\hline 1995 & ESNERR & $3(1.9)$ & $50(30.9)$ & $104(64.2)$ & $5(3.1)$ & 273 & 162 \\
\hline 1996 & SRNWR & $3(8.8)$ & $10(29.4)$ & $20(58.8)$ & $1(2.9)$ & 53 & 34 \\
\hline
\end{tabular}


Table 3. Fate of Caspian Tern eggs and chicks for 1994 and 1995 at Elkhorn Slough (ESNERR) and 1996 at Salinas River (SRNWR). Percentage of eggs in parentheses. $(+)$ denotes an estimate. Number dead describes number of dead chicks retrieved.

\begin{tabular}{llcccccc}
\hline Year & Location & $\begin{array}{c}\text { Number } \\
\text { Hatched }\end{array}$ & $\begin{array}{c}\text { Number } \\
\text { Fledged }\end{array}$ & $\begin{array}{c}\text { Number } \\
\text { Dead }\end{array}$ & $\begin{array}{c}\text { Addled/Death } \\
\text { at Pipping }\end{array}$ & $\begin{array}{c}\text { Unknown } \\
\text { Fate }\end{array}$ \\
\hline 1994 & ESNERR & 189 & $150+(46.4)$ & $40(12.4)$ & $20(6.2)$ & $74(22.9)$ \\
1995 & ESNERR & 36 & 7 & $(2.6)$ & $65+(23.8)$ & $92+(33.7)$ & $80(29.3)$ \\
1996 & SRNWR & 12 & 0 & $4(7.6)$ & $21(39.6)$ & $16(30.2)$ \\
\hline
\end{tabular}


Table 4. Hatching, fledging, breeding success, and mean fledging rates for Caspian Terns nesting during 1994 and 1995 at Elkhorn Slough and 1996 at Salinas River. Where EL denotes number of eggs laid, CH denotes number of chicks hatched (and survived past week five), and CF denotes number of chicks fledged.

\begin{tabular}{lccc}
\hline & 1994 & 1995 & 1996 \\
\hline Total Number of Nests & 188 & 162 & 34 \\
$\begin{array}{l}\text { Mean Clutch Size } \\
\text { Standard Error }\end{array}$ & 1.75 & 1.72 & 1.71 \\
\% Hatching Success & 0.55 & 0.52 & 0.53 \\
$\begin{array}{l}\text { CH/EL x 100 } \\
\text { \% Fledging Success }\end{array}$ & 58.51 & 13.19 & 22.64 \\
CF/CH x 100 & & & \\
\% Breeding Success & 79.37 & 19.44 & 0 \\
CF/EL x 100 & & & \\
Mean Fledging Rate & 46.44 & 2.56 & 0 \\
CH/\# Nests & & & \\
\hline
\end{tabular}




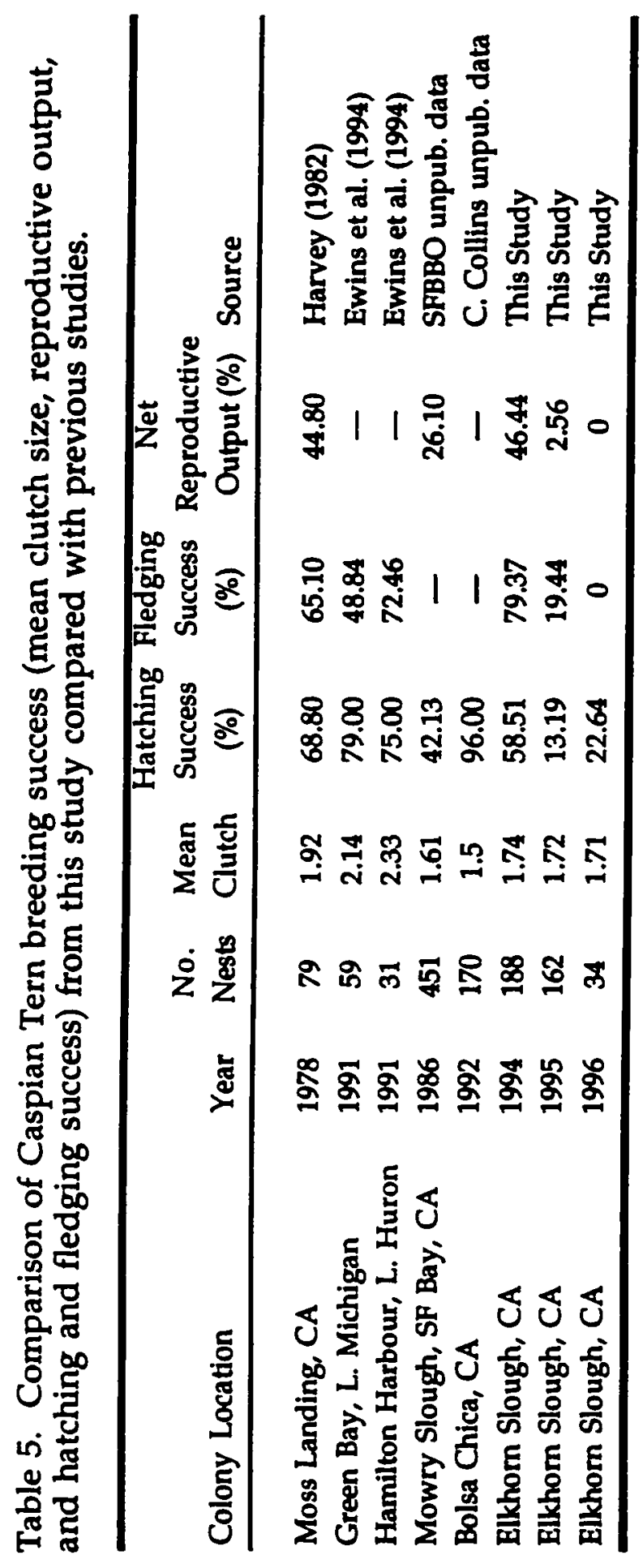


Table 6. Mean percent number (\%N), mean percent mass (\%M), mean percent frequency of occurrence (\%FO), and mean index of relative importance (IRI) of prey items based on otoliths found in Caspian Tern nest cups collected in Elkhorn Slough, CA during 1994. Standard error in parentheses. Listed in decreasing order of $\mathrm{IRI}$ values.

\begin{tabular}{lccccc}
\hline \multicolumn{1}{c}{ Prey Species } & $\begin{array}{c}\text { Mean \%N } \\
\text { (SE) }\end{array}$ & $\begin{array}{c}\text { Mean \%M } \\
\text { (SE) }\end{array}$ & \multicolumn{2}{c}{ \%FO } & \multicolumn{2}{c}{$\begin{array}{c}\text { Mean IRI } \\
\text { (SE) }\end{array}$} \\
\hline Procambarus clarkit & $\mathbf{4 2 . 3 6 ( 4 . 7 5 )}$ & $54.87(6.88)$ & 92.86 & $9029.31(1080.74)$ \\
Cymatogaster aggregata & $36.96(7.12)$ & $26.77(7.23)$ & 85.71 & $5463.06(1230.27)$ \\
Leptocottus armatus & $6.45(3.19)$ & $2.04(0.96)$ & 28.57 & 242.64 & $(118.53)$ \\
Atherinops affinis & $5.96(3.75)$ & $3.81(2.09)$ & 21.43 & 209.40 & $(125.26)$ \\
Genyonemus lineatus & $2.21(1.51)$ & $7.24(4.97)$ & 14.29 & 135.14 & $(92.66)$ \\
Embiotocidae sp. & $2.21(1.51)$ & $2.47(1.74)$ & 14.29 & 66.96 & $(46.41)$ \\
Engraulis mordax & $2.84(2.13)$ & $0.74(0.63)$ & 14.29 & 51.14 & $(39.59)$ \\
Phanerodon furcatus & $1.02(1.02)$ & $1.89(1.89)$ & 7.14 & 20.81 & $(20.81)$ \\
\hline
\end{tabular}


Table 7. Mean percent number (\%N), mean percent mass (\%M), mean percent frequency of occurrence (\%FO), and mean index of relative importance (IRI) of prey items based on otoliths found in Caspian Tern nest cups collected in Elkhorn Slough, CA during 1995. Standard error in parentheses. Listed in decreasing order of IRI values.

\begin{tabular}{lccccc}
\hline \multicolumn{1}{c}{ Prey Species } & $\begin{array}{c}\text { Mean \%N } \\
\text { (SE) }\end{array}$ & $\begin{array}{c}\text { Mean \%M } \\
\text { (SE) }\end{array}$ & \%FO & \multicolumn{1}{c}{ Mean IRI } \\
\hline Cymatogaster aggregata & $46.24(5.85)$ & $\mathbf{4 2 . 7 9 ( 6 . 0 7 )}$ & 82.76 & $7368.49(986.97)$ \\
Procambarus clarkii & $20.31(5.85)$ & $21.52(5.92)$ & 55.17 & $2307.44(649.86)$ \\
Leptocottus armatus & $7.79(2.89)$ & $5.64(2.79)$ & 34.48 & $463.34(196.05)$ \\
Atherinops affinis & $5.49(1.27)$ & $3.71(0.98)$ & 44.83 & $412.59(101.13)$ \\
Genyonemus lineatus & $3.75(1.64)$ & $7.49(2.63)$ & 27.59 & $310.15(117.80)$ \\
Porichthys notatus & $7.11(3.78)$ & $10.49(4.67)$ & 17.24 & $303.42(145.71)$ \\
Atherinopsis californiensis & $2.35(0.93)$ & $5.22(2.18)$ & 20.69 & $156.53(64.39)$ \\
Engraulis mordax & $3.98(1.50)$ & $1.27(0.43)$ & 27.59 & 145.09 & $(53.29)$ \\
Chilara taylori & $0.65(0.45)$ & $0.34(0.19)$ & 10.34 & 10.24 & $(6.67)$ \\
Citharichthys stigmaeus & $1.72(1.72)$ & $1.04(1.04)$ & 3.45 & 9.54 & $(9.54)$ \\
Phanerodon furcatus & $0.49(0.39)$ & $0.41(0.29)$ & 6.90 & 6.18 & $(4.76)$ \\
Spirinchus starksi & $0.12(0.08)$ & $0.02(0.02)$ & 6.90 & 0.99 & $(0.69)$ \\
\hline
\end{tabular}


Table 8. Mean percent number (\%N), mean percent mass (\%M), mean percent frequency of occurrence (\%FO), and mean index of relative importance (IRI) of prey items based on otoliths found in Caspian Tern regurgitated pellets collected at Salinas River during 1996. Standard error in parentheses. Listed in decreasing order of IRI values.

\begin{tabular}{lccccc}
\hline \multicolumn{1}{c}{ Prey Species } & Mean \%N & Mean \%M & $\%$ FO & \multicolumn{2}{c}{$\begin{array}{c}\text { Mean IRI } \\
\text { (SE) }\end{array}$} \\
\hline Cymatogaster aggregata & \multicolumn{1}{c}{ (SE) } & \multicolumn{1}{c}{ (SE) } & \multicolumn{2}{c}{ (SE) } \\
Atherinops affinis & $60.14(8.36)$ & $64.35(8.62)$ & 78.30 & $9747.67(1329.66)$ \\
Engraulis mordax & $22.10(7.44)$ & $20.78(7.34)$ & 34.78 & 1491.46 & $(513.85)$ \\
Procambarus clarkii & $9.78(5.15)$ & $7.56(4.58)$ & 17.39 & 301.68 (169.18) \\
Atherinopsis californiensis & $4.35(4.35)$ & $4.35(4.35)$ & 4.35 & 37.83 & $(37.82)$ \\
& $1.45(1.45)$ & $2.97(2.97)$ & 4.35 & 19.22 & $(19.22)$ \\
\hline
\end{tabular}




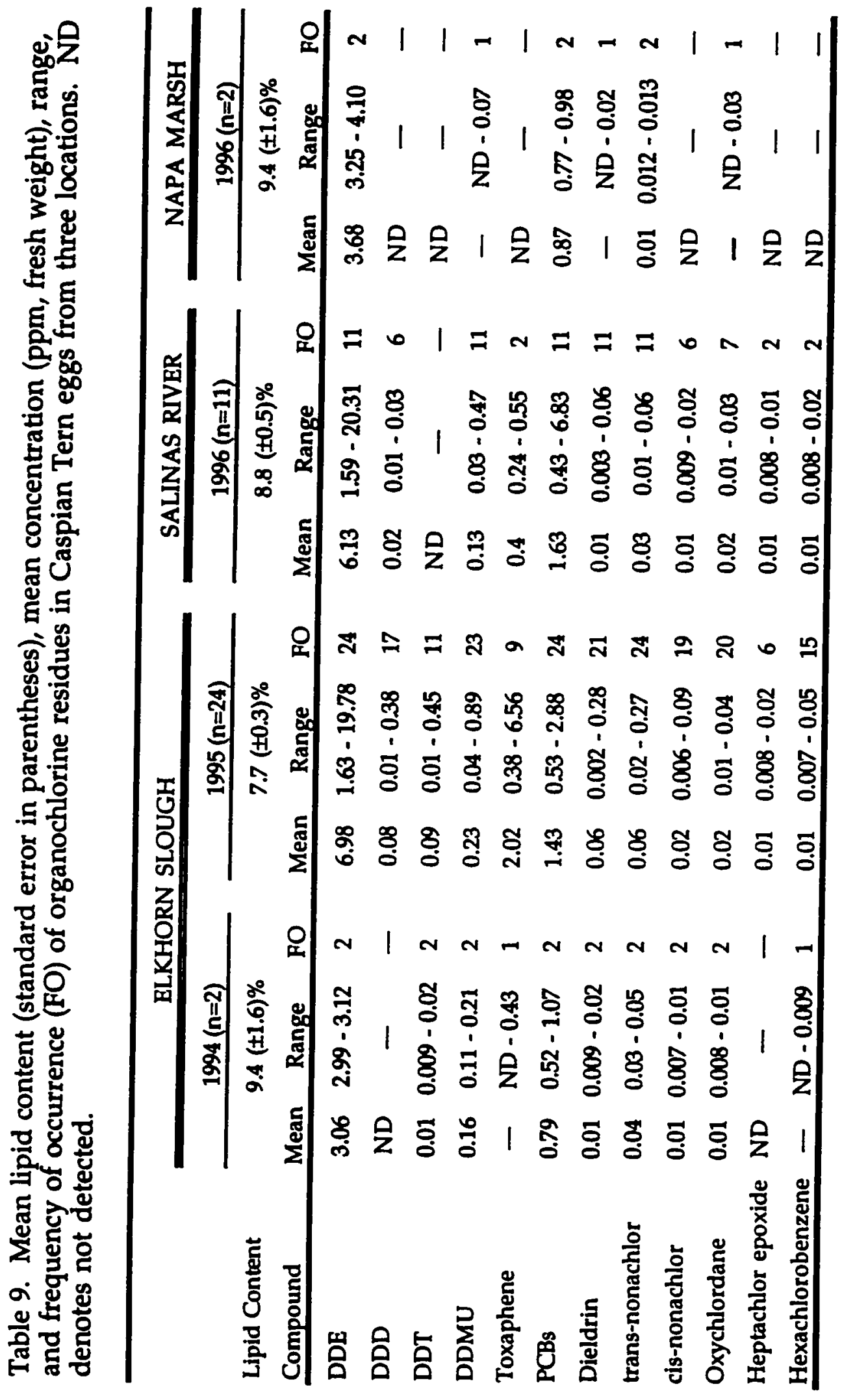




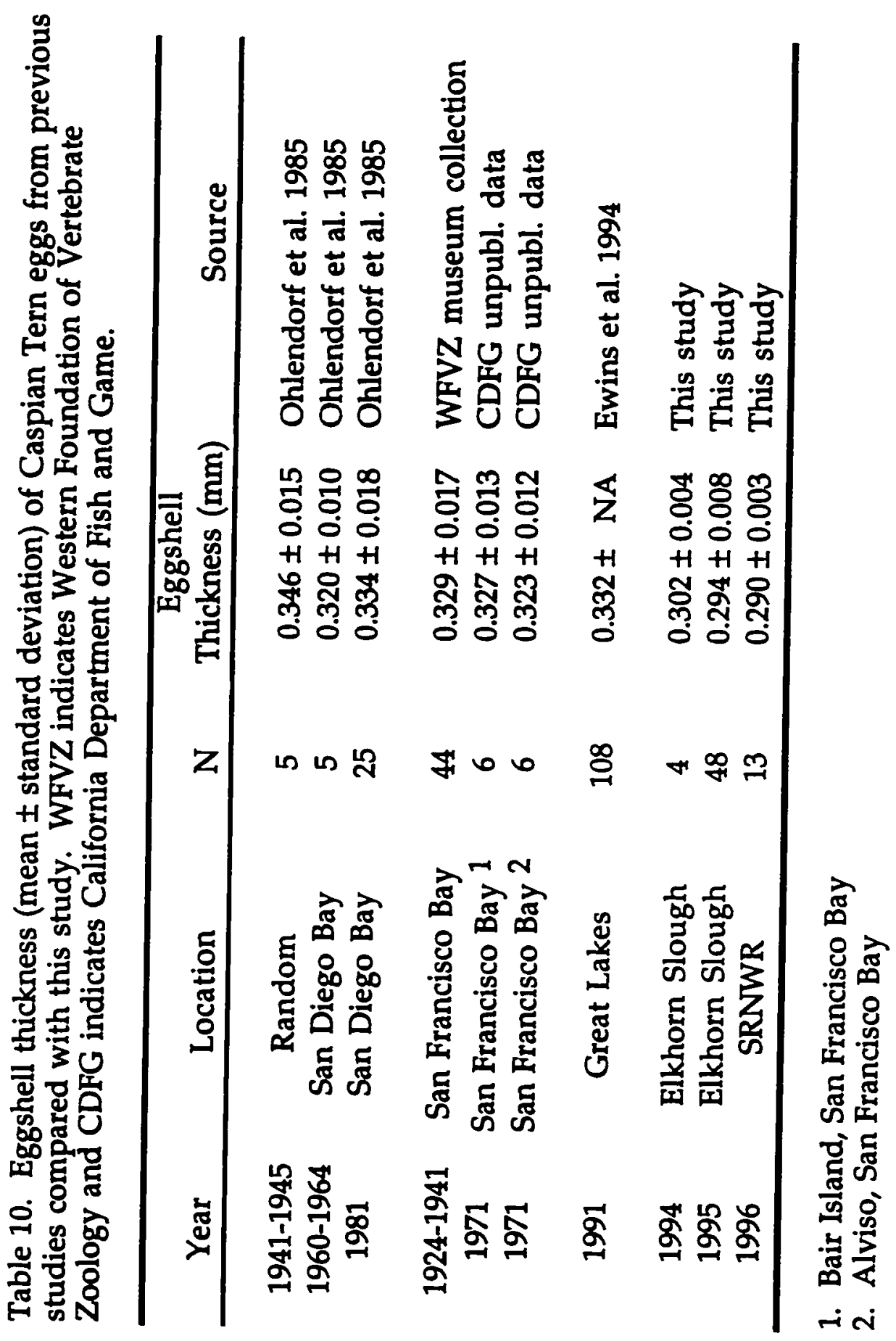




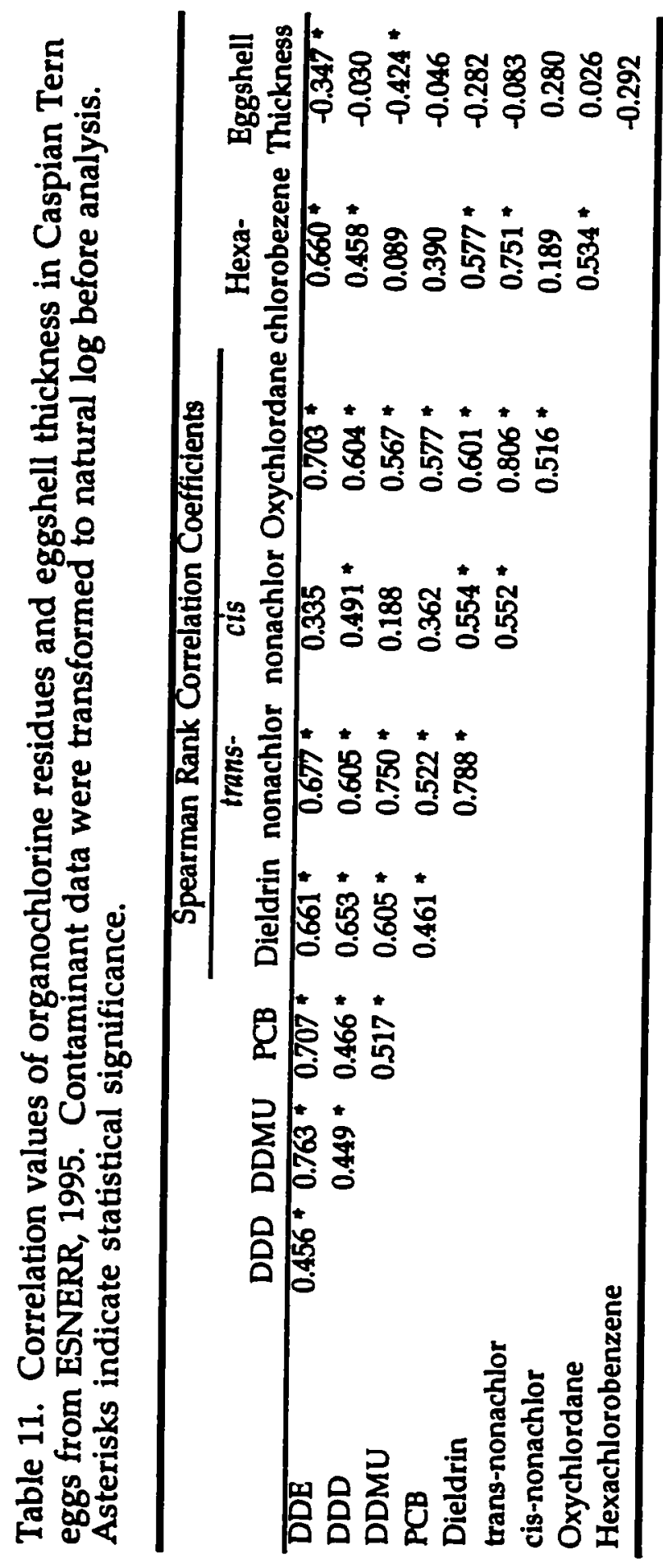




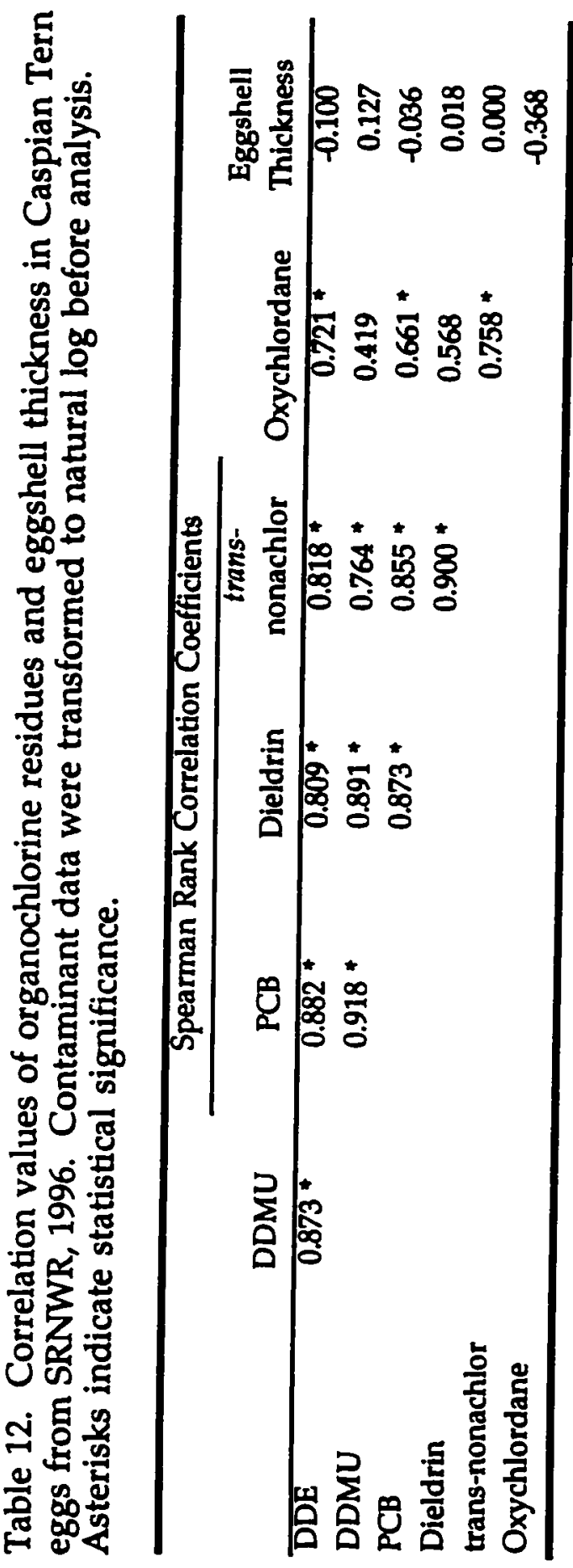


Table 13. Mean DDE concentrations (ppm, fresh weight) and mean percent lipid contents in prey items of Caspian Terns collected from Elkhorn Slough, 1994 to 1996 and Pajaro River and Watsonville Slough, 1997. Mixed fish included: shiner surfperch and northern anchovy (1994 to 1996); Pacific herring (Clupea pallasii) (1994 to 1995); topsmelt (1995 to 1996); and staghorn sculpin (1995).

\begin{tabular}{ccccccccc}
\hline & & & \multicolumn{2}{c}{ DDE } & & \multicolumn{2}{c}{ \% Lipid } \\
Year & Prey Item & $\mathrm{N}$ & Mean & SD & & Mean & SD \\
\hline 1994 & mixed fish & 3 & 0.02 & 0.01 & & 3.33 & 0.55 \\
1995 & mixed fish & 9 & 0.12 & 0.14 & & 1.5 & 1.66 \\
1996 & mixed fish & 5 & 0.07 & 0.04 & 0.6 & 0.22 \\
1997 & crayfish & 8 & 1.98 & 1.96 & na & na \\
\hline
\end{tabular}




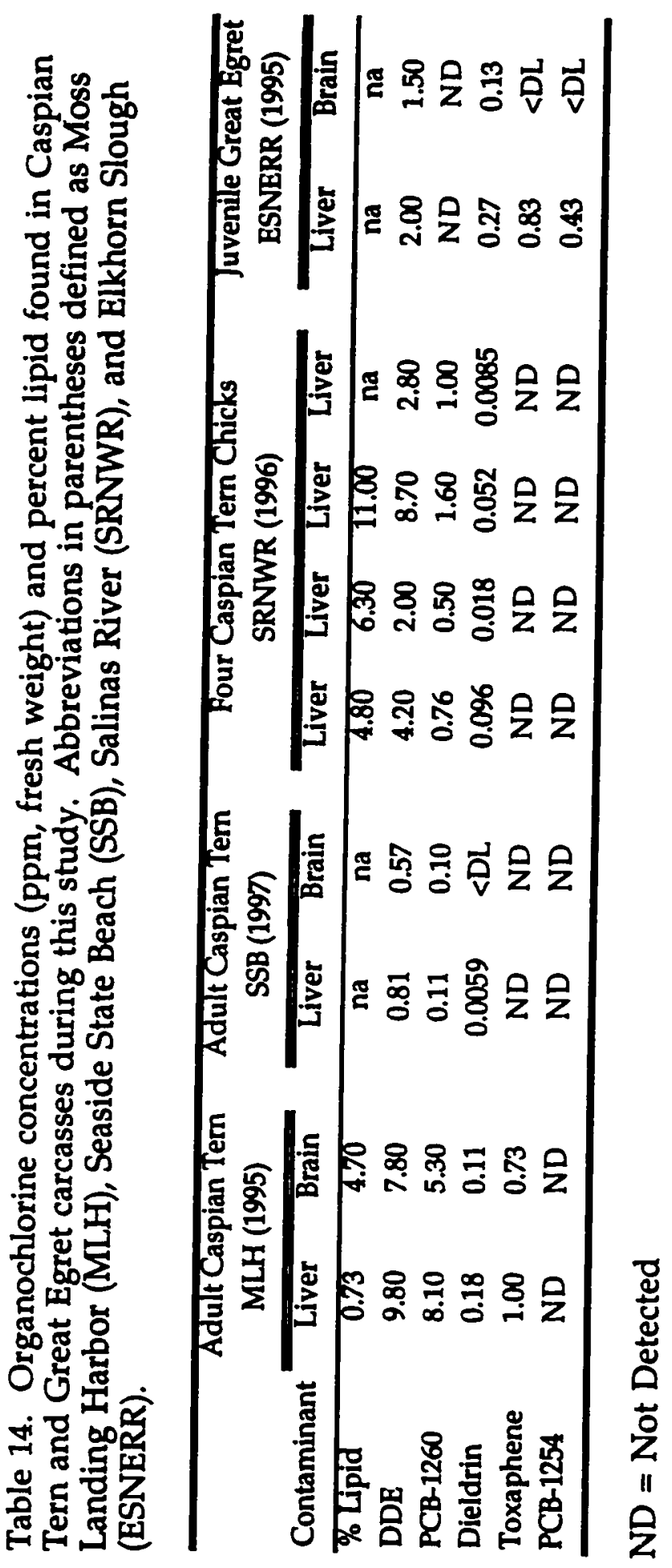




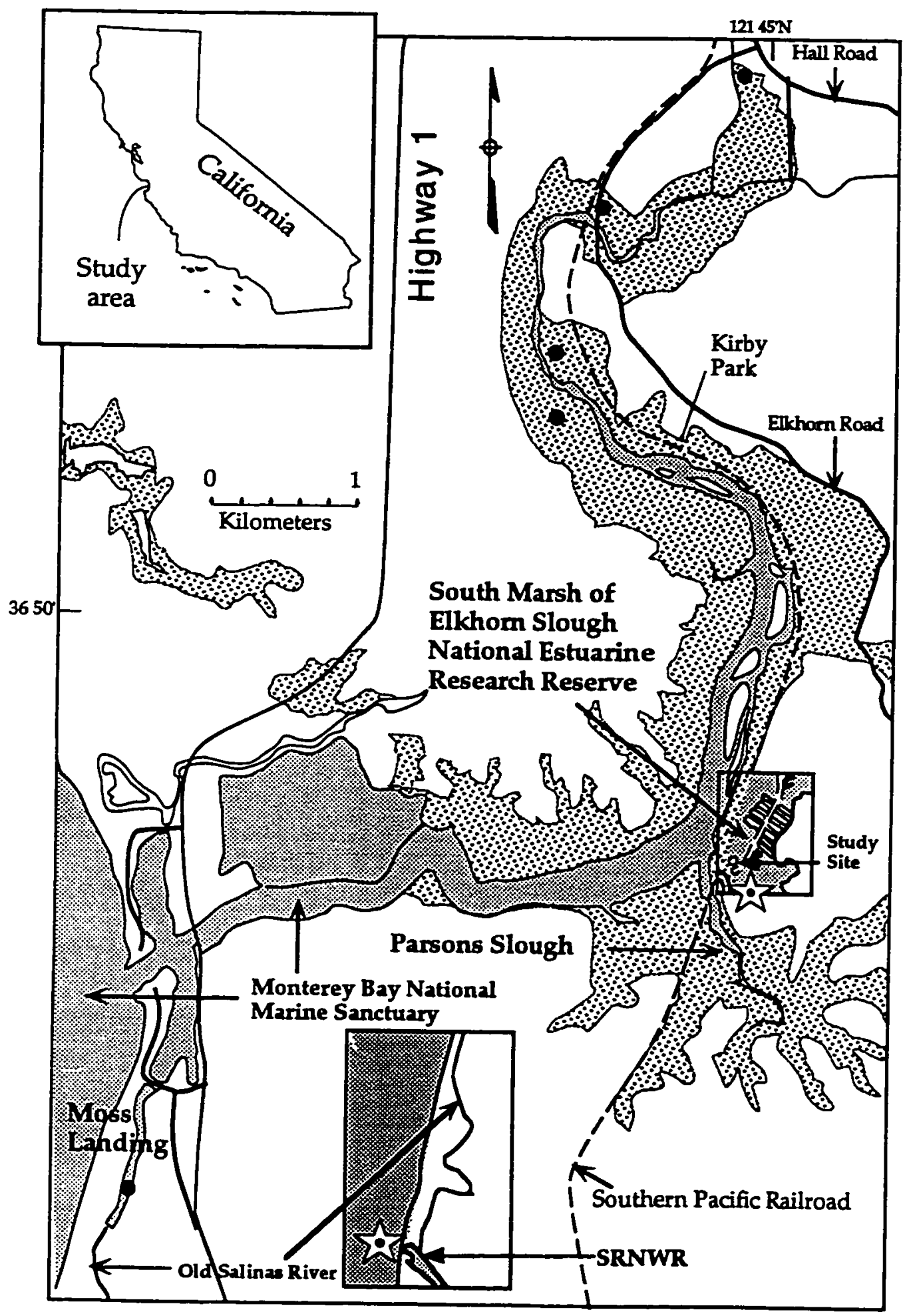

Figure 1. Study sites (C) at Elkhorn Slough National Estuarine Research Reserve (ESNERR) and Salinas River National Wildlife Refuge (SRNWR). $(\bullet)^{\prime}$ s indicate areas where grab samples were collected. 


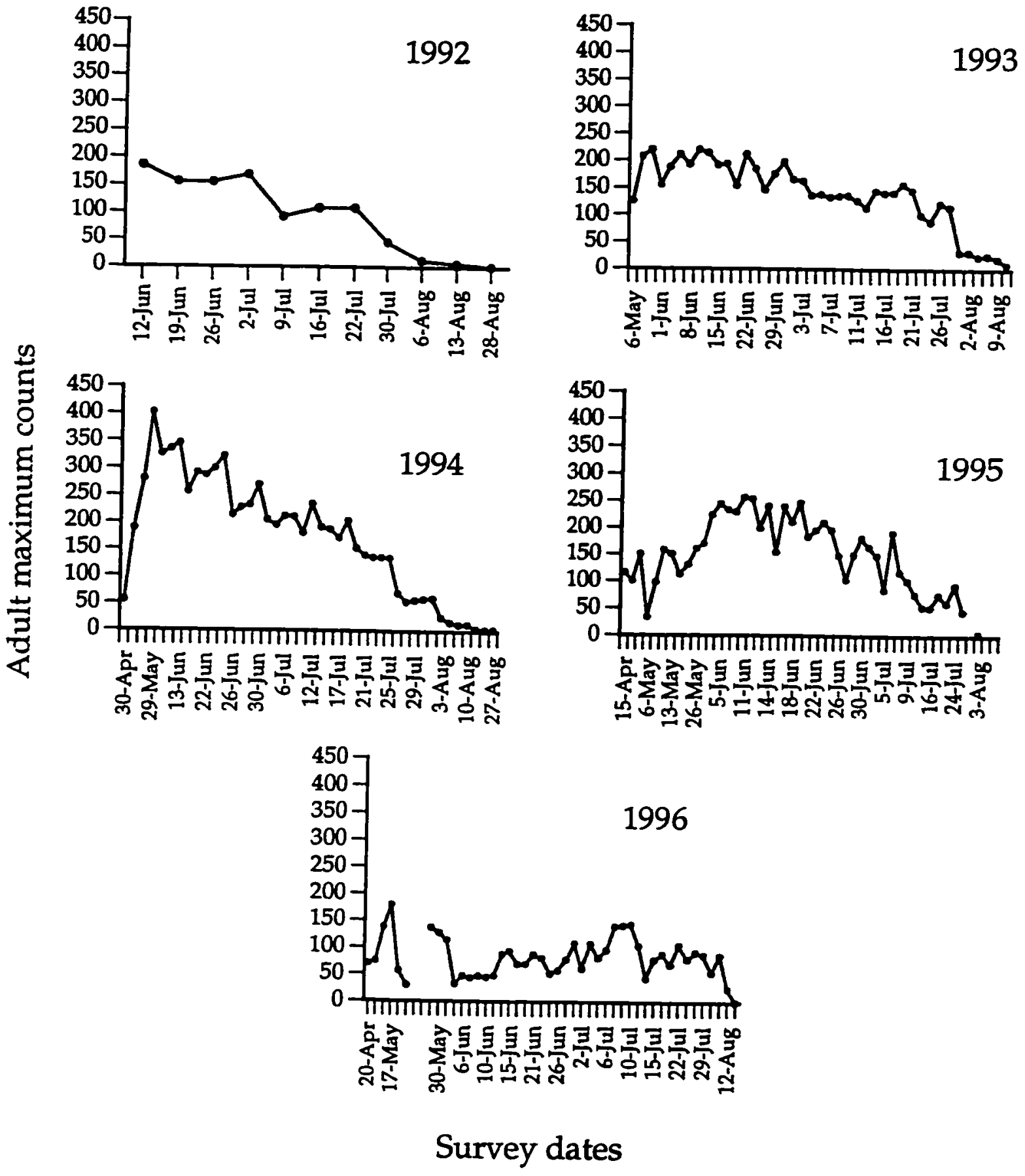

Figure 2. Maximum counts of Caspian Tern adults at the ESNERR breeding colony (1992-1995) and at both ESNERR (20 April to 25 May) and SRNWR during 1996. Counts were conducted weekly during 1992 and several days per week in 1993-1996. 

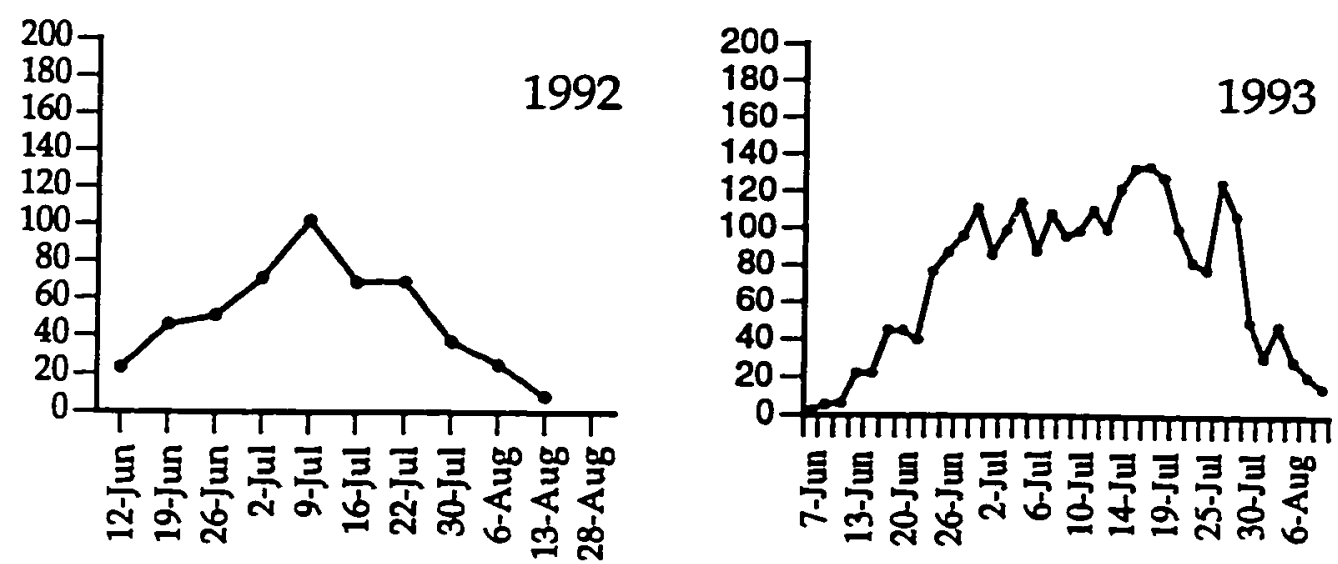

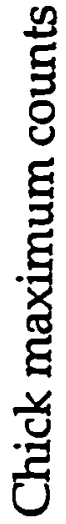
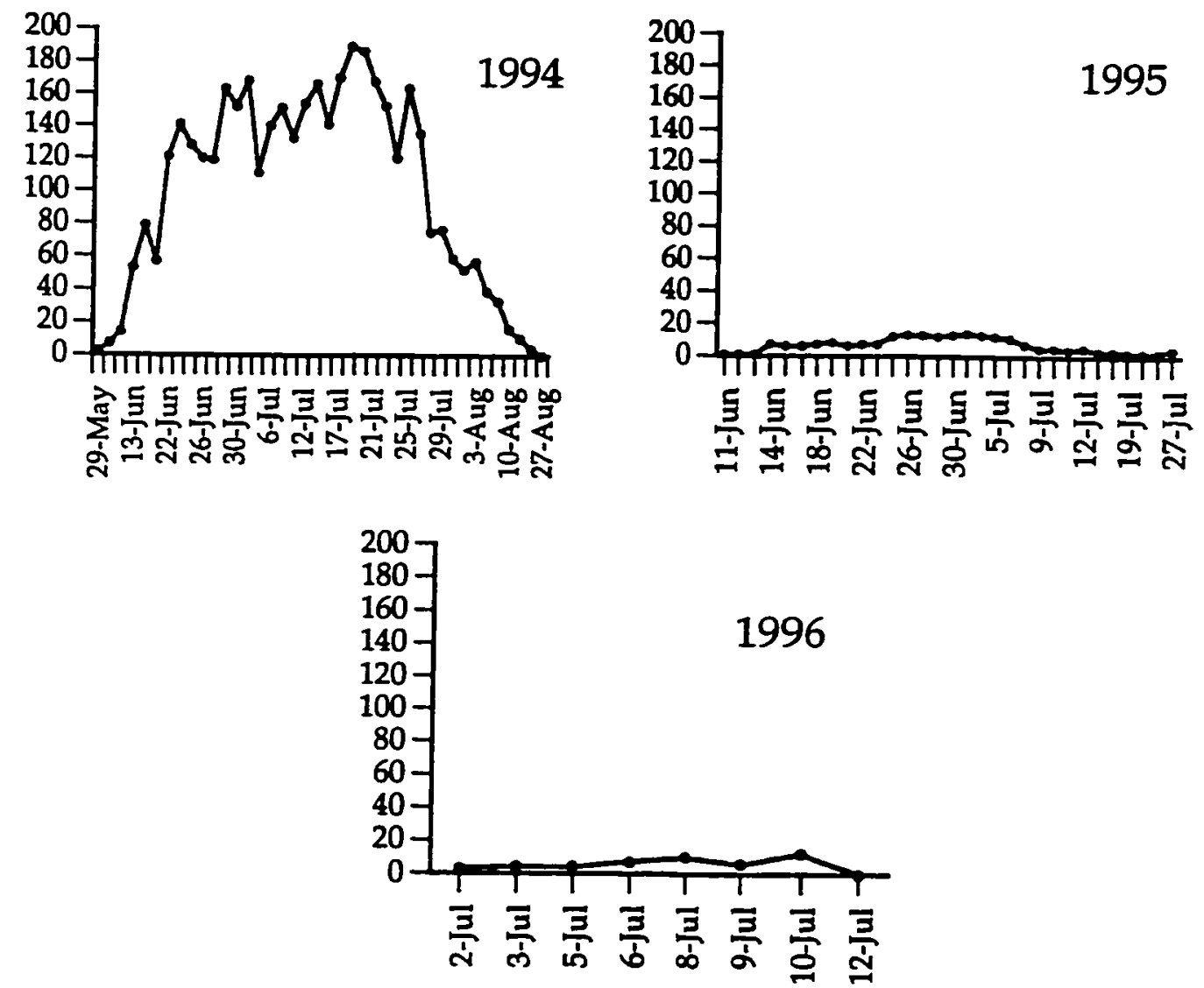

Survey dates

Figure 3. Maximum counts of Caspian Tern chicks at the ESNERR (1992-1995) and SRNWR (1996) breeding colonies. Counts were conducted weekly during 1992 and several days per week during 1993-1996. 

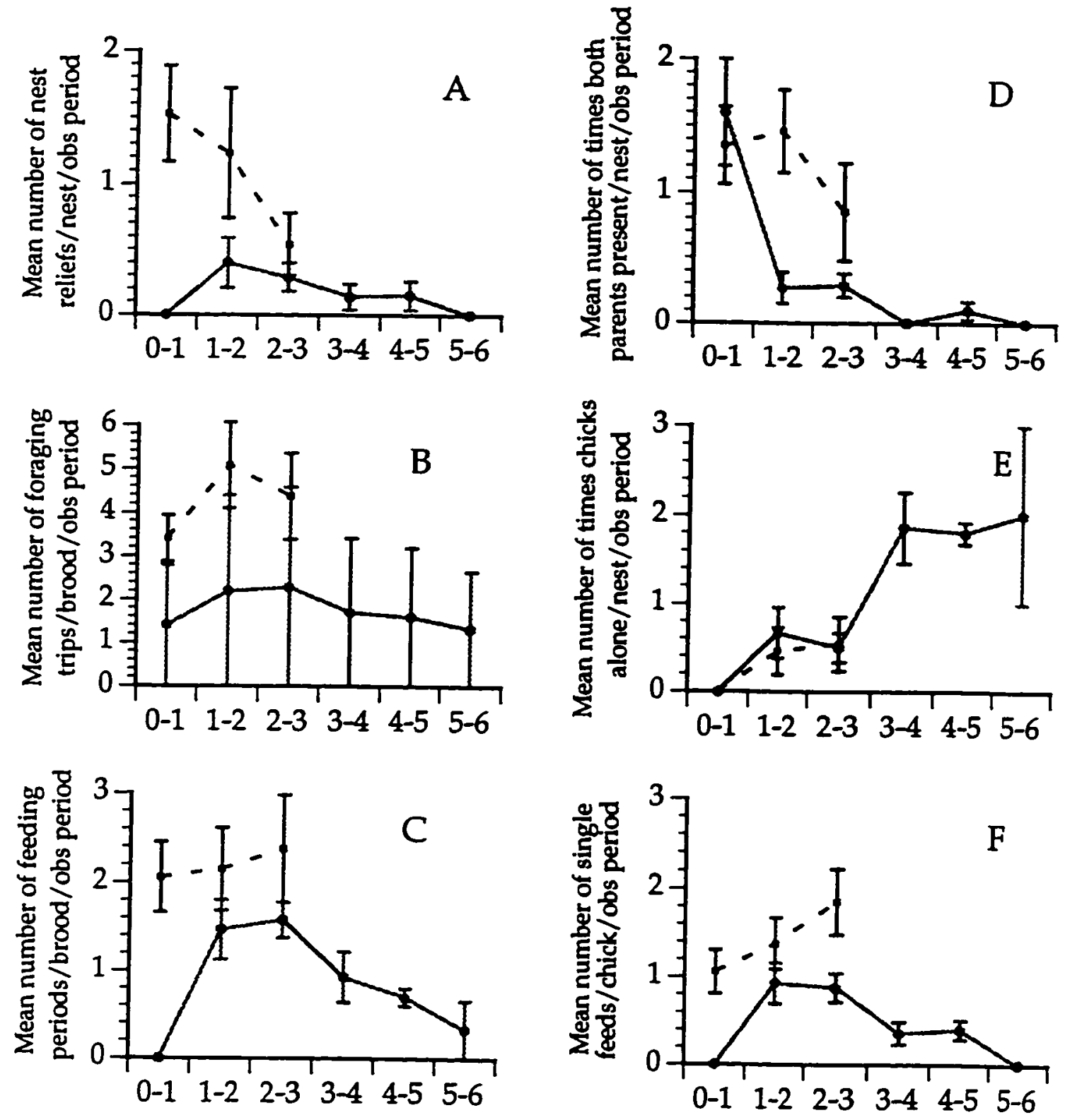

Chick age

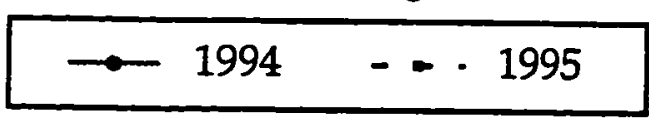

Figure 4. Weekly variation in Caspian Tern parental activities as a function of brood age by week. Vertical bars indicate standard error. For all figures, 1994 sample sizes by chick age are 5, 15, 24, 14, 20, and 3; and sample sizes for 1995 are 17, 13, and 13. 


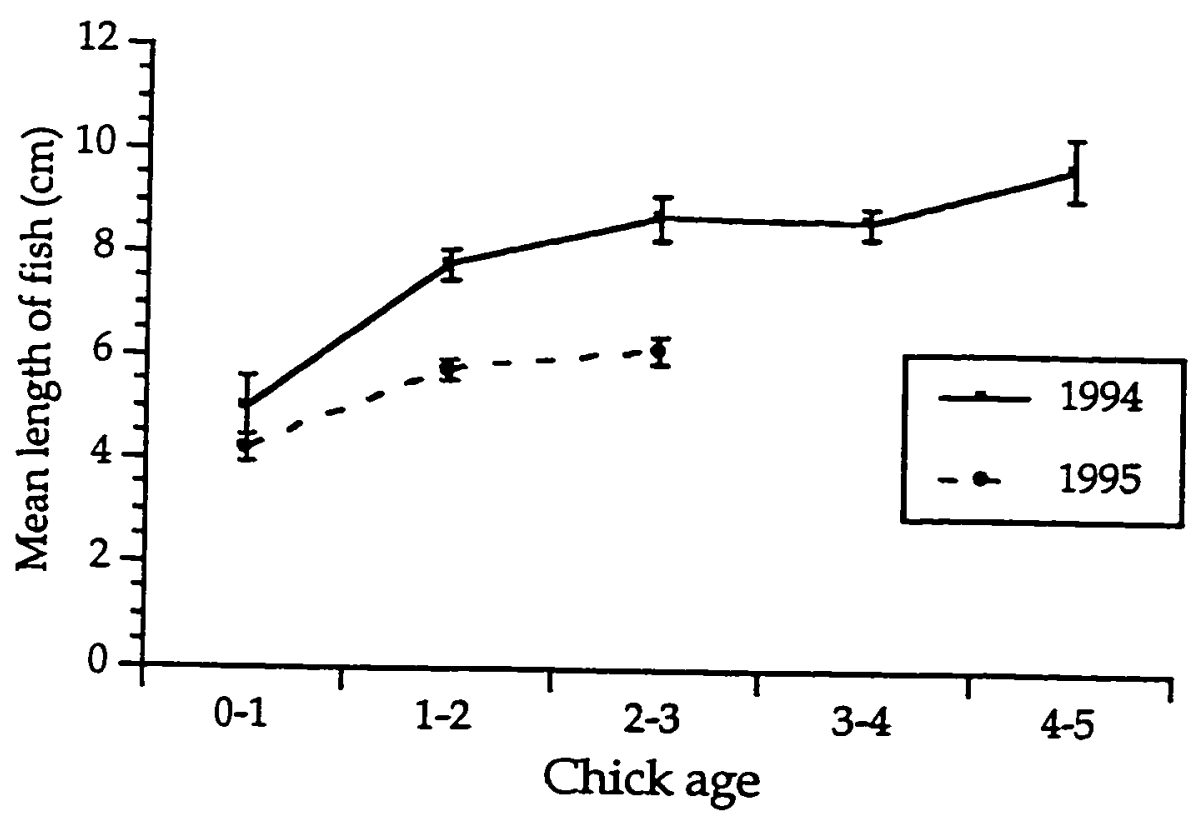

Figure 5. Weekly variation in mean length of fish fed to Caspian Tern chicks as a function of chick age. Vertical bars indicate standard error. Sample sizes by chick age for 1994 are 16, 41, 35, 26, and 12; and sample sizes for 1995 are 25, 34, and 22. 

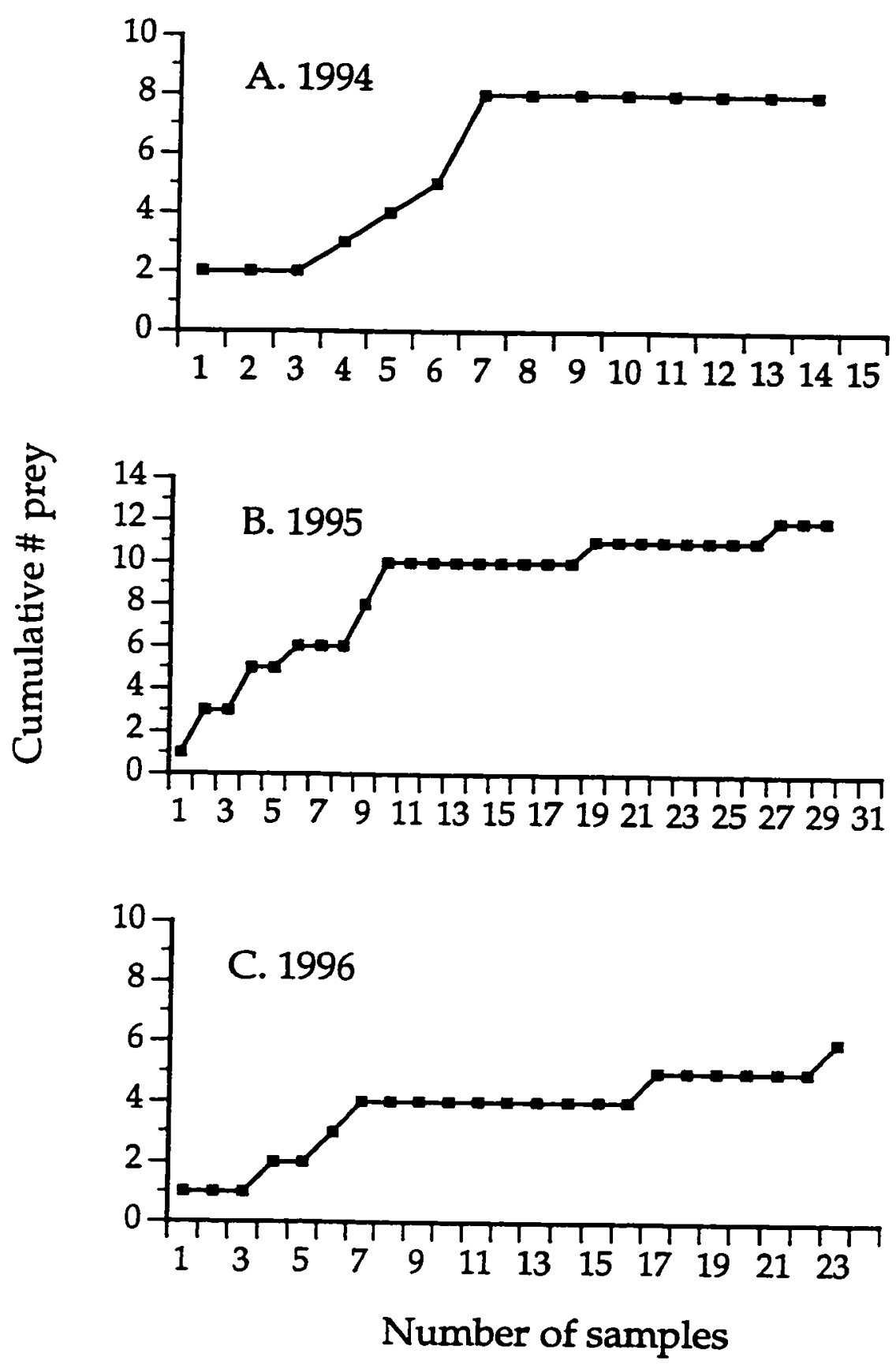

Figure 6. Cumulative species curves for samples collected from Caspian Tern nest cups at ESNERR (1994 and 1995) and regurgitated pellets collected at SRNWR (1996). 


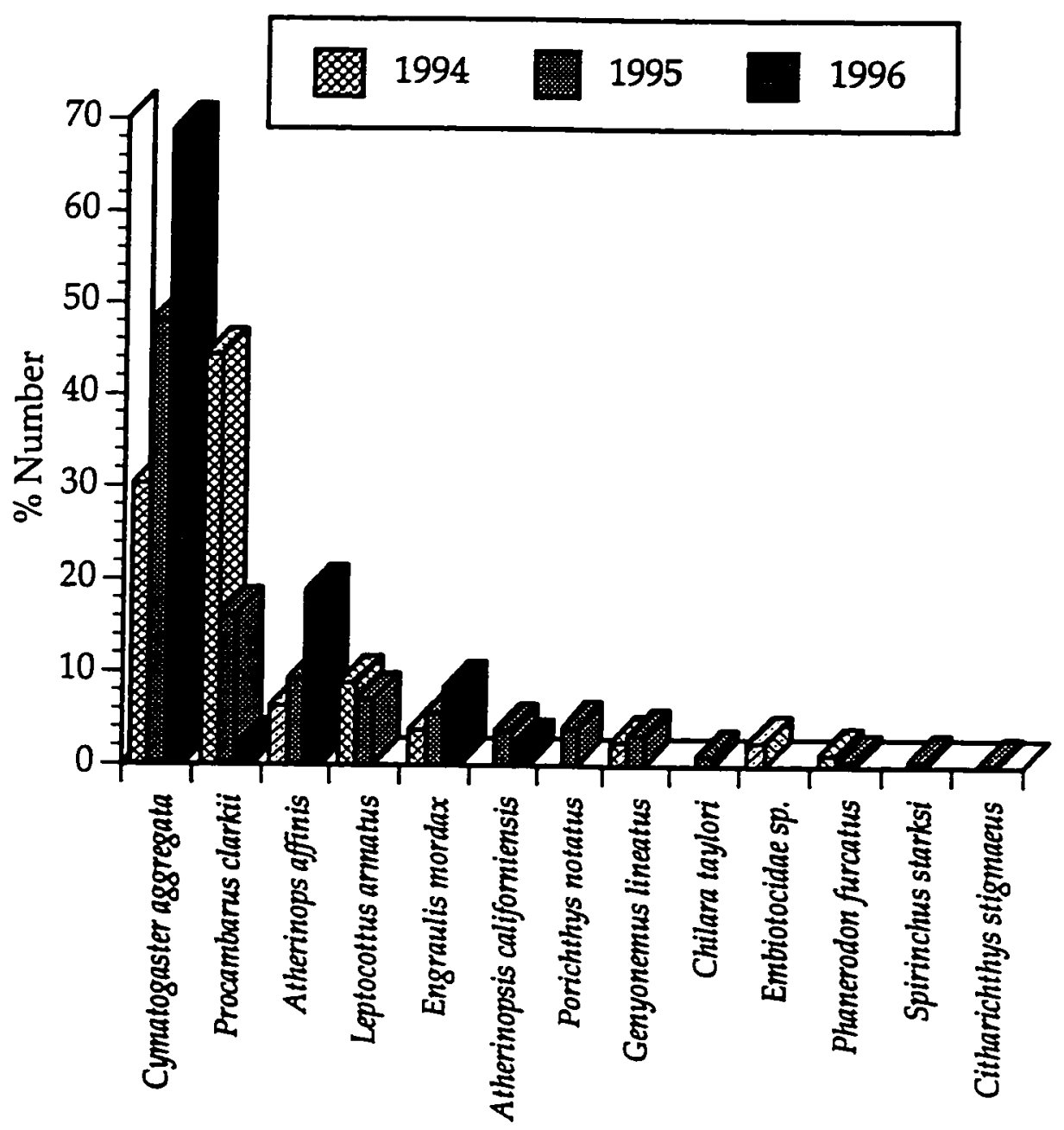

Species

Figure 7. Species comparison among years, using percent number of prey identified in Caspian Tern nest cup samples during 1994 and 1995, and regurgitated pellets collected during 1996. 


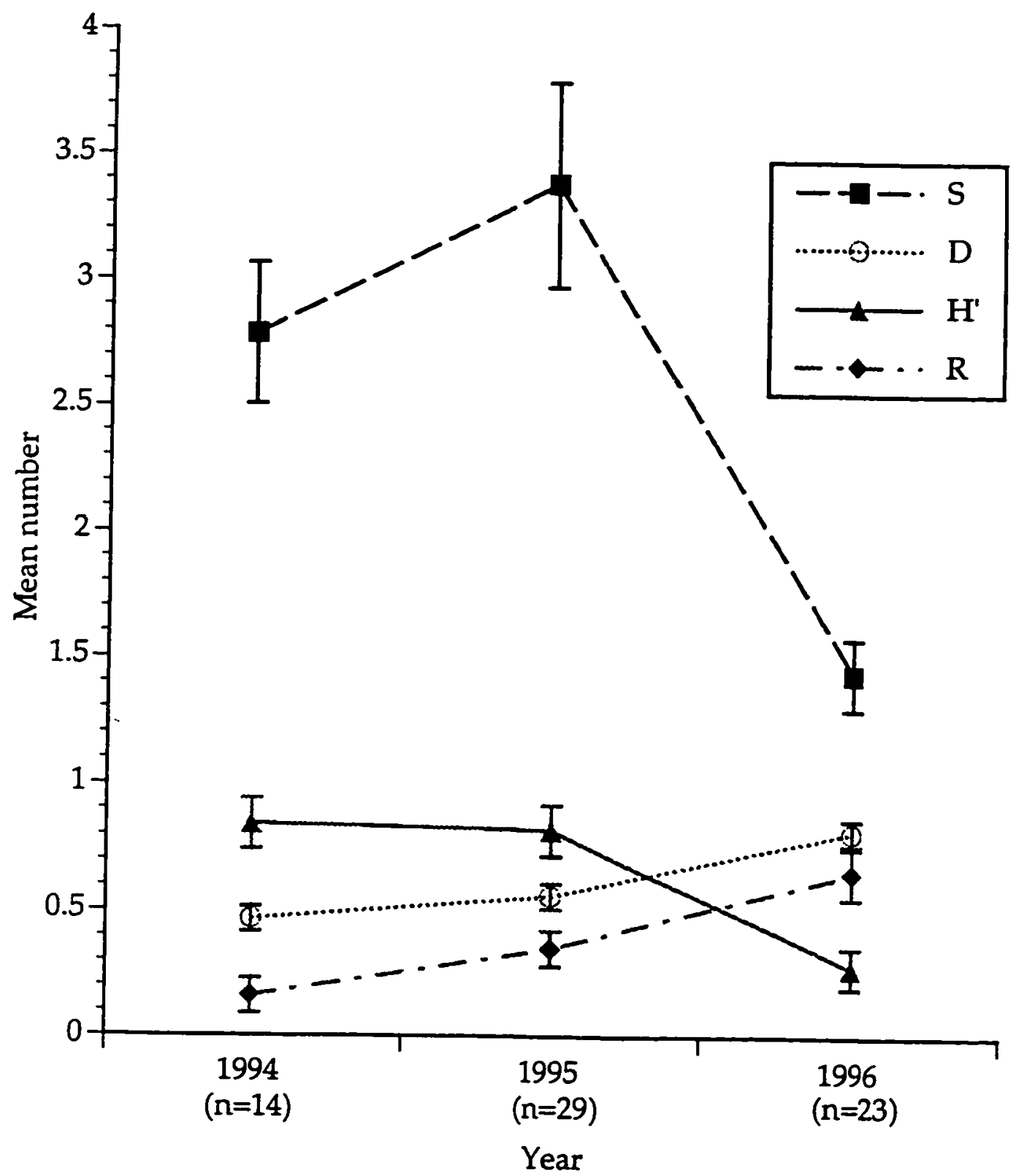

Figure 8. Annual variation in mean number of species (S), mean diversity index $(\mathrm{H})$, index of specialization (R), and dominance (D) of prey of Caspian Terns identified from nest cup samples (1994 and 1995) collected from Elkhorn Slough and pellet samples (1996) collected from Salinas River Mouth, CA. Veritical bars indicate standard error. 


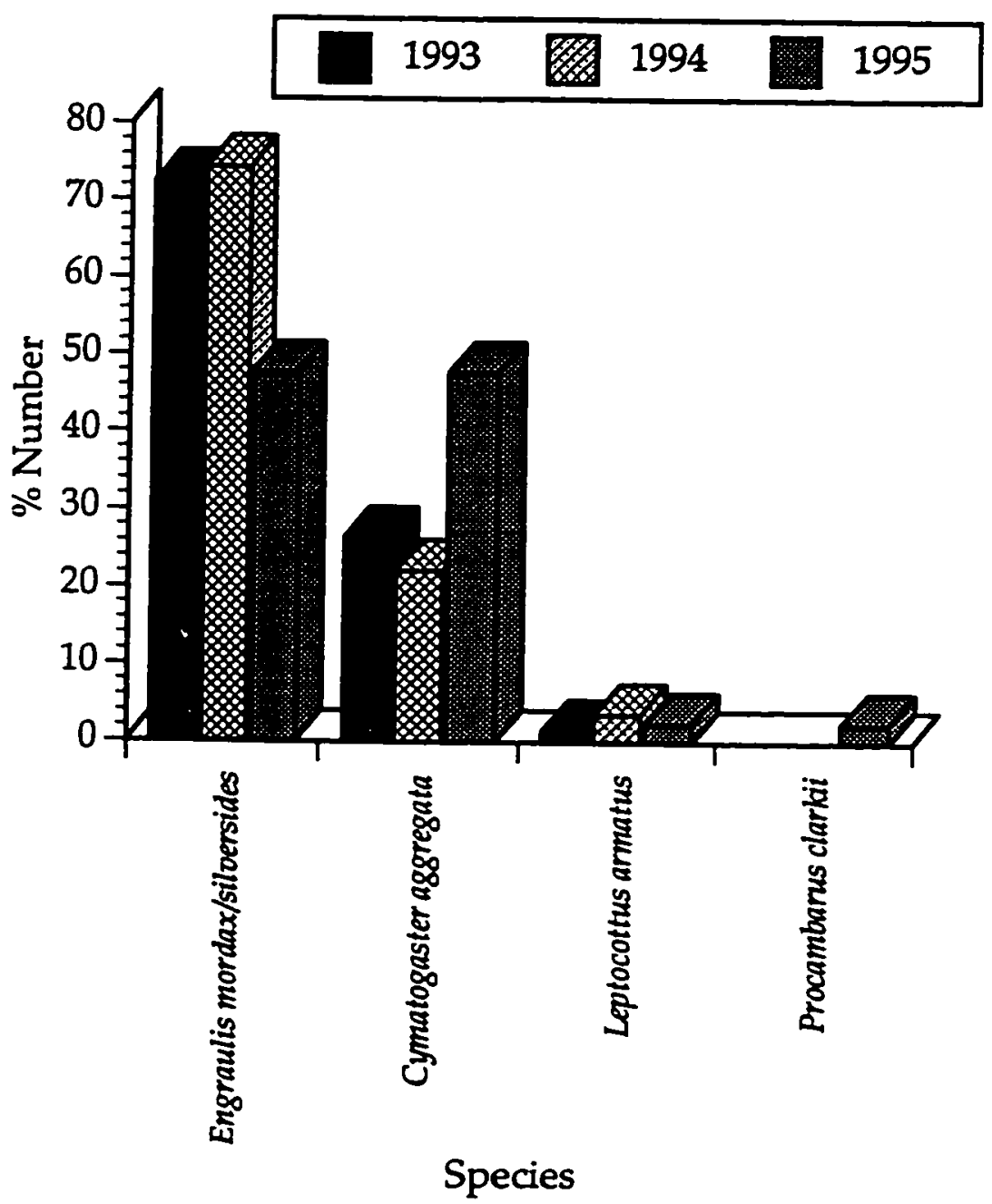

Figure 9. Species comparison among years, using percentage number of prey identified from direct observations of Caspian Tern foraging trips during 1993-1995. 


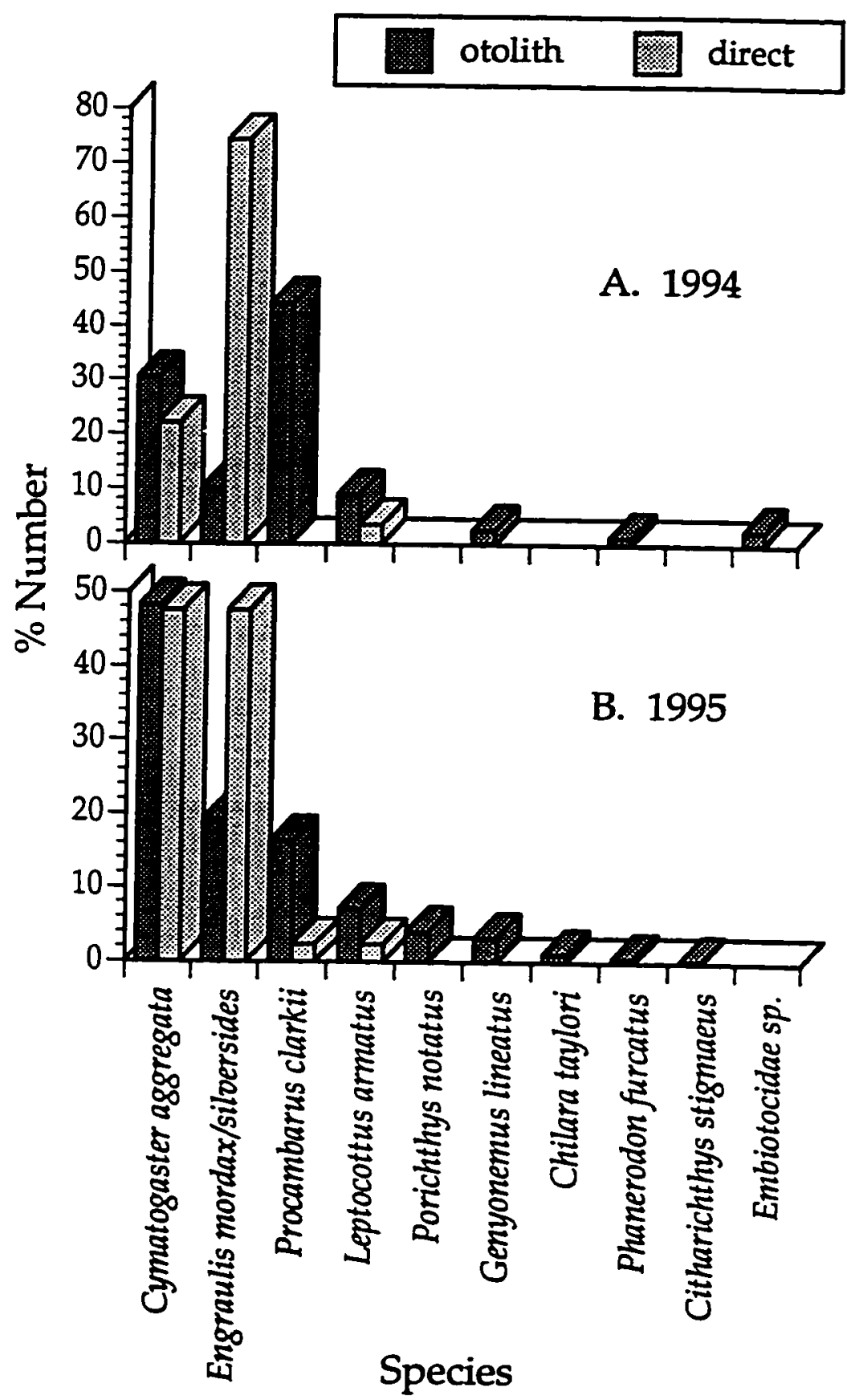

Figure 10. Species comparison, using percentage number, between prey identified in Caspian Tern nest cups (otolith) and by direct observations in Elkhorn Slough, CA during 1994 (A) and 1995 (B). 

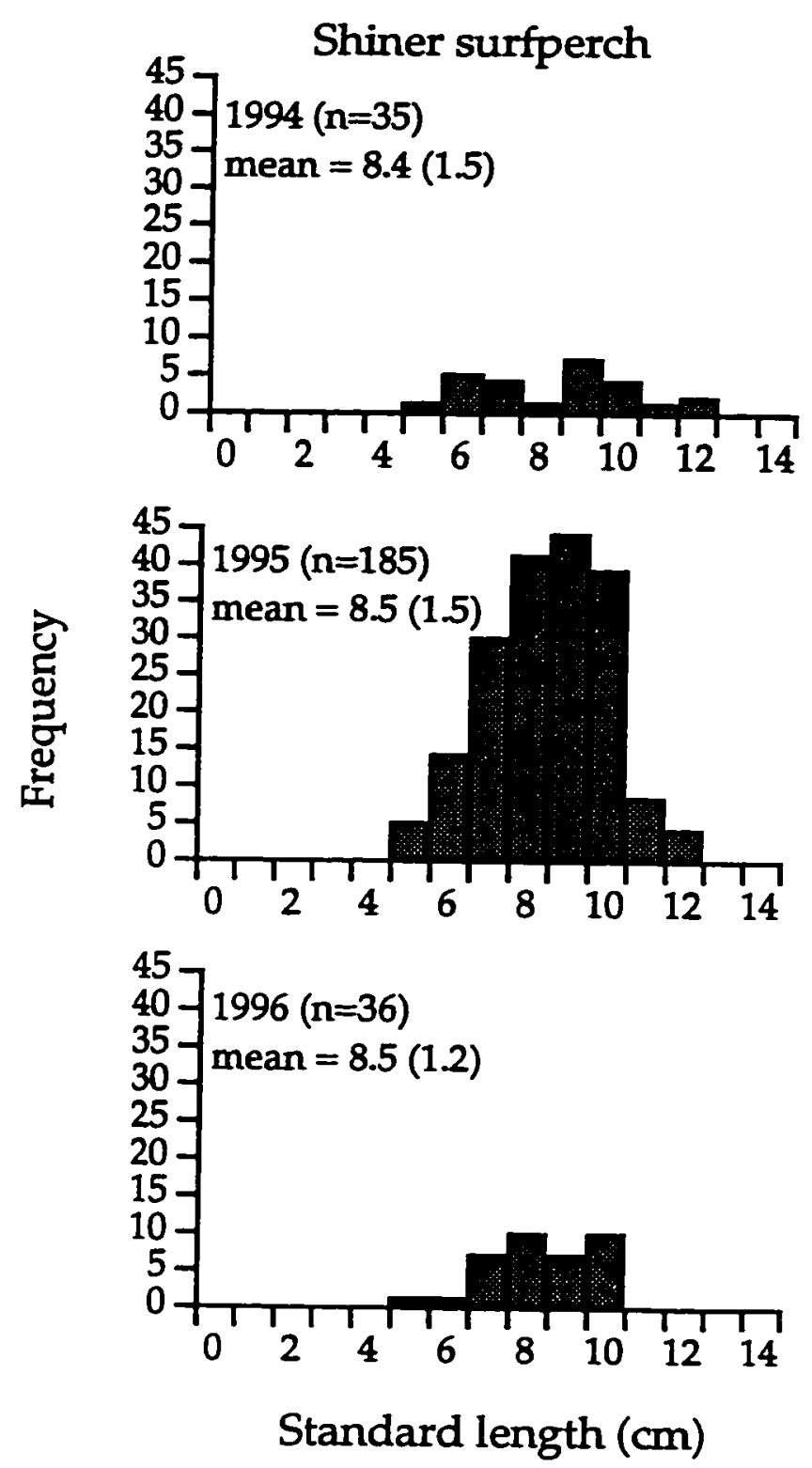

Figure 11. Frequency histograms of the estimated length of shiner surfperch using otoliths recovered from Caspian Tern nest cups and pellets collected at Elkhorn Slough during 1994 and 1995 and the Salinas River mouth during 1996. Including year, mean, standard deviation (SD), and number of fish sampled (n). 
Northern anchovy
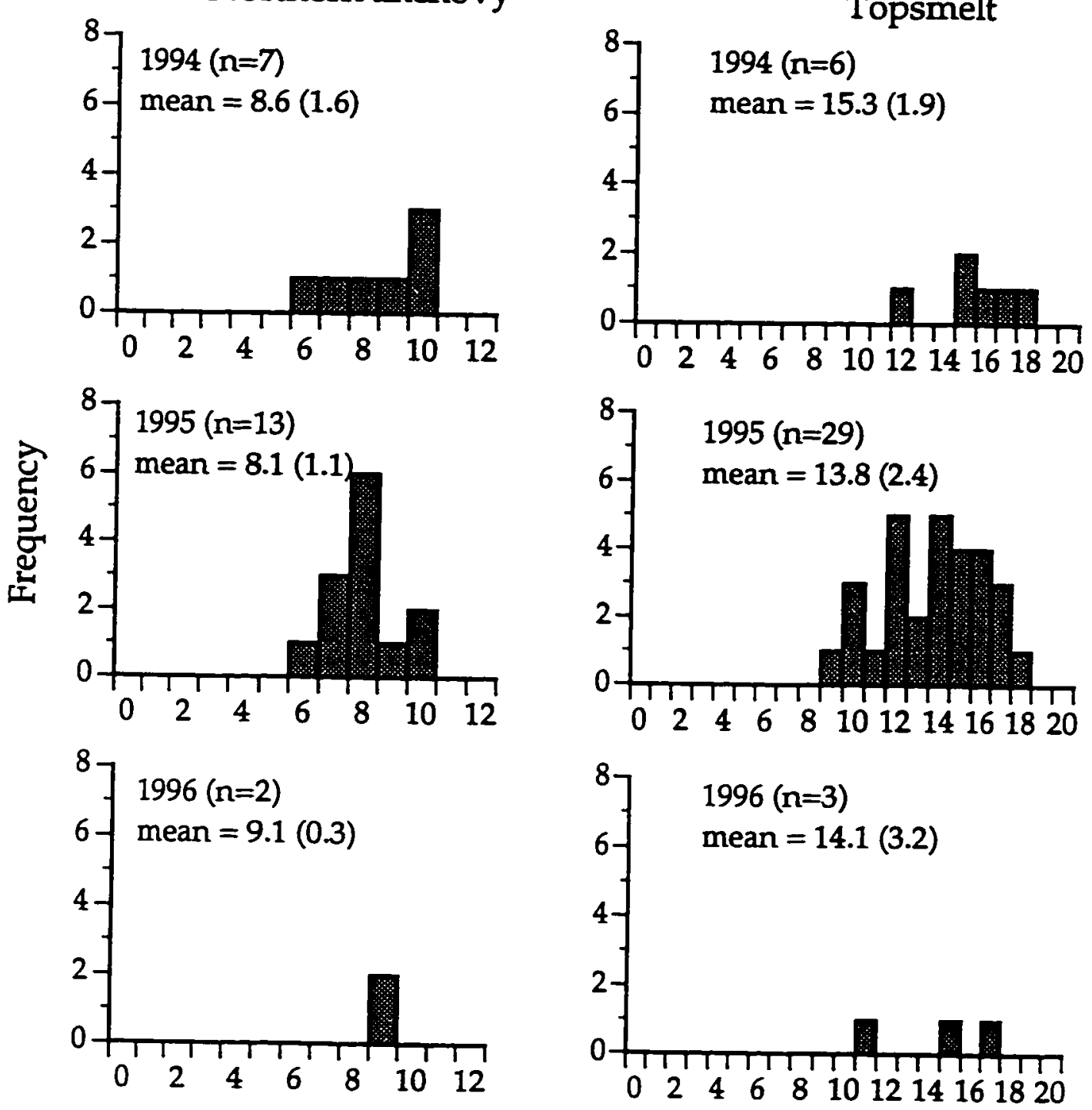

Standard length $(\mathrm{cm})$

Figure 12. Frequency histograms of the estimated length of northern anchovy and topsmelt using otoliths recovered from Caspian Tern nest cup samples at Elkhorn Slough during 1994 and 1995 and pellets at Salinas River Mouth during 1996. Including year, mean, standard deviation (SD), and number of fish sampled (n). 
White croaker

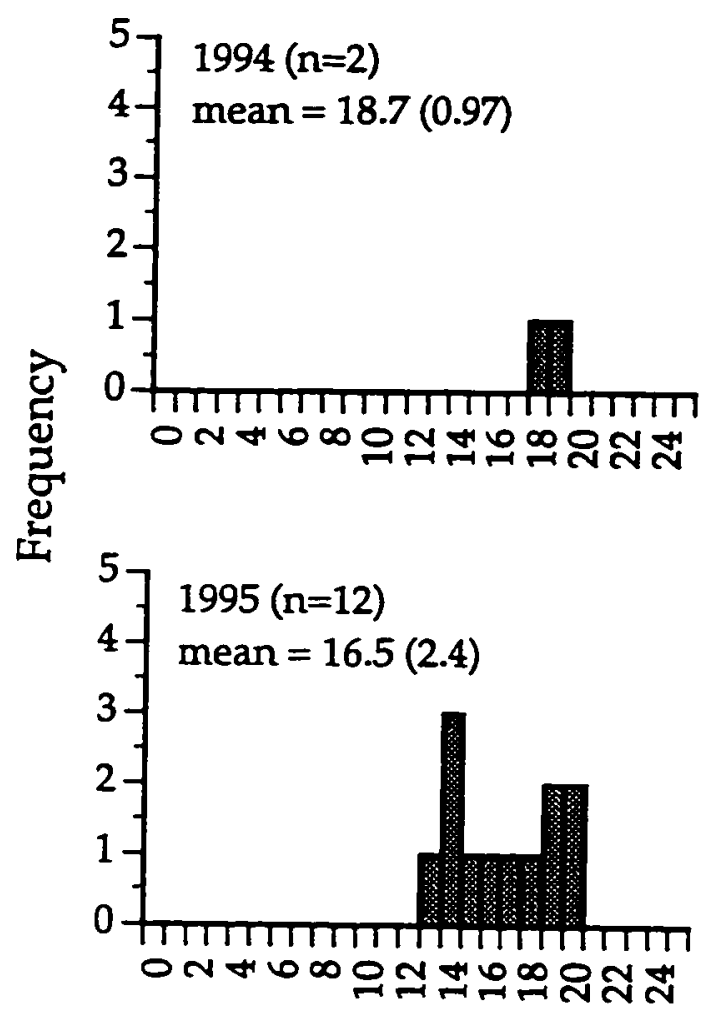

Staghorn sculpin
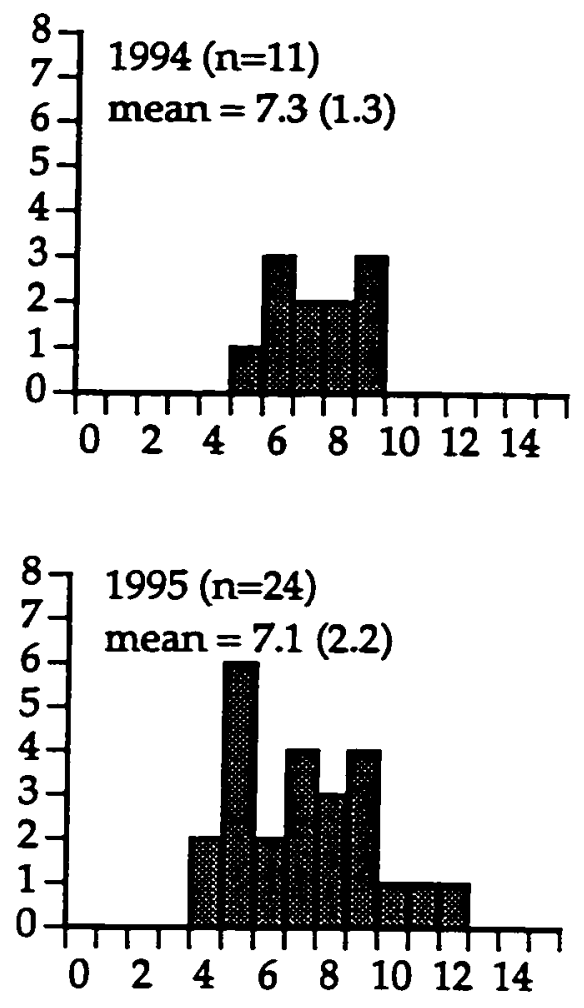

\section{Standard length $(\mathrm{cm})$}

Figure 13. Frequency histograms of the estimated length of white croaker and Pacific staghorn sculpin using otoliths recovered from Caspian Tern nest cup samples collected in Elkhorn Slough, CA. Including year, mean, standard deviation (SD), and number of fish sampled (n). 
Plainfin midshipman

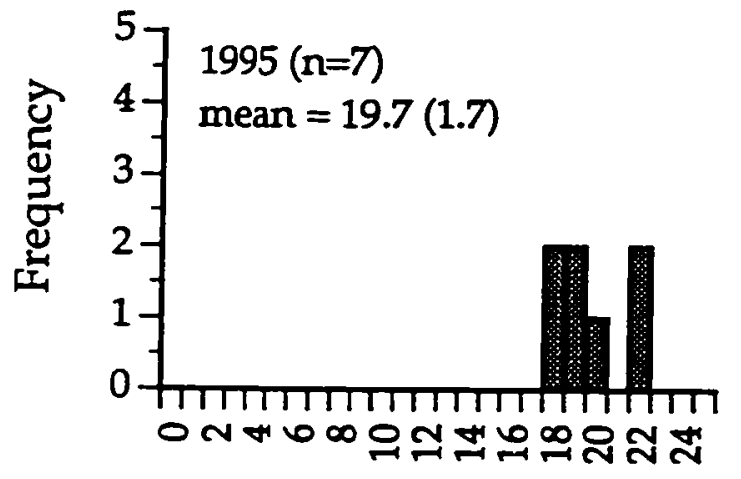

\section{Jacksmelt}

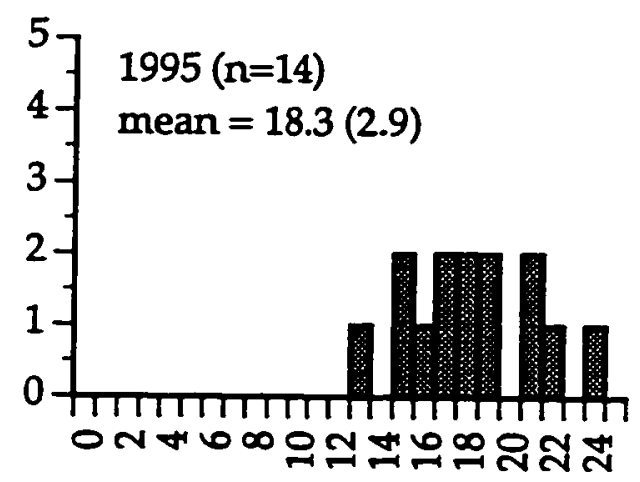

\section{Standard length $(\mathrm{cm})$}

Figure 14. Frequency histograms of the estimated length of plainfin midshipman and jacksmelt using otoliths recovered from Caspian Tem nest cup samples at Elkhorn Slough, CA. Including year, mean, standard deviation (SD) and number of fish sampled (n). 
Shiner surfperch
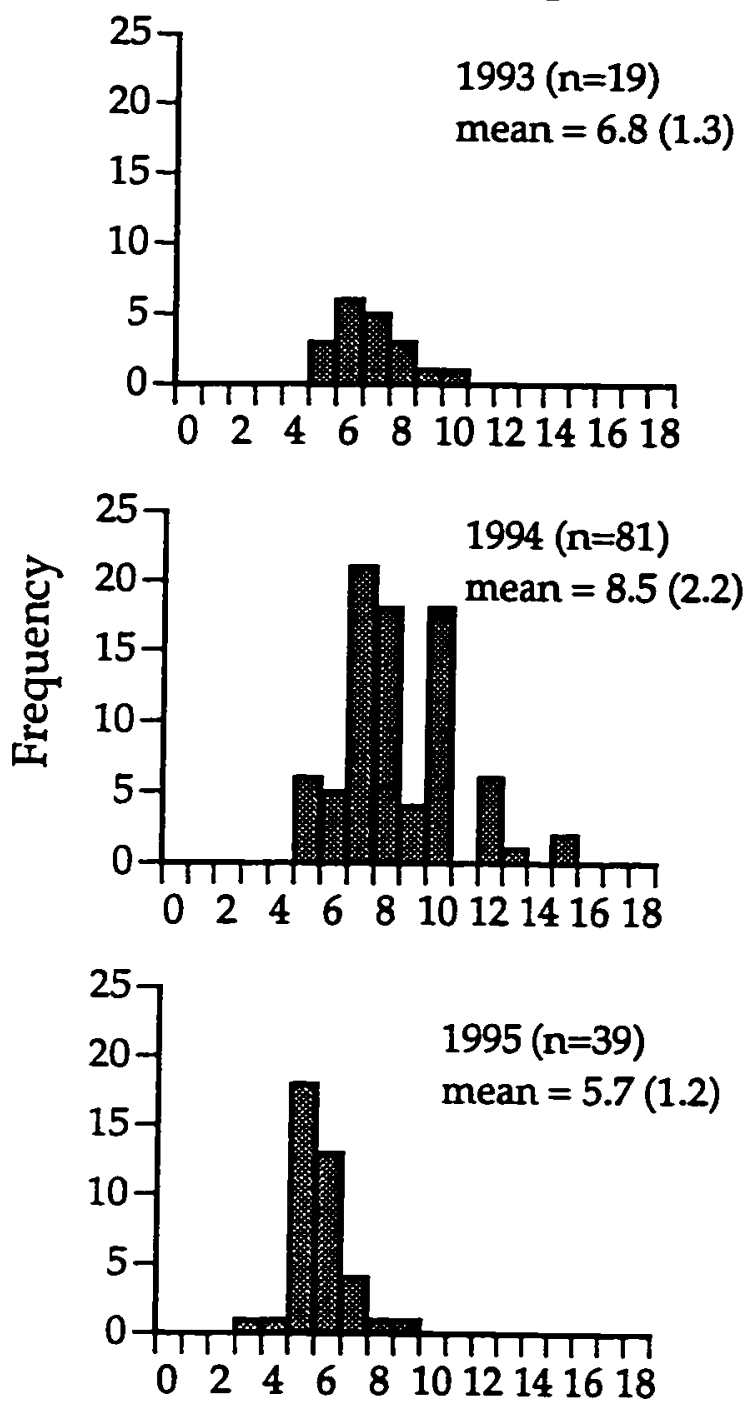

Northern anchovy/silversides
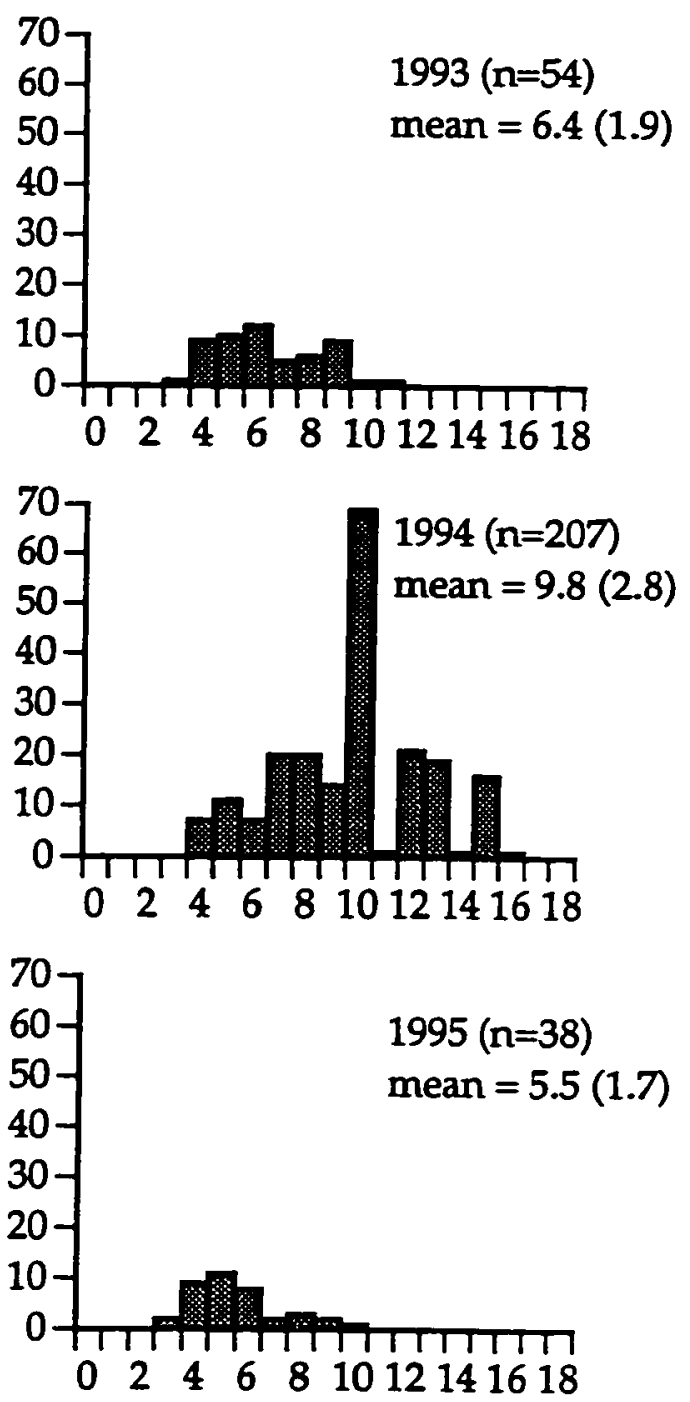

\section{Standard length $(\mathrm{cm})$}

Figure 15. Frequency histograms of the estimated length of shiner surfperch and northen anchovy/silversides recorded from direct observations of Caspian Tern feeding trips in Elkhom Slough, CA. Including year, mean, standard deviation (SD), and number of fish sampled (n). 

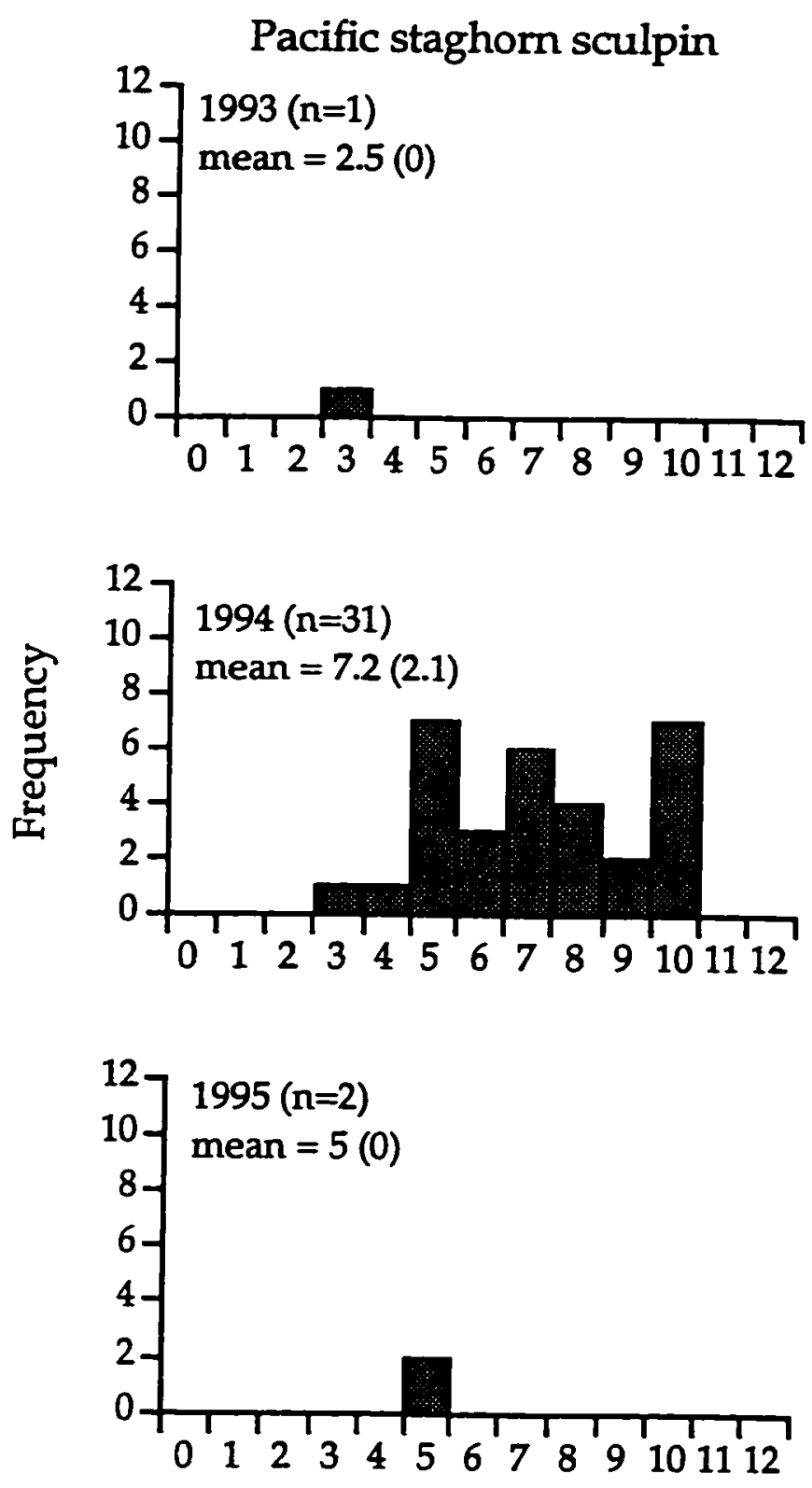

Standard length $(\mathrm{cm})$

Figure 16. Frequency histograms of the estimated length of Pacific staghorn sculpin recorded from direct observations of Caspian Tern feeding trips at Elkhorn Slough, CA. Including year, mean, standard deviation (SD), and number of fish sampled (n). 


\section{APPENDIX A}

California Department of Fish and Game, Pesticide Chemistry Laboratory, Analytical Procedure for Determination of Organochlorine Pesticides and Polychlorinated Biphenyl residues in Egg Samples

1. Run glassware blanks for each sample.

2. Weigh out $5-\mathrm{g}$ samples into $400 \mathrm{ml}$ beaker.

3. Dry and macerate each 5-g sample with anhydrous granular sodium sulfate.

4. Transfer sample to a $500 \mathrm{ml}$ flask with a powder funnel.

5. Add $125-\mathrm{ml}$ of petroleum ether and 1-ml of $\mathrm{OCH}$ surrogate in iso-octane, stopper with a glass stopper, and shake for $5 \mathrm{~min}$.

6. Decant liquid into a Buchner funnel using \#42 filter paper and filter flask set up.

7. Add another $125-\mathrm{ml}$ of petroleum ether to flask with tissue sample, shake for $5 \mathrm{~min}$.

8. Transfer complete sample to the Buchner funnel and vacuum filter.

9. Transfer liquid filtrate to a KD-flask and concentrator tube. Add a boiling stone, attach a Snyder column, evaporate to $10-\mathrm{ml}$.

10. Clean-up the extract with florisil column.

11. Divide extract into two portions, 2-ml through a preconditioned standard 4-in florisil column and 8-ml reserved for lipid analysis.

12. Elute with $220-\mathrm{ml}$ of petroleum ether, $200-\mathrm{ml}$ of $6 \%$ ether/petroleum ether, and $200-\mathrm{ml}$ of $15 \%$ ether/petroleum ether.

13. For each fraction, add a boiling stone and 1-ml iso-octane. 
14. For the petroleum ether fraction, evaporate to 2-ml after attaching a Snyder column.

15. For the $6 \%$ and $15 \%$ fractions, evaporate to $2-\mathrm{ml}$, add $50-\mathrm{ml}$ petroleum ether from the top of the Snyder column, evaporate to 2-ml, cool, add a new boiling stone, attach a micro-Snyder column, and evaporate to 1-ml.

16. Quantitatively transfer each fraction to a precalibrated $10-\mathrm{ml}$ vial and dilute to $10-\mathrm{ml}$ with iso-octane.

17. Add a standard of $0.1-\mathrm{ml}$ isooctane to each extract and to glassware blanks.

18. Check for OCH pesticides and PCBs on GC-ECD with capillary columns.

Lipid Analysis:

1. Pour the 8-ml extract for lipid analysis into a preweighed aluminum planchet.

2. Evaporate off the petroleum ether in the hood.

3. Place the remaining lipid sample in oven at $80^{\circ} \mathrm{C}$ to remove any moisture, cool for $30 \mathrm{~min}$, weigh the planchet, and calculate the percentage lipids. 
